Portland State University

PDXScholar

Spring 6-4-2013

\title{
Investigations into the Regional and Local Timescale Variations of Subglacial Drainage Networks
}

Justin Hiester

Portland State University

Follow this and additional works at: https://pdxscholar.library.pdx.edu/open_access_etds

Part of the Geology Commons, Glaciology Commons, and the Hydrology Commons Let us know how access to this document benefits you.

Recommended Citation

Hiester, Justin, "Investigations into the Regional and Local Timescale Variations of Subglacial Drainage Networks" (2013). Dissertations and Theses. Paper 1022.

https://doi.org/10.15760/etd.1022

This Thesis is brought to you for free and open access. It has been accepted for inclusion in Dissertations and Theses by an authorized administrator of PDXScholar. Please contact us if we can make this document more accessible: pdxscholar@pdx.edu. 
Investigations into the Regional and Local Timescale Variations of Subglacial Drainage

Networks
by
Justin Hiester

Justin Hiester

A thesis submitted in partial fulfillment of the requirements for the degree of

\author{
Master of Science \\ in \\ Geology
}

Thesis Committee:

Christina L. Hulbe, Chair

Olga V. Sergienko

Scott F. Burns

Portland State University

2013 


\begin{abstract}
Subglacial water plays an important role in the regulation of an ice sheet's mass balance. It may be the dominant control on the velocities of ice streams and outlet glaciers on scales of months to millennia. Recent satellite observations of ice surface elevation changes have given researchers new insights into how subglacial water is stored and transported. Localized uplift and settling of the ice surface implies that lakes exist beneath the ice sheet that are being filled and drained on relatively short time scales.
\end{abstract}

Here, a numerical investigation of the mechanisms of transport and storage of subglacial water and the associated time scales is presented. Experiments are carried out using a finite element model of coupled ice and water flow. The first experiment seeks to understand the relationship between the depth of a basal depression and the area over which the feature affects basal water flow. It is found that as the perturbation to a topographic depression's depth is increased, water is rerouted in response to the perturbation. Additionally it is found that the relationship between perturbation depth and the extent upstream to which its effects reach is nonlinear. The second experiment examines how the aspect ratio of bed features (prolate, oblate, or equidimensional) influences basal water flow. It is found that the systems that develop and their interactions are mediated by both the topography and the feedbacks taken into account by the coupling of the systems in the model. Features oriented parallel to ice and water flow are associated with distributed fan systems that develop branches which migrate laterally across the domain and interact with one another on monthly and yearly timescales. Laterally oriented features develop laterally extensive ponds. As the ratio of longitudinal to lateral dimension of the topography is increased, a combination of these two water distributions is seen. 


\section{ACKNOWLEDGMENTS}

It is nearly impossible to do anything of note without the help of others. I would like to express my gratitude and say thank you to all of the people who have helped get me where I am today.

I thank my family and friends for their support. My parents in particular deserve a standing ovation. They have always been there for me when I needed help and have provided me with no small amount of support over the years as I pursued my goals. I owe them a debt of gratitude I will probably not be able to repay in this lifetime.

I am grateful to Christina and Olga for the opportunities they have provided me and for the time and effort they invested in me, particularly in helping me to improve my writing ability. I would like to thank Christina in particular for encouraging me to try and think about things from points of view that I otherwise would not have considered. I would like to thank Olga for imparting to me her knowledge of ice mechanics and modeling. I always walked away from our conversations with a deeper understanding of the problems at hand and how best to approach them.

I owe a debt of thanks to Nancy Eriksson and Paul Brooks. Nancy's expertise in navigating the sea of bureaucracy at PSU was indispensable. Paul's expertise with computers, fonts, and $\mathrm{ET}_{\mathrm{E} X} \mathrm{X}$ as extremely helpful as I was writing and formatting my thesis.

Thank you all. 


\section{TABLE OF CONTENTS}

Abstract $\quad$ i

Acknowledgments $\quad$ ii

List of Tables $\quad \mathrm{v}$

List of Figures $\quad$ vi

List of Notations $\quad$ xiv

1 Introduction 1

1.1 Ice sheets and their importance . . . . . . . . . . . . . . . 3

1.2 Ice streams . . . . . . . . . . . . . . . . . . . . . . . . . . . . .

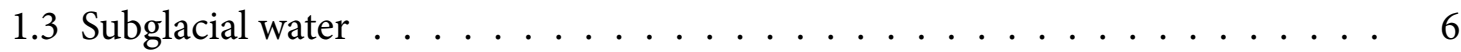

1.4 Purpose and scope of work . . . . . . . . . . . . . 8

2 Methods 9

2.1 Model domain description $\ldots \ldots \ldots$. . . . . . . . . . . . . 9

2.2 Ice flow model . . . . . . . . . . . . . . . . . . . . . . . 11

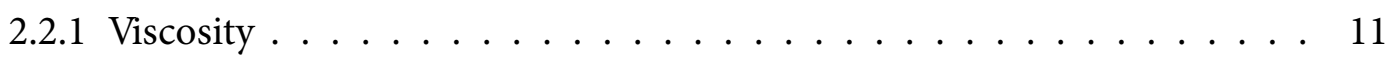

2.2 .2 Ice thickness . . . . . . . . . . . . . . . . . . 12

2.2.3 Initial and boundary conditions on the ice flow model . . . . . . . . 13

2.3 Water flow model . . . . . . . . . . . . . . . . . . . . . 13

2.3.1 Initial and boundary conditions on the water flow model . . . . . 15

2.4 Model coupling . . . . . . . . . . . . . . . . . . 15

2.5 Solving the system of equations . . . . . . . . . . . . . . . . . 17

2.5.1 Finite element method . . . . . . . . . . . . . . . . . . 17

2.5.2 Solution procedure .................... 18 
3 Experiments and Results 20

3.1 Lake provinciality . . . . . . . . . . . . . . . . 20

3.1 .1 Experiment description . . . . . . . . . . . . . . . 20

3.1 .2 Results . . . . . . . . . . . . . . . . 20

3.2 Basal topography . . . . . . . . . . . . . . . . 31

3.2 .1 Experiment description . . . . . . . . . . . . . . . 31

3.2 .2 Results . . . . . . . . . . . . . . . . . . 32

4 Discussion and conclusions $\quad 58$

4.1 Lake provinciality . . . . . . . . . . . . . . . . . . 58

4.2 Basal topography . . . . . . . . . . . . . . . . . 59

$\begin{array}{ll}\text { References } & 64\end{array}$ 


\section{LIST OF TABLES}

3.1 Summary of average streamline data after 10 years for the six different bed geometries reported on in this study. Values shown are averages of the variables calculated using 25 streamlines in the domain spaced at $5 \mathrm{~km}$ increments (figure 3.41). . . . . . . . . . . . . . . . . . . 57 
LIST OF FIGURES

1.1 Image from the National Snow and Ice Data Center's MODIS Mosaic of Antarctica showing prominent features of the Ross embayment, West Antarctica. The Siple Coast ice streams are shown to the left. The grounding line is indicated by the yellow dashed line following the work of Brunt et al. (2010). Satellite observations made on these ice streams provide the impetus for this

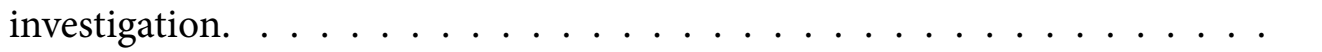

1.2 Repeat along track elevation profiles from ICESat data that cross areas of oscillating surface elevations. The oscillations in the surface elevation profiles are interpreted as indications of an active subglacial hydrologic system. From Fricker et al., (2007) . . . . . . . . . . . . . . .

2.1 Depiction of the idealized ice stream domain $\Gamma$ used in this work. Ice and water flow down slope in the positive $\mathrm{x}$-direction. The bed is inclined $1^{\circ} \ldots \quad$. 10

2.2 The upper two panels show model results in which ice and water flow are one-way coupled-the ice flow model is influenced by the water flow but the water flow is not influenced by the ice flow. The lower two panels illustrate the effects that two-way coupling has on the results. Very different results are achieved when the models are able to influence one another. . . . . . . . 16 
3.1 A)Basal topography (m) and B) water depth distrubution (m) of the reference configuration. . . . . . . . . . . . . . . 22

3.2 A)Basal topography ( $m$ ) and B) water depth distrubution ( $m$ ) for a depression $10 \mathrm{~m}$ below the reference. . . . . . . . . . . . . . . 23

3.3 A)Basal topography ( $\mathrm{m}$ ) and B) water depth distrubution ( $\mathrm{m}$ ) for a depression $20 \mathrm{~m}$ below the reference. . . . . . . . . . . . . . . . . 24

3.4 A)Basal topography ( $m$ ) and B) water depth distrubution ( $m$ ) for a depression $30 \mathrm{~m}$ below the reference. . . . . . . . . . . . . . . 25

3.5 A)Basal topography ( $\mathrm{m}$ ) and B) water depth distrubution ( $\mathrm{m}$ ) for a depression $40 \mathrm{~m}$ below the reference. . . . . . . . . . . . . . 26

3.6 A)Basal topography ( $\mathrm{m})$ and $\mathrm{B}$ ) water depth distrubution ( $\mathrm{m}$ ) for a depression $50 \mathrm{~m}$ below the reference. . . . . . . . . . . . . . . 27

3.7 Difference in water depth distribution $(\mathrm{m})$ between the initial configuration and the configuration with a depression that is $10 \mathrm{~m}$ deeper. . . . . . . . .

3.8 Difference in water depth distribution $(\mathrm{m})$ between the initial configuration and the configuration with a depression that is 20 m deeper. . . . . . . . . 28

3.9 Difference in water depth distribution $(\mathrm{m})$ between the initial configuration and the configuration with a depression that is 30 m deeper. . . . . . . . 29

3.10 Difference in water depth distribution $(\mathrm{m})$ between the initial configuration and the configuration with a depression that is $40 \mathrm{~m}$ deeper. . . . . . . .

3.11 Difference in water depth distribution $(\mathrm{m})$ between the initial configuration and the configuration with a depression that is $50 \mathrm{~m}$ deeper. . . . . . . . . 30 
3.12 Maximum distance upstream to which the effects of increasing the perturbation reach (dashed line). Ratio of the distance upstream to which the effects of the increased perturbation reach to the depth of the perturbation (dotted line). . . . . . . . . . . . . . . . . . 30

3.13 A) Points in the domain at which water depth $(\mathrm{m})$ is tracked over 150 years. The coordinates of the points are $A=(174 \mathrm{~km}, 35 \mathrm{~km}), \mathrm{B}=(130 \mathrm{~km}, 59 \mathrm{~km})$, $\mathrm{C}=(168 \mathrm{~km}, 35 \mathrm{~km}), \mathrm{D}=(160 \mathrm{~km}, 46 \mathrm{~km})$, and $\mathrm{E}=(192 \mathrm{~km}, 35 \mathrm{~km}) . \ldots$

3.14 Values of water depth at five different points in the domain. The label of the panel corresponds to the point at which the water depth was tracked (figure 3.13). Notice that the trends do not all have the same sign. . . . . . . . . .

3.15 A) Values and spatial distributions of the bed topography (m) with $n_{x}=1$ and $\left.n_{y}=3, \mathrm{~B}\right)$ ice surface elevation $\left.(\mathrm{m}), \mathrm{C}\right)$ ice surface velocity $\left(\right.$ myear $\left.^{-1}\right)$, and D) the depth of the subglacial water layer $(\mathrm{m})$ after 10 years. . . . . . 33

3.16 Change in the depth and spatial distribution of the subglacial water layer (m) from its initial state (A) over monthly timescales. B) Distribution after 1 month. C) Distribution after 2 months. D) Distribution after 3 months. Nascent branching features can be seen after 2 months and become more apparent as the model evolves. . . . . . . . . . . . . . . . . . 34

3.17 Change in the depth and spatial distribution of the subglacial water layer from its initial state (A) over several years. B) Distribution after 1 year. C) Distribution after 5 years. D) Distribution after 10 years. The branching pattern is well established after 5 years and continues to evolve. Changes in the patterns occur in both the longitudinal and lateral directions. Migration, combination, and divergence of the branches is most apparent in the lateral dimension. . . . . . . . . . . . . . . . . . . . . . 35 
3.18 A) A probe was placed at $x=176 \mathrm{~km}, y=38 \mathrm{~km}$ on the bed-indicated by the black + symbol. At this point the evolution of ice surface elevation, ice surface velocity, and water depth were tracked over 10 years. B) Water depth and ice surface height over 10 years. C) Water depth and ice surface velocity over 10 years. . . . . . . . . . . . . . . . . 36

3.19 Values and spatial distributions of the bed topography with $n_{x}=3$ and $n_{y}=1$ (A), ice surface elevation (B), ice surface velocity (C), and the depth of the subglacial water layer (D) after 10 years. . . . . . . . . . . . 37

3.20 Change in the depth and spatial distribution of the subglacial water layer from its initial state (A) over monthly timescales. B) Distribution after 1 month. C) Distribution after 2 months. D) Distribution after 3 months. A laterally extensive pond develops at the downstream end of the domain. . . 38

3.21 Change in the depth and spatial distribution of the subglacial water layer from its initial state (A) over several years. B) Distribution after 1 year. C) Distribution after 5 years. D) Distribution after 10 years. The water depth fluctuates over the lateral extent of the domain's downstream end suggesting that the water within the pond migrates. . . . . . . . . . . . 38

3.22 A) A probe was placed at $x=188 \mathrm{~km}, y=50 \mathrm{~km}$ on the bed-indicated by the black + symbol. At this point the evolution of ice surface elevation, ice surface velocity, and water depth were tracked over 10 years. B) Water depth and ice surface height over 10 years. C) Water depth and ice surface

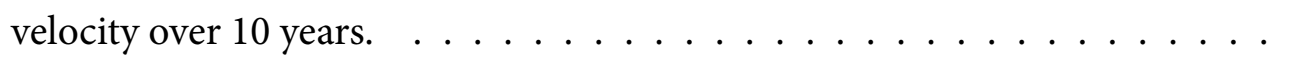

3.23 Values and spatial distributions of the bed topography with $n_{x}=1$ and $n_{y}=10(\mathrm{~A})$, ice surface elevation (B), ice surface velocity (C), and the depth of the subglacial water layer (D) after 10 years. . . . . . . . . . . . 40 
3.24 Change in the depth and spatial distribution of the subglacial water layer from its initial state (A) over monthly timescales. B) Distribution after 1 month. C) Distribution after 2 months. D) Distribution after 3 months. Nascent branching features can be seen after 2 months and become more apparent after 3 months. . . . . . . . . . . . . . . . . 41

3.25 Change in the depth and spatial distribution of the subglacial water layer from its initial state (A) over several years. B) Distribution after 1 year. C) Distribution after 5 years. D) Distribution after 10 years. The branching pattern is well established after 5 years and continues to evolve. Changes in the patterns occur in both the longitudinal and lateral directions. Migration, combination, and divergence of the branches is most apparent in the lateral dimension. . . . . . . . . . . . . . . . . . . . . . 42

3.26 A) A probe was placed at $x=184 \mathrm{~km}, y=69 \mathrm{~km}$ on the bed-indicated by the black + symbol. At this point the evolution of ice surface elevation, ice surface velocity, and water depth were tracked over 10 years. B) Water depth and ice surface height over 10 years. C) Water depth and ice surface

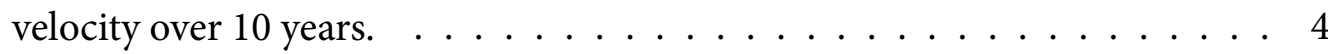

3.27 Values and spatial distributions of the bed topography with $n_{x}=10$ and $n_{y}=1$ (A), ice surface elevation (B), ice surface velocity (C), and the depth of the subglacial water layer (D) after 10 years. . . . . . . . . . . . 44

3.28 Change in the depth and spatial distribution of the subglacial water layer from its initial state (A) over monthly timescales. B) Distribution after 1 month. C) Distribution after 2 months. D) Distribution after 3 months. Nascent branching features can be seen after 2 months and become more apparent after 3 months. . . . . . . . . . . . . . . . . . 45 
3.29 Change in the depth and spatial distribution of the subglacial water layer from its initial state (A) over several years. B) Distribution after 1 year. C) Distribution after 5 years. D) Distribution after 10 years. The branching pattern is well established after 5 years and continues to evolve. Changes in the patterns occur in both the longitudinal and lateral directions. Migration, combination, and divergence of the branches is most apparent in the lateral dimension. . . . . . . . . . . . . . . . . . . . . 46

3.30 A) A probe was placed at $x=159 \mathrm{~km}, y=50 \mathrm{~km}$ on the bed-indicated by the black + symbol. At this point the evolution of ice surface elevation, ice surface velocity, and water depth were tracked over 10 years. B) Water depth and ice surface height over 10 years. C) Water depth and ice surface velocity over 10 years. . . . . . . . . . . . . . . . . . . 47

3.31 A) A probe was placed at $x=198 \mathrm{~km}, y=50 \mathrm{~km}$ on the bed-indicated by the black + symbol. At this point the evolution of ice surface elevation, ice surface velocity, and water depth were tracked over 10 years. B) Water depth and ice surface height over 10 years. C) Water depth and ice surface

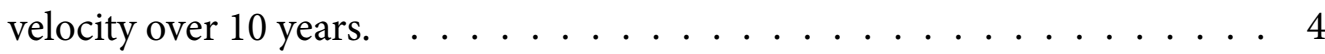

3.32 Values and spatial distributions of the bed topography with $n_{x}=10$ and $n_{y}=20$ (A), ice surface elevation (B), ice surface velocity (C), and the depth of the subglacial water layer (D) after 10 years. . . . . . . . . . .

3.33 Change in the depth and spatial distribution of the subglacial water layer from its initial state (A) over monthly timescales. B) Distribution after 1 month. C) Distribution after 2 months. D) Distribution after 3 months. Nascent branching features can be seen after 2 months and become more apparent after 3 months. . . . . . . . . . . . . . . 
3.34 Change in the depth and spatial distribution of the subglacial water layer from its initial state (A) over several years. B) Distribution after 1 year. C) Distribution after 5 years. D) Distribution after 10 years. The branching pattern is well established after 5 years and continues to evolve. Changes in the patterns occur in both the longitudinal and lateral directions. Migration, combination, and divergence of the branches is most apparent in the lateral dimension. . . . . . . . . . . . . . . . . . . . . . 50

3.35 Difference plots of the evolution of the depth and spatial distribution of the subglacial water layer. A) Difference between the initial state and 5 years. B) Difference between 10 years and 5 years. Most of the activity is confined to the upper right portion of the domain. . . . . . . . . . . . . . 50

3.36 A) A probe was placed at $x=180 \mathrm{~km}, y=77 \mathrm{~km}$ on the bed-indicated by the black + symbol. At this point the evolution of ice surface elevation, ice surface velocity, and water depth were tracked over 10 years. B) Water depth and ice surface height over 10 years. C) Water depth and ice surface

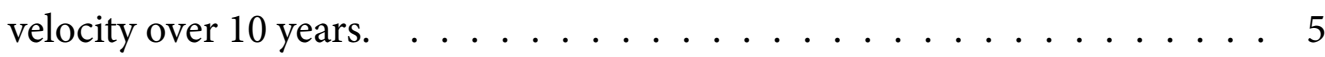

3.37 Values and spatial distributions of the bed topography with $n_{x}=20$ and $n_{y}=10(\mathrm{~A})$, ice surface elevation (B), ice surface velocity (C), and the depth of the subglacial water layer (D) after 10 years. . . . . . . . . . . 53

3.38 Change in the depth and spatial distribution of the subglacial water layer from its initial state (A) over monthly timescales. B) Distribution after 1 month. C) Distribution after 2 months. D) Distribution after 3 months. Nascent branching features can be seen after 2 months and become more apparent after 3 months. . . . . . . . . . . . . . . . . . 53 
3.39 Change in the depth and spatial distribution of the subglacial water layer from its initial state (A) over several years. B) Distribution after 1 year. C) Distribution after 5 years. D) Distribution after 10 years. The branching pattern is well established after 5 years and continues to evolve. Changes in the patterns occur in both the longitudinal and lateral directions. Migration, combination, and divergence of the branches is most apparent in the lateral dimension. . . . . . . . . . . . . . . . . . . . . 54

3.40 A) A probe was placed at $x=169 \mathrm{~km}, y=56 \mathrm{~km}$ on the bed-indicated by the black + symbol. At this point the evolution of ice surface elevation, ice surface velocity, and water depth were tracked over 10 years. B) Water depth $(m)$ and ice surface height $(m)$ over 10 years. C) Water depth and ice surface velocity $\left(m y r^{-1}\right)$ over 10 years. . . . . . . . . . . . 55

3.41 Streamlines for the topography with $n_{x}=1$ and $n_{y}=3$. The lines are spaced out at $5 \mathrm{~km}$ intervals. The distribution of points along the streamlines increases downstream as the mesh is refined. . . . . . . . . . . 56

4.1 Upper panel, results from model showing water distribution after 10 years. Flow is from left to right. Lower panel, results from Catania and Paola (2001). Flow is from top to bottom. Panel A shows the distribution of channels after 1.5 hours. Panel B shows the distribution of channels after 18.5 hours. Panel C shows the distribution of channels after 34 hours. . . . . . . 62 


\section{LIST OF NOTATIONS}

A Amplitude-height and depth - of topographic features, $50 \mathrm{~m} \ldots \ldots \ldots \ldots$

$a_{G}$ Coefficient used to determine the orientation of the Gaussian function $\ldots \ldots \ldots 10$

$\dot{a} \quad$ Ice surface accumulation rate, $3 \mathrm{~cm} \mathrm{yr}^{-1} \ldots \ldots \ldots \ldots \ldots \ldots \ldots \ldots \ldots \ldots \ldots \ldots \ldots \ldots \ldots$

$\bar{B}$ Depth-averaged ice stiffness parameter, $1.68 \mathrm{E} 8 \mathrm{~Pa} \mathrm{~s}^{1 / 3} \ldots \ldots \ldots \ldots \ldots \ldots \ldots \ldots$

$B_{0}$ Empirically derived constant used to determine ice stiffness $\ldots \ldots \ldots \ldots \ldots \ldots 12$

$b_{G}$ Coefficient used to determine the orientation of the Gaussian function $\ldots \ldots \ldots 10$

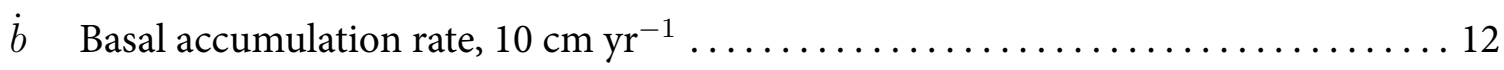

C Empirical constant used to determine ice stiffness $\ldots \ldots \ldots \ldots \ldots \ldots \ldots \ldots \ldots \ldots$

$c_{G}$ Coefficient used to determine the orientation of the Gaussian function $\ldots \ldots \ldots \ldots$

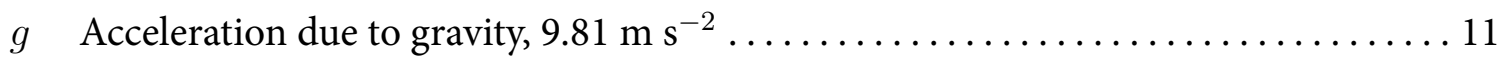

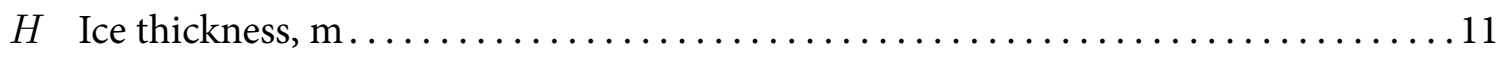

$K$ Hydraulic conductivity of water sheet, $10^{-6} \mathrm{~m} \mathrm{~s}^{-1} \ldots \ldots \ldots \ldots \ldots \ldots \ldots \ldots \ldots \ldots$

$k \quad$ Empirical constant used to determine ice stiffness $\ldots \ldots \ldots \ldots \ldots \ldots \ldots \ldots \ldots \ldots \ldots \ldots \ldots$ 


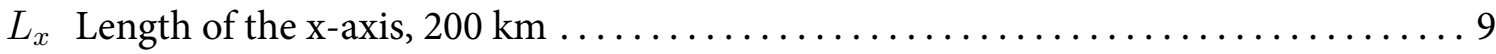

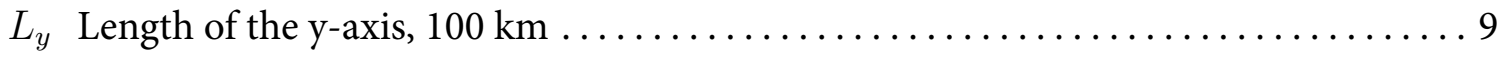

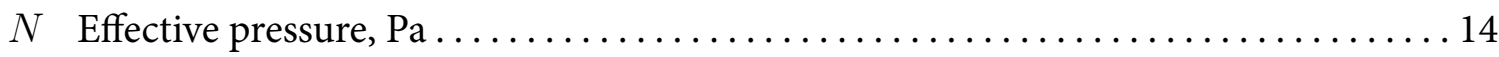

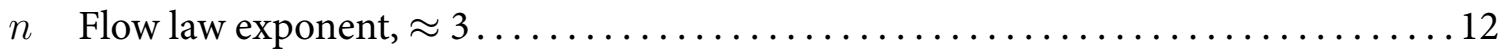

$n_{x}$ Number of topographic features in the $\mathrm{x}$-direction $\ldots \ldots \ldots \ldots \ldots \ldots \ldots \ldots$

$n_{y}$ Number of topographic features in the $y$-direction $\ldots \ldots \ldots \ldots \ldots \ldots \ldots \ldots$

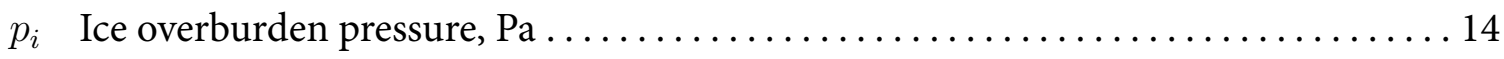



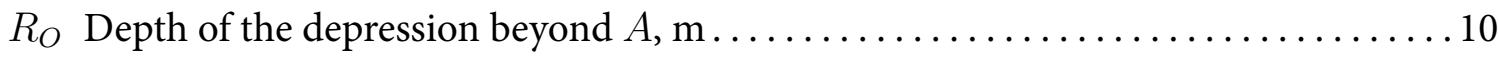

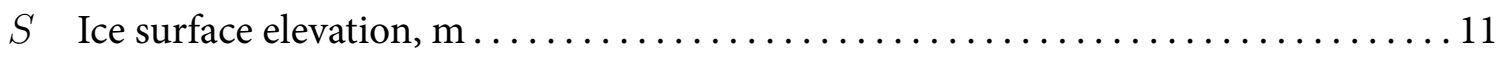

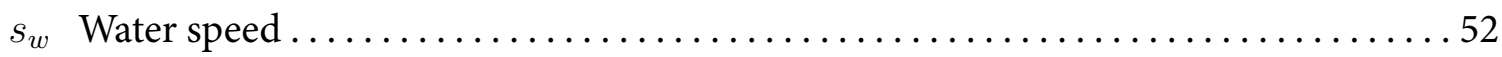

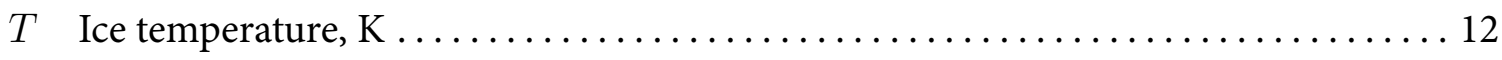

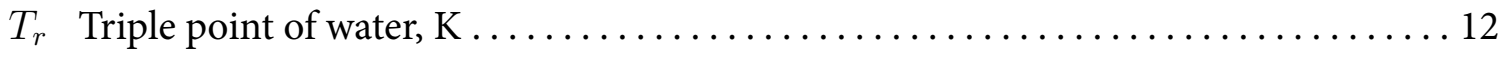

$\mathrm{u}_{\mathrm{i}} \quad$ Two dimensional ice velocity vector, $\mathrm{m} \mathrm{s}^{-1} \ldots \ldots \ldots \ldots \ldots \ldots \ldots \ldots \ldots \ldots \ldots \ldots \ldots$

$\mathrm{u}_{\mathrm{w}}$ Two-dimensional, depth-averaged water velocity vector, $\mathrm{m} \mathrm{s}^{-1} \ldots \ldots \ldots \ldots \ldots 14$

$u_{i} \quad$ Ice velocity in the $\mathrm{x}$-direction, $\mathrm{m} \mathrm{s}^{-1} \ldots \ldots \ldots \ldots \ldots \ldots \ldots \ldots \ldots \ldots \ldots \ldots \ldots \ldots$

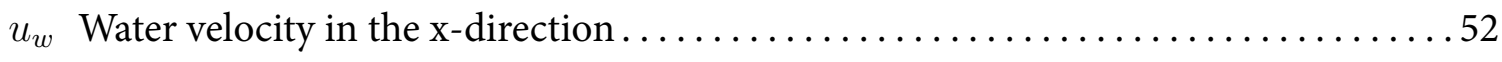

$v_{i} \quad$ Ice velocity in the y-direction, $\mathrm{m} \mathrm{s}^{-1} \ldots \ldots \ldots \ldots \ldots \ldots \ldots \ldots \ldots \ldots \ldots \ldots \ldots \ldots$ 


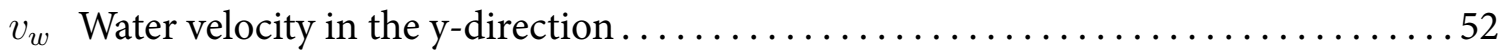

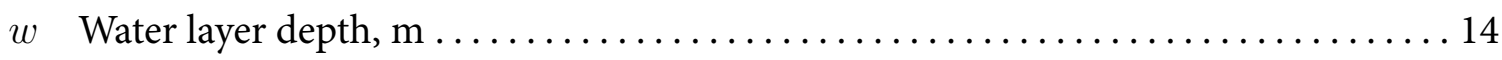

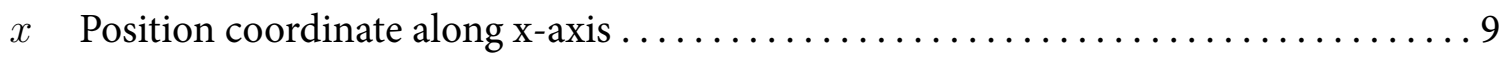

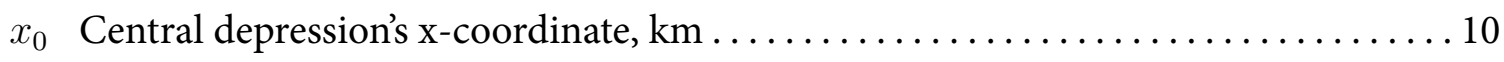



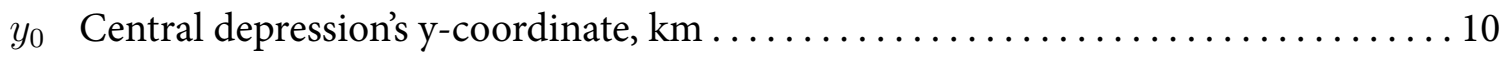

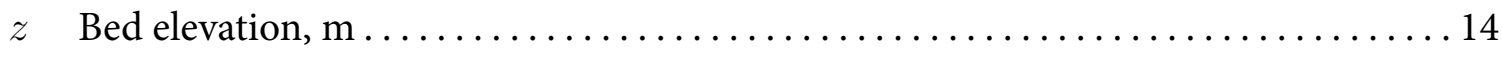

$\beta \quad$ Basal traction parameter, $1 \mathrm{E} 10 \mathrm{~Pa} \mathrm{~s}^{-1} \ldots \ldots \ldots \ldots \ldots \ldots \ldots \ldots \ldots \ldots \ldots \ldots \ldots$

$\beta_{C}$ Background value of basal traction parameter $\ldots \ldots \ldots \ldots \ldots \ldots \ldots \ldots \ldots \ldots$

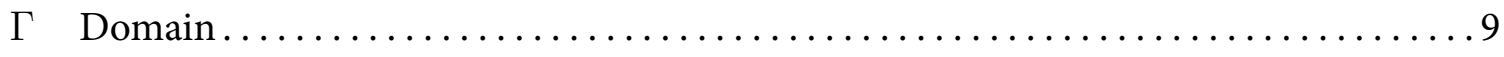

$\theta \quad$ Clockwise rotation of the Gaussian function, $\frac{\pi}{2}$ radians $\ldots \ldots \ldots \ldots \ldots \ldots \ldots$

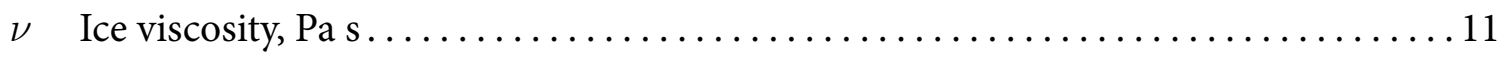

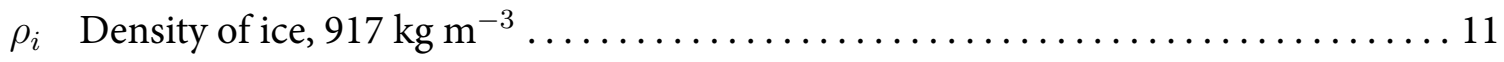

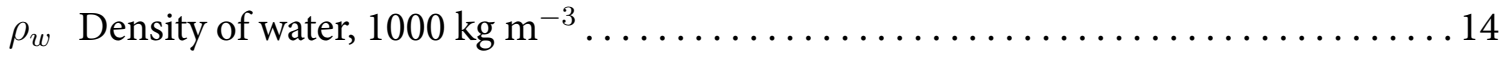

$\sigma_{x}$ Width of the Gaussian function in the x-direction, $0.001 \ldots \ldots \ldots \ldots \ldots \ldots \ldots$

$\sigma_{y}$ Width of the Gaussian function in the y-direction, $0.002 \ldots \ldots \ldots \ldots \ldots \ldots \ldots$

$\phi \quad$ Hydraulic potential field $\ldots \ldots \ldots \ldots \ldots \ldots \ldots \ldots \ldots \ldots \ldots \ldots \ldots \ldots \ldots \ldots$

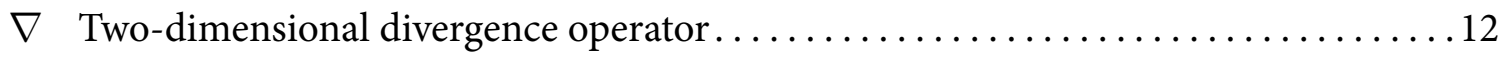

xvi 


\section{CHAPTER 1}

\section{INTRODUCTION}

The Antarctic Ice Sheet covers an area of approximately $14 \times 10^{6} \mathrm{~km}^{2}$ (Drewry et al., 1982, King and Turner, 1997) and stores enough water to raise sea level by 60 to $70 \mathrm{~m}$ (Siegert, 2001) if it melted. It can be divided geographically along the Transantarctic Mountain Range. To the west of the Transantarctic Mountains is the West Antarctic Ice Sheet (WAIS) and to the east is the East Antarctic Ice Sheet (EAIS). Though these two ice sheets are neighbors, their responses to a warming climate are expected to be quite different. The EAIS is primarily grounded on continental cratonic rocks which are stiff and resist ice flow (Anderson, 1999). This situation makes the ice sheet slow to respond to perturbations to its boundary conditions. The bed upon which the WAIS rests is predominantly below sea level (Lythe et al., 2001), slopes inland (Schoof, 2007), and is overlain with a layer of marine and glaciogenic sediments (Blankenship et al., 1986). Weak, water-saturated subglacial material promotes fast ice flow, and the reverse slope of the bed promotes rapid migration of the margins (Schoof, 2007). In addition, the WAIS has many ice streams and outlet glaciers that drain its mass and terminate in large, embayed ice shelves-Ross and Ronne-Filchner-whereas the EAIS is drained primarily by outlet glaciers and has few embayed ice shelves (figure 1.1). 


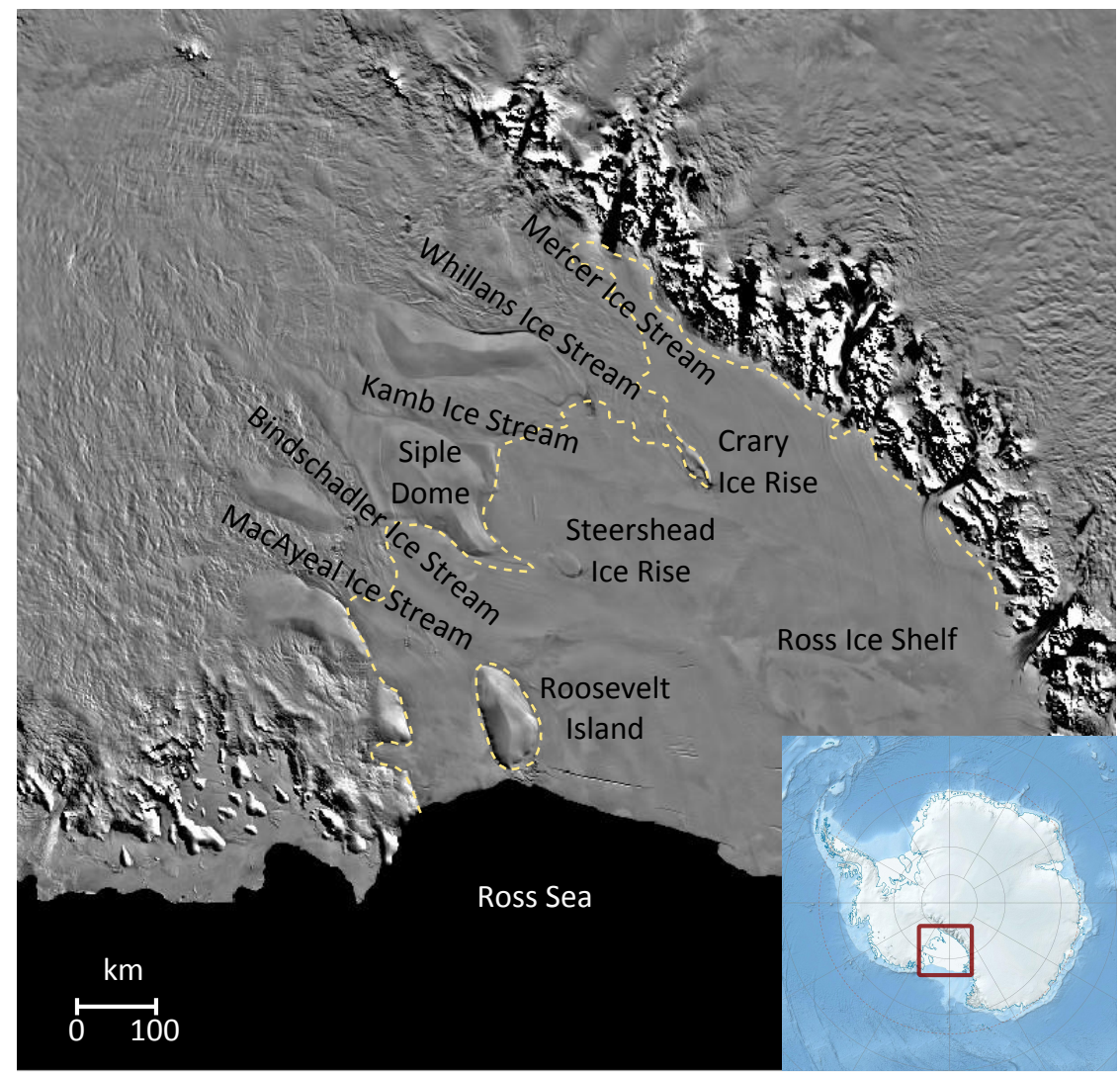

Figure 1.1 Image from the National Snow and Ice Data Center's MODIS Mosaic of Antarctica showing prominent features of the Ross embayment, West Antarctica. The Siple Coast ice streams are shown to the left. The grounding line is indicated by the yellow dashed line following the work of Brunt et al. (2010). Satellite observations made on these ice streams provide the impetus for this investigation. 
John Mercer was among the first to raise the question of how vulnerable to collapse the WAIS would be in the coming decades of a warming climate (Mercer, 1978, Joughin and Alley, 2011). The large volume of water stored in polar ice sheets-a combined estimate of $76 \mathrm{~m}$ of seal level equivalent (Bamber and Layberry, 2001, Lythe et al., 2001) -and its potential impact on ecosystems and the built environment make answering such a question an important scientific and policy goal. It is of great interest to determine how the ice sheets will respond to processes that can induce rapid changes in their configuration (geometry and flow), on what time scales those changes will proceed, and what the resulting contribution to global sea level change will be.

In order to make accurate and useful projections of future change in Earth's ice sheets, their dynamics must be understood and well represented in computational models. The most recent report from the Intergovernmental Panel on Climate Change (IPCC) did not include the effects of ice dynamics on ice sheet mass balance in its sea level projection (Lemke et al., 2007). One reason for this omission was that uncertainties about basal conditions beneath ice sheets and glaciers limit the ability to make projections of their contributions to sea level rise.

\subsection{Ice sheets and their importance}

Ice sheets are continental-sized bodies of ice that deform and flow under their own weight. They are important components of Earth's climate system. Their influence on climate is due largely to their size, and that they are covered with snow. The snow cover imparts a high albedo over a large surface area that reflects the majority of the incident sunlight back into the atmosphere. Recent work studying the orographic effects of ice sheets suggests that they are capable of altering the climates in regions remote to the ice sheets themselves (Roe 
and Lindzen, 2000). The orography and geometry of the ice sheets also play a role in ocean circulation. Experiments conducted by Schmittner et al. (2011) - in which the height of the Earth's mountains and ice sheets were progressively reduced in height to $0 \mathrm{~m}$ above sea level in a coupled ocean-atmosphere model-suggest that the orography of the Antarctic Ice Sheet is partly responsible for the formation of deepwater in the North Atlantic, a critical component in the Earth's climate system. Schmittner et al. (2011) also concluded that the Antarctic ice sheet's orographic effects on the zonal wind stress over the Southern Ocean are necessary for the present strength of the Antarctic circumpolar current as well as the modern position of upwelling in the Southern Ocean. Altering the geometry of the ice sheet could weaken the Antarctic circumpolar current as well as slow the rates of deepwater formation in the North Atlantic.

\subsection{Ice streams}

On the timescales of interest in this work-one to ten years-ice streams are the most important factors controlling the mass balance of the WAIS. Ice streams are bodies of fast flowing ice surrounded by relatively stagnant ice, and they are characterized by their slippery beds, low driving stresses, and narrow shear margins (Truffer and Echelmeyer, 2003). The West Antarctic ice streams drain ice from the interior of the ice sheet, moving it to the coast where the ice goes afloat to form the Ross Ice Shelf. The grounding line marks the transition between grounded and floating ice and delineates the downstream end of the ice stream. Ice streams move at velocities from 100 to several $100 \mathrm{~m} \mathrm{a}^{-1}$ (Whillans and Van der Veen, 1993, Bindschadler, 1993, Joughin et al., 2002). The distribution of basal water and its ability to saturate the fine-grained marine sediments underlying much of the WAIS allow ice streams to form and achieve such high velocities despite relatively low surface slopes 
(Tulaczyk et al., 2000, Bindschadler and Choi, 2007).

Ice-streams flow by three mechanisms: internal deformation, deformation of the underlying substrate, and basal sliding. Internal deformation in ice-streams occurs primarily as longitudinal stretching and shearing near lateral margins. Internal deformation rates are controlled by the temperature of the ice, the pressure gradients in the ice, the size of the individual ice crystals and their orientation, and the impurities in the ice (Van der Veen, 1999, Kuffey and Paterson, 2010).

Much of the WAIS is underlain by a water-saturated till (Alley et al., 1986, Alley et al., 1987, Blankenship et al., 1986, Blankenship et al., 1987). The yield strength of the till depends on its porosity and porewater pressure. If the porosity and the porewater pressure are high, the till will deform easily and allow the overlying ice to move. Experiments done on a sample of till collected from beneath Whillans Ice Stream (Engelhardt et al., 1990) showed that the deformation was strongly dependent on effective stress and nearly independent of strain rates (Tulaczyk et al., 2000). In sum, the till is a weak, deformable, fine-grained substrate that allows the ice streams to attain their high velocities despite their relatively low driving stresses.

Basal sliding is the term used to refer to the motion of ice that is not due to deformation of till but to translation across the bed. It is most important in areas where ice at the interface with the bed may be at the pressure melting point. Sliding on a hard bed may be with or without cavitation (Lliboutry, 1968, Weertman, 1957). There is a long and interesting history regarding the development of sliding theory (Fowler, 2010). Common to both theories is the notion of a controlling obstacle size. This size determines which mechanism is responsible for the flow of the ice. Weertman (1957) put forth two theories for the flow 
of ice over a hard bed: regelation and enhanced creep. Regelation occurs with relatively small obstacles and is the process by which ice flows past obstacles. Regelation is the result of higher pressure on the stoss side of the obstacle that causes the ice to melt. The melt water flows around the obstacle and refreezes on the lee side. The energy released by the refreezing of the water is conducted back through the obstacle and maintains the temperature difference (Weertman, 1957 , Van der Veen, 1999). In his other theory, Weertman puts forth that stress concentrations near obstacles-larger than those found in the process of regelation-causes the creep of ice to occur more quickly or to be enhanced. Lliboutry's theories incorporate regelation and enhanced creep in addition to cavitation-a sliding mechanism in which the ice separates from the bed in the lee of obstacles (Lliboutry, 1968). Lliboutry's theory of basal sliding with cavitation allows ice to flow around smaller obstacles without invoking regelation. Water can fill the cavities and reduce the friction between the bed and the ice. This amounts to drowning the small obstacles and allowing ice to be lifted-to some extent - and slide more freely past them on the water layer.

\subsection{Subglacial water}

The existence of fresh water beneath the Antarctic ice sheets was first postulated by the Russian anarcho-communist and scientist Piotr Kropotkin towards the end of the 19th century (Zotikov, 2006). Kropotkin realized that the pressures experienced by deep ice at its bed would be enough to lower the melting point of water. Subglacial water has been demonstrated to play an important role in the behavior of glaciers through its effect on basal sliding (Iken, 1981, Iken and Bindschadler, 1986, Fountain and Walder, 1998). In alpine glacier settings, water-and its effect on ice flow-varies on seasonal, daily, and hourly scales. Prior to some recent satellite observations, the view was that the subglacial hydrologic networks 
beneath ice sheets were relatively stable, changing slowly from one configuration to another. Modern satellite laser altimetry observations of surface elevation changes in West Antarctica offer new insights into the basal water system.

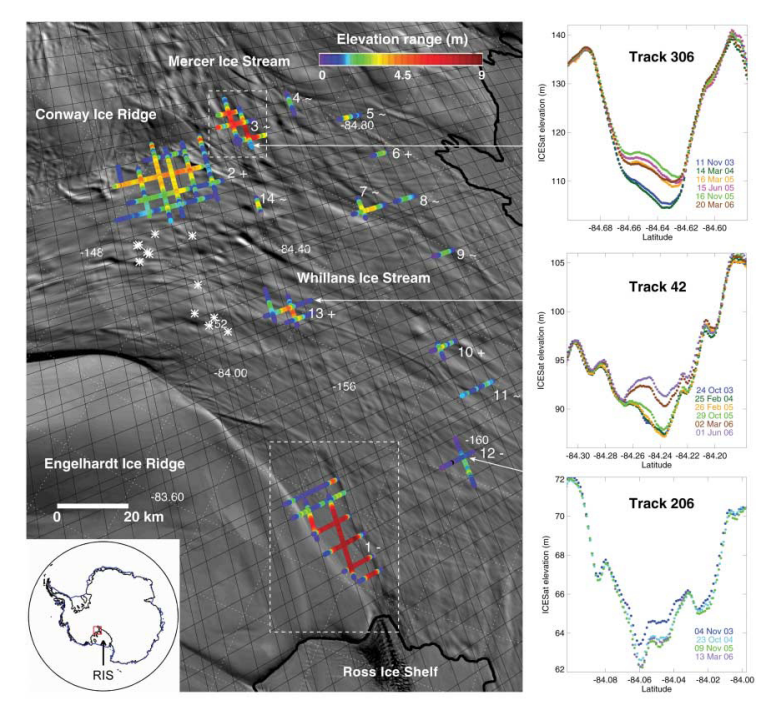

Figure 1.2 Repeat along track elevation profiles from ICESat data that cross areas of oscillating surface elevations. The oscillations in the surface elevation profiles are interpreted as indications of an active subglacial hydrologic system. From Fricker et al., (2007)

Short timescale-one to three years-changes in ice surface elevation have been interpreted as representing the movement and storage of subglacial water (Gray et al., 2005, Fricker et al., 2007, Carter et al., 2011) (figure 1.2). These observations have provided scientists with the ability to track changes in and map the locations of ponded subglacial water (Gray et al., 2005, Wingham et al., 2006, Fricker et al., 2007, Fricker and Scambos, 2009). The conclusions drawn from these observations are that the subglacial hydrologic networks can be extensive-connecting "lakes" up to $290 \mathrm{~km}$ apart-and capable of undergoing rapid, large-volume discharge events (Wingham et al., 2006, Carter et al., 2009). Stearns et al. (2008) observed a 10\% increase in the velocity of Byrd Glacier, East Antarctica, between December of 2005 and February 2007. The acceleration — and eventual deceleration—of 
the glacier was coincident with the drainage of two subglacial lakes. Stearns et al.'s 2008 work provides direct evidence that subglacial water systems can cause changes in ice dynamics on relatively short timescales. Subglacial lakes have been detected along the length of some ice streams, from their catchments to their grounding lines, and as a component of the subglacial hydrologic system must be intimately associated with fast ice flow (Siegert and Bamber, 2000, Fricker et al., 2007, Tulaczyk et al., 2008).

Subglacial lakes have been identified and classified in terms of their signatures in ice penetrating radar (Carter et al., 2007) and their temporal attributes have been examined using repeat laser altimetry (Carter et al., 2011). Lake location tends to follow the shape of the subglacial bed, and apparent transfer of water along lake networks is related to geographic setting in some way. While documented in a few examples, the relationship between subglacial water flow—or storage — and bed shape has not been explored.

\subsection{Purpose and scope of work}

The purpose of the present work is to investigate the overall influence of the basal topography on the water distribution beneath an ice stream, as well as how the ice and water flow may affect one another. These interests are motivated by recent observations of short time scale surface elevation change (Gray et al., 2005 and Fricker et al., 2007) but follow in the long standing tradition of water and basal sliding studies. The present study will employ a coupled model of ice and subglacial water flow to undertake several experiments that are designed to address important and presently unanswered questions regarding the feedbacks, timescales and stability of the ice-stream/subglacial water system. 


\section{CHAPTER 2}

\section{METHODS}

\subsection{Model domain description}

A two-dimensional, vertically integrated, coupled model of ice flow, ice thickness, and water flow is developed to explore the effects of the subglacial topography on water routing beneath ice streams. The finite element method is used to solve this coupled system of partial differential equations. The model is set in an idealized, rectangular domain $\Gamma$ in the horizontal $x-y$ plane (figure 2.1). The dimensions of the domain are $200 \mathrm{~km}$ in the $\mathrm{x}-$ direction-along flow-and $100 \mathrm{~km}$ in the $\mathrm{y}$-direction-transverse to the flow. The bed of the ice stream is inclined by $1^{\circ}$ sloping downward in the direction of ice flow (figure 2.1). Various idealized basal topographies are used in the model. They are created using

$$
Z=A \sin \left(\frac{n_{x} x \pi}{L_{x}}\right) \sin \left(\frac{n_{y} y \pi}{L_{y}}\right)
$$

in which the maximum height of the features is given by $A, n_{x}$ and $n_{y}$ are uniquely specified for each model and determine how many features will be created in the $\mathrm{x}$ and $\mathrm{y}$ directions respectively, $x$ and $y$ refer to a location within the domain, and $L_{x}$ and $L_{y}$ correspond to the length of the domain along the $\mathrm{x}$ and $\mathrm{y}$ axis respectively. A suite of experiments is carried 
out concerning the provinciality of topographic depressions. A Gaussian function

$$
Z_{G}=R_{O} e^{-\left[a_{G}\left(x-x_{0}\right)^{2}+2 b_{G}\left(x-x_{0}\right)\left(y-y_{0}\right)+c_{G}\left(y-y_{0}\right)^{2}\right]}
$$

in which $R_{O}$ is the depth of the depression extending below the value of $A, x_{0}$ and $y_{0}$ determine the center of the depression, and the coefficients $a_{G}, b_{G}$, and $c_{G}$ determine the orientation of the depression is subtracted from equation 2.1 to incrementally deepen a depression. The coefficients are

$$
\begin{aligned}
& a_{G}=\frac{\cos ^{2} \theta}{2 \sigma_{x}^{2}}+\frac{\sin ^{2} \theta}{2 \sigma_{y}^{2}} \\
& b_{G}=\frac{-\sin 2 \theta}{4 \sigma_{x}^{2}}+\frac{\sin 2 \theta}{4 \sigma_{y}^{2}} \\
& c_{G}=\frac{\sin ^{2} \theta}{2 \sigma_{x}^{2}}+\frac{\cos ^{2} \theta}{2 \sigma_{y}^{2}}
\end{aligned}
$$

in which $\theta$ controls the clockwise rotation of the Gaussian function and $\sigma_{x}$ and $\sigma_{y}$ determine the width of the function in the $\mathrm{x}$ and $\mathrm{y}$ directions respectively.

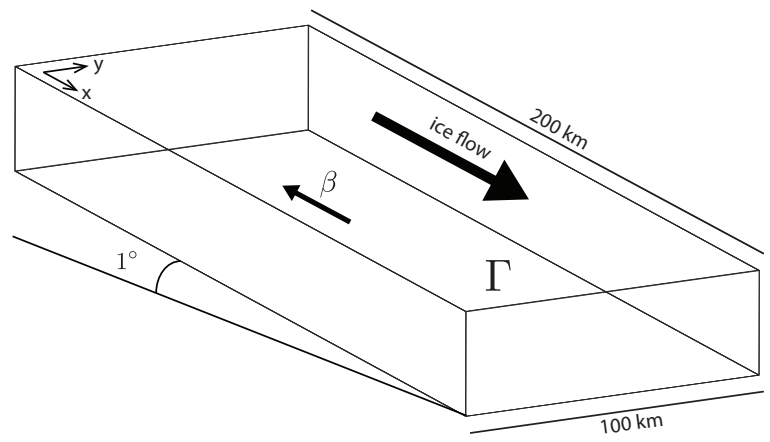

Figure 2.1 Depiction of the idealized ice stream domain $\Gamma$ used in this work. Ice and water flow down slope in the positive $\mathrm{x}$-direction. The bed is inclined $1^{\circ}$. 


\subsection{Ice flow model}

The ice flow model used in this work follows that of MacAyeal (1989). This model was chosen because it produces credible results, is relatively simple to implement, and has been widely used in various studies (Joughin et al., 2004, Schoof, 2006, Schoof, 2007, Sergienko et al., 2007, Sergienko and Hulbe, 2011). Following MacAyeal's formulation for ice flow over a very weak substrate, the horizontal velocities are assumed to be independent of the vertical coordinate and the stress balance is assumed to be intransient. The vertically-integrated stress balance equations for the flow of ice are

$$
\begin{aligned}
& \frac{\partial}{\partial x}\left[2 \nu H\left(2 \frac{\partial u_{i}}{\partial x}+\frac{\partial v_{i}}{\partial y}\right)\right]+\frac{\partial}{\partial y}\left[\nu H\left(\frac{\partial u_{i}}{\partial y}+\frac{\partial v_{i}}{\partial x}\right)\right]=\rho_{i} g H \frac{\partial S}{\partial x}+\beta u_{i} \\
& \frac{\partial}{\partial y}\left[2 \nu H\left(2 \frac{\partial v_{i}}{\partial y}+\frac{\partial u_{i}}{\partial x}\right)\right]+\frac{\partial}{\partial x}\left[\nu H\left(\frac{\partial u_{i}}{\partial y}+\frac{\partial v_{i}}{\partial x}\right)\right]=\rho_{i} g H \frac{\partial S}{\partial y}+\beta v_{i}
\end{aligned}
$$

where $\nu$ is the temperature dependent ice viscosity, $H$ is the ice thickness, $S$ is the surface elevation of the ice, $u_{i}$ and $v_{i}$ are ice flow velocity components in the $\mathrm{x}$ and $\mathrm{y}$ directions respectively, $\rho_{i}$ is the density of ice, $g$ is the acceleration due to gravity, and $\beta$ is a positive definite basal traction parameter. The terms of the left hand side represent the depthintegrated viscous stress divergence and those on the right hand side represent the gravity induced stresses and the component of basal friction. The equations state that the stress divergence in the ice must balance the flow of the ice due to gravity and the resistance to that flow.

\subsubsection{Viscosity}

Following the usual convention, the relatively thin firn layer atop the ice stream is ignored, and the ice is assumed to be incompressible. Nye's generalization of Glen's flow law (Nye, 
1953 ) is used to express the relationship between strain rates and stresses in the ice (Van der Veen, 1999). The flow law is implemented using an effective ice viscosity that is dependent on both the strain rates and temperature of the ice. The ice viscosity is

$$
\nu=\frac{\bar{B}}{2\left[\left(\frac{\partial u}{\partial x}\right)^{2}+\left(\frac{\partial v}{\partial y}\right)^{2}+\frac{1}{4}\left(\frac{\partial u}{\partial y}+\frac{\partial v}{\partial x}\right)^{2}+\frac{\partial u}{\partial x} \frac{\partial v}{\partial y}\right]^{\frac{n-1}{n}}}
$$

in which $\bar{B}$ is a depth-averaged, temperature dependent ice stiffness parameter. The formula for determining $B$ is

$$
\bar{B}=B_{0} e^{-T_{0} / T-C /\left(T_{r}-T\right)^{k}}
$$

in which $B_{0}$ is an empirically derived constant used to determine ice stiffness, $T$ is the temperature of the ice expressed in kelvin, $T_{r}$ is the triple point of water expressed in kelvin, $k$ and $C$ are empirically derived constants, and $n$ is the flow law exponent. Experiments conducted to determine the value of $n$ support a value of $n \approx 3$ (Van der Veen, 1999). These relations indicate that warmer ice corresponds to a lower stiffness parameter $B$ thus having a lower viscosity and flowing more freely.

\subsubsection{Ice thickness}

The vertically integrated ice mass balance is

$$
\frac{\partial H}{\partial t}=-\nabla \cdot\left(\mathbf{u}_{\mathrm{i}} H\right)+\dot{a}+\dot{b}
$$

in which $\nabla$ is the two-dimensional divergence operator, $\mathrm{u}_{\mathrm{i}}$ is the two dimensional ice velocity vector, and $\dot{a}$ and $\dot{b}$ are the surface and basal accumulation rates respectively. The equation introduces time as an independent variable to the system of equations describing ice flow and is thus sometimes called the "prognostic equation," meaning that it allows future ice sheet geometries to be computed from initial geometries. 


\subsubsection{Initial and boundary conditions on the ice flow model}

The domain has six distinct boundaries for which conditions must be set on both the momentum and mass equations. In the ice flow model the surface and basal accumulation rates are set to $\dot{a}$ and $\dot{b}$ respectively. At the lateral margins the velocity is subject to a Dirichlet boundary condition (Haberman, 2004) such that $\mathrm{u}_{\mathrm{i}}=0$. At the longitudinal ends of the domain a periodic boundary condition is applied. This condition allows the flow of the idealized ice stream to be simulated as though it were part of a larger ice sheet.

The ice stream thickness is initially set to a uniform value of $1 \mathrm{~km}$. At the upstream end the thickness is prescribed to be $1 \mathrm{~km}$ thick. Along all the other margins a zero flux boundary condition is applied. Artificial diffusion is added to the model in the form of a weak contribution to improve numerical stability.

\subsection{Water flow model}

The water flow model used to determine the spatial distribution and depth of the fresh water layer beneath the ice stream over time is based on a Hele-Shaw description of fluid flow between two parallel plates (Lamb, 1945). The model assumes that the basal water is stored in a distributed system in which the flow is sheet-like, and the velocity is proportional to the gradient in the hydraulic potential (Clarke, 2005 Le Brocq et al., 2009 Sergienko and Hulbe, 2011). The governing equation is

$$
\frac{\partial w}{\partial t}=-\nabla \cdot\left(\mathbf{u}_{\mathrm{w}} w\right)+\dot{b}
$$


in which $w$ is the depth of the water layer and $\mathbf{u}_{\mathrm{w}}$ is the two-dimensional, depth-averaged water velocity vector. Following Clarke (2005) the water velocity is

$$
\mathrm{u}_{\mathrm{w}}=-\frac{K}{\rho_{w} g} \nabla \phi
$$

in which $K$ is the hydraulic conductivity of the water layer, $\rho_{w}$ is the density of water, and $\phi$ is the hydraulic potential field. The hydraulic potential field is a function of the water pressure and elevation. It is found using

$$
\phi=p_{w}+\rho_{w} g z
$$

where $p_{w}$ is the water pressure and $z$ is the elevation of the basal topography. The water pressure is calculated as

$$
p_{w}=\rho_{i} g H-N
$$

where $N$ is the effective pressure. The effective pressure is the difference between the ice overburden pressure $p_{i}$ and the water pressure, $N \equiv p_{i}-p_{w}$. The water pressure in a distributed system can be assumed to be approximately equal to the ice overburden pressure. Thus, $N=0$ in equation 2.11. Combining this simplification with equation 2.10 and applying the two-dimensional divergence operator results in

$$
\nabla \phi=\rho_{i} g \nabla S+\left(\rho_{w}-\rho_{i}\right) g \nabla z
$$

Equation 2.12 represents the hydraulic gradient beneath a body of ice. An interesting and well-known consequence of equation 2.12 is that the surface slope of the ice plays a more important role in determining the water's path. The ice surface slope is approximately ten times more important to the potential gradient than the topography beneath the ice stream due to the small difference in the densities of water and ice. 


\subsubsection{Initial and boundary conditions on the water flow model}

The initial condition imposed on the water flow equations is given by equaiton 2.13a. A Dirichlet condition is imposed at the upstream margin, equation 2.13b. Neumann conditions (Haberman, 2004), given by equation 2.13c, are imposed on the lateral margins of the domain. At the downstream longitudinal margin, a Neuman condition is applied such that the flux is proportional to the water flow velocity in the $\mathrm{x}$-direction $u_{w}$, equation $2.13 \mathrm{~d}$. As with the ice flow model, artificial diffusion is added to the model in the form of a weak contribution to aid numerical stability.

$$
\begin{aligned}
w(x, y, t=0) & =0 \\
w(x=0, y, t) & =0 \\
\frac{\partial}{\partial y} w(x, y=0, L y, t) & =0 \\
\frac{\partial}{\partial x}\left[u_{w} w(x, y=L y, t)\right] & =0
\end{aligned}
$$

\subsection{Model coupling}

To date few works have incorporated a two-way coupled ice and water flow. Many models account for the flow of ice and of water, but without two-way coupling, feedbacks that may alter the geometry and flow of both materials are missing (figure 2.2). Changes in the geometry will affect the flow of water by altering the gradients in the hydraulic potential and could redistribute the water in such a way as to reinforce or halt further changes in ice geometry. The ice and water models are coupled via the basal sliding parameter $\beta$. When the model is one-way coupled-i.e., no feedbacks-a static water distribution results (Upper panels of figure 2.2). It is only when the system is two-way coupled that feedbacks allow 
transient water distribution to become a feature of the system (Lower panels of figure 2.2).
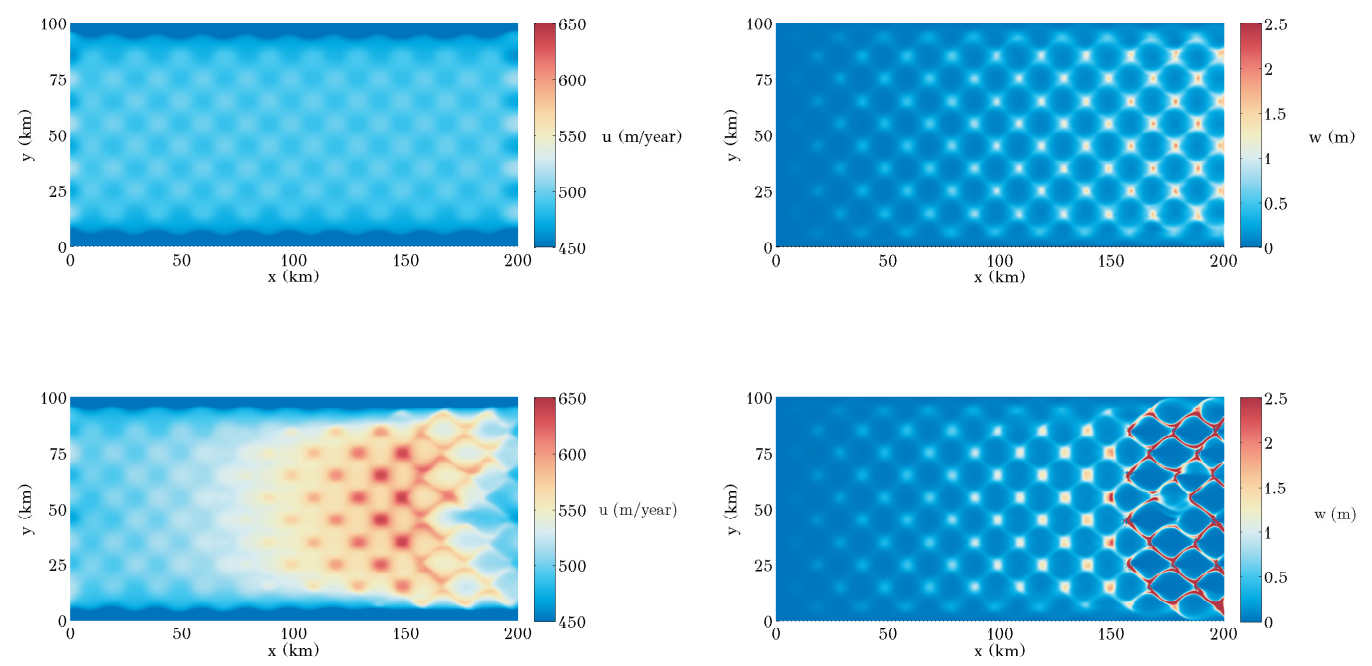

Figure 2.2 The upper two panels show model results in which ice and water flow are one-way coupled-the ice flow model is influenced by the water flow but the water flow is not influenced by the ice flow. The lower two panels illustrate the effects that two-way coupling has on the results. Very different results are achieved when the models are able to influence one another.

There is no tried and true approach for incorporating basal sliding into ice sheet models. One approach that provides good agreement between observations and model results is to assume $\beta \propto \mathrm{u}_{\mathrm{i}}$ (MacAyeal, 1989). Here, a different approach is taken. The ice and water flow models are coupled together by making the basal traction a function of the water layer depth via

$$
\beta(w)= \begin{cases}\beta_{c} \cdot(0.5-|w|) & \text { if } \mathrm{w}<0.5 \mathrm{~m} \\ 0 & \text { if } \mathrm{w} \geq 0.5 \mathrm{~m}\end{cases}
$$

where $\beta_{C}$ is a constant value of basal traction and $|w|$ is the absolute value of the water thickness. This states that there exists a background level of basal traction $\beta_{C}$ resisting the flow of the ice that is modified depending on the depth of the water layer. As the water layer depth approaches $0.5 \mathrm{~m}$, the basal traction declines. In regions where the depth is equal 
to or in excess of $0.5 \mathrm{~m}$, the basal traction is reduced to zero. Essentially, the background traction is modified by the presence of a sufficiently deep layer of water capable of altering the velocity of the ice flow.

\subsection{Solving the system of equations}

\subsubsection{Finite element method}

The equations describing the behavior of ice and water flow-equations $2.4 \mathrm{a}, 2.4 \mathrm{~b}, 2.7$, and 2.8-are the central equations of this work. They are solved numerically over the idealized domain (figure 2.1) using the commercially available finite-element solver COMSOL Multiphysics ${ }^{\circ}$-referred to throughout the rest of the document as simply COMSOL. COMSOL has been successfully implemented in previous studies of glaciers and ice sheets (Johnson and Staiger, 2007, Sergienko et al., 2007, Campbell, 2009 Sergienko and Hulbe,2011).

The procedure can be broken down into three stages: preprocessing, analysis, and postprocessing. The preprocessing step involves the construction of the model domain and the division of this domain into discrete elements that are connected at nodes. The model domain is divided into a set of finite intervals called elements (in this case, in two dimensions), defined by a set of nodes. If these intervals are sufficiently small, solutions to the differential equations that comprise the model may be approximated in finite terms over these intervals. In the case of the finite element approach, the second step then is to create a set of interpolation functions that represent the relationships amongst the elements in the domain and allow the equations to be integrated over the intervals. The postprocessing step involves analysing the results of the model for reasonability and using them to refine the model or make inferences regarding the behavior of the system given the physics that went 
into the processing step. If necessary, the physics can be modified to account for more or fewer aspects of the system and the process repeated until the results are satisfactory.

\subsubsection{Solution procedure}

The model is initialized in a two-step process, beginning with the ice thickness and velocity and then moving on to couple these with the water flow model. Coupling proceeds in two steps, first one-way, between an initial water field and the overlying ice, and then finally the full two-way coupling is enacted. The sequence is required to ensure convergence of the model equations at the final step. A combination of steady state and transient solution methods are used in the first step to create initial distributions of ice surface velocity, ice thickness, and water depth. The ice flow equations are solved with the given boundary conditions and parameters to produce initial, steady state ice thickness and velocity fields. Steady state ice surface velocity, ice thickness, and water depths are taken to be reached when the absolute value of the difference between the current solution and the previous solution is less than some arbitrarily set threshold-the solution has converged. In this work that threshold is $1 \cdot 10^{-6} \mathrm{~m}_{\text {year }}{ }^{-2}$ in the case of the ice surface velocity and $1 \cdot 10^{-6} \mathrm{~m}_{\text {year }}{ }^{-1}$ in the case of the ice thickness and water depth.

The water depth field is initialized by calculating forward five years using the water depth equation and the ice-flow-only steady state ice thickness and velocity. A steady state water depth is then calculated using this transient water depth solution as its initial condition. A steady state water depth distribution has been achieved when the changes in the field occur on the order of $1 \cdot 10^{-6} \mathrm{~m}$. At this point an uncoupled, steady state solution to the system of equations has been obtained. The systems are not necessarily internally consistent in that the results form the ice flow model may not correspond to what would be expected given 
the calculated basal water distribution.

To bring the water depth distribution, ice surface velocity, and ice thickness results into agreement, the results from the first step are used as the initial conditions for a second set of calculations, now with one-way coupling. That is, the sliding parameter is made a function of the water depth following equations $2.13 \mathrm{a}$ and $2.13 \mathrm{~b}$. The ice surface velocity and ice thickness equations are solved iteratively until a steady state-using the same criteria for convergence as in the first step-has been reached. The water flow equations are not solved, in other words, ice flow responds to the presence of water, but the water flow does not respond to changes in the ice flow.

Finally, the full set of two-way coupled equations are solved in a transient simulation, using the results of the prior steps as initial conditions. After the solutions have converged, the model results are exported to MATLAB ${ }^{\circledR}$ for post processing.

There are some issues with the implementation of the water flow model. In some model experiments numerical instabilities cause the water layer depth to spike at various times in the calculations. This does not occur in all experiments. These values are believed to be spurious because they occur locally at only one node in the mesh; they are in excess of physically reasonable values, and they gradually disappear. Instabilities like these are known to appear in numerical models of thin film flows, for example Le Brocq et al. (2009). The excess water produced by the instability is not part of the correct solution to the governing equations - that is, it is not water produced by melting or transported from elsewhere-and thus should not be retained as part of the solution to equation 2.8. Thus, a maximum threshold on water depth is set and applied. Any depth greater than $10 \mathrm{~m}$ is categorized as invalid and reduced to $10 \mathrm{~m}$. The procedure affects very few nodes in the model domain. 
CHAPTER 3

EXPERIMENTS AND RESULTS

\subsection{Lake provinciality}

\subsubsection{Experiment description}

The effect of basal topography on water storage and the length scales over which individual basal features influence water flow are investigated here. Model bed morphologies are generated using equations 2.1 and 2.2 with $n_{x}=5$ and $n_{y}=3$. The depression centered a $x=100 \mathrm{~km}, y=50 \mathrm{~km}$ is progressively deepened from a reference depth of $R=0 \mathrm{~m}$ in increments of $10 \mathrm{~m}$ up to $R=50 \mathrm{~m}$. The model equations are two-way coupled and solved as described in Chapter 2.

\subsubsection{Results}

The difference in basal water distribution between each modified bed result and the model run with the reference bed were determined by subtracting the reference bed distribution from that of the modified beds (figures 3.7, 3.8, 3.9, 3.10, 3.11). Positive values of the difference indicate that water depths increase with an increase in the depth of the depression 
whereas negative values indicate a decrease. The differences in the water distributions are on the order of centimeters.

The water thickness anomaly is similar across all of the experiments (Figures 3.7 to 3.11 ). The pattern of the anomaly is an elongated crescent, with increased water depth over the modified basal low and decreased water depth immediately upstream and in a wake downstream of the basal low. The thinned wake is flanked by linear regions of modest water layer thickening. The pattern becomes more pronounced as the magnitude of the perturbation to the bed shape grows and at the extreme range of the perturbation, the central part of the wake thickens.

The pattern in the thickness anomaly reflects the effect of changing ice thickness on the hydraulic potential. Increasing the depth of the central depression increases the thickness of the ice over it. The thicker ice over the depression results in thicker ice downstream over the adjacent topographic high. These changes alter the hydraulic potential around the topographic high such that lows in the hydraulic potential occur at lower elevations on the topographic high. Because water flows from areas of high potential to low potential, it flows to these regions increasing the depth.

Increasing the depression's depth results in decreasing water depths over greater areas upstream of the pond and a combination of increases and decreases in areas downstream of the pond. At its greatest extent this effect influences water depths up to $46 \mathrm{~km}$ upstream of the depression. The relationship between the perturbation depth and the distance upstream to which the effects extend is nonlinear (figure 3.12). The extent of the effect grows as the perturbation grows, but the effectiveness of deepening declines once the depth of the subglacial well is more than half its width (figure 3.12). 

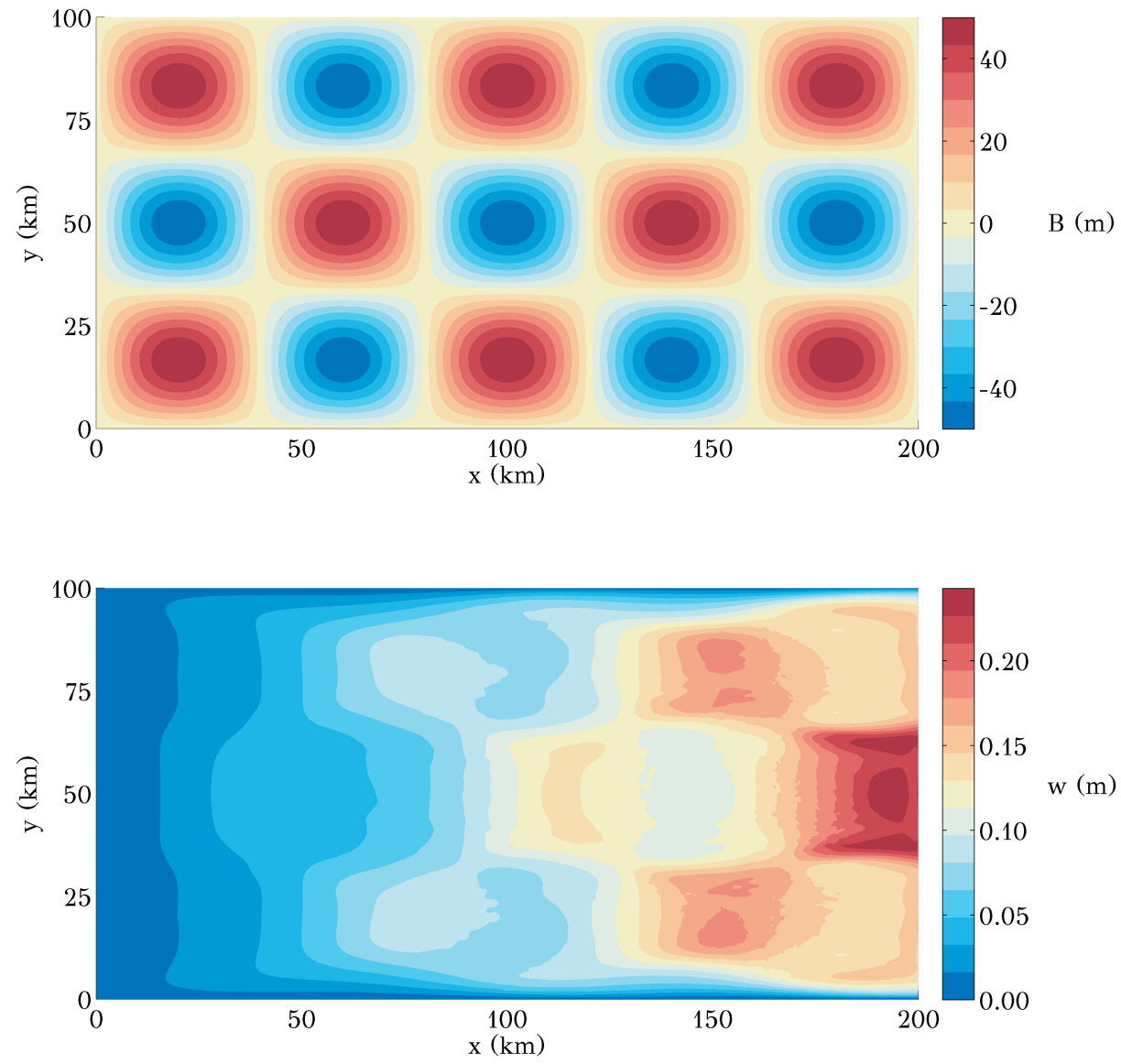

Figure 3.1 A)Basal topography (m) and B) water depth distrubution (m) of the reference configuration. 

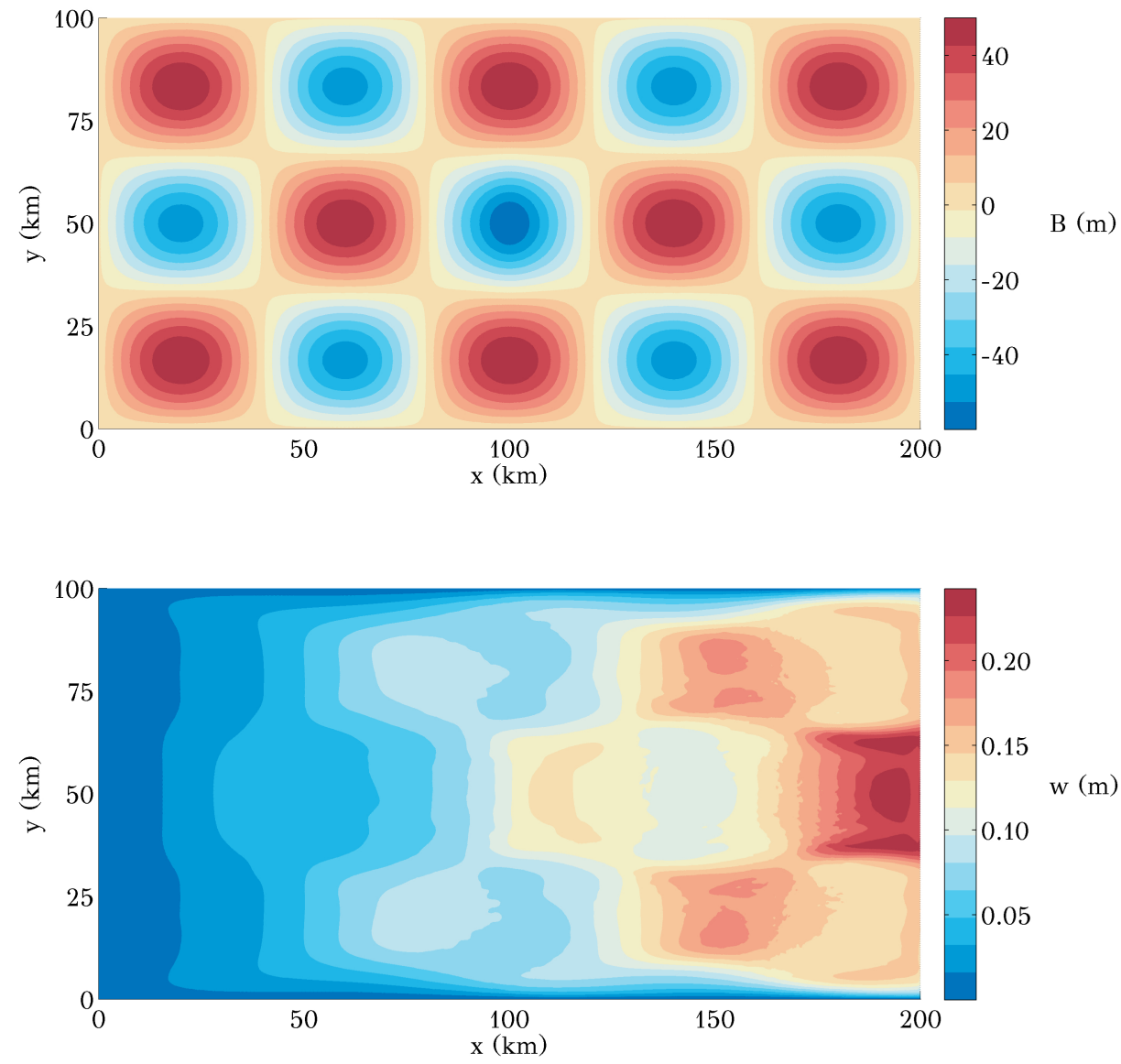

Figure 3.2 A)Basal topography (m) and B) water depth distrubution (m) for a depression $10 \mathrm{~m}$ below the reference. 

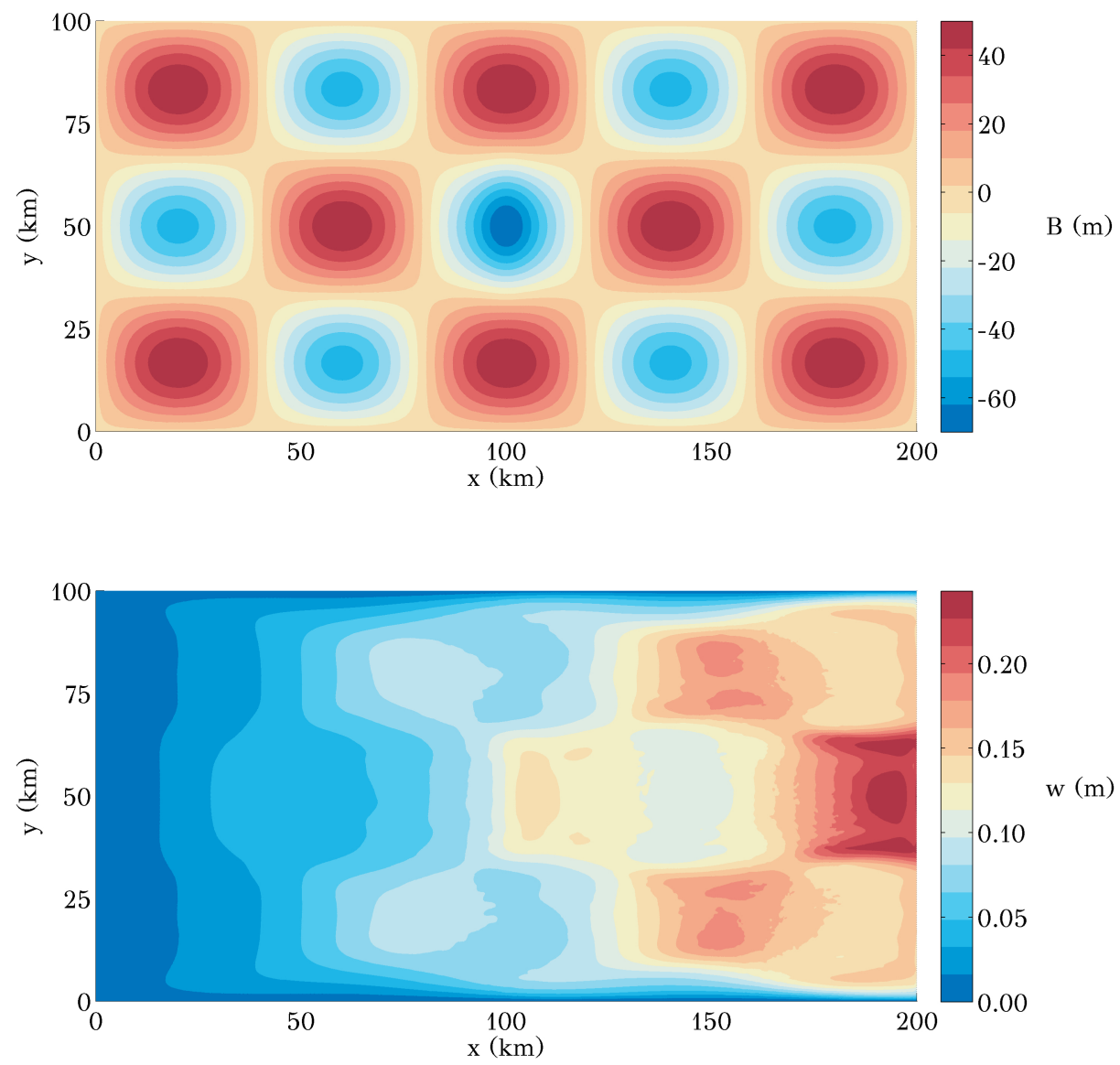

Figure 3.3 A)Basal topography (m) and B) water depth distrubution (m) for a depression $20 \mathrm{~m}$ below the reference. 

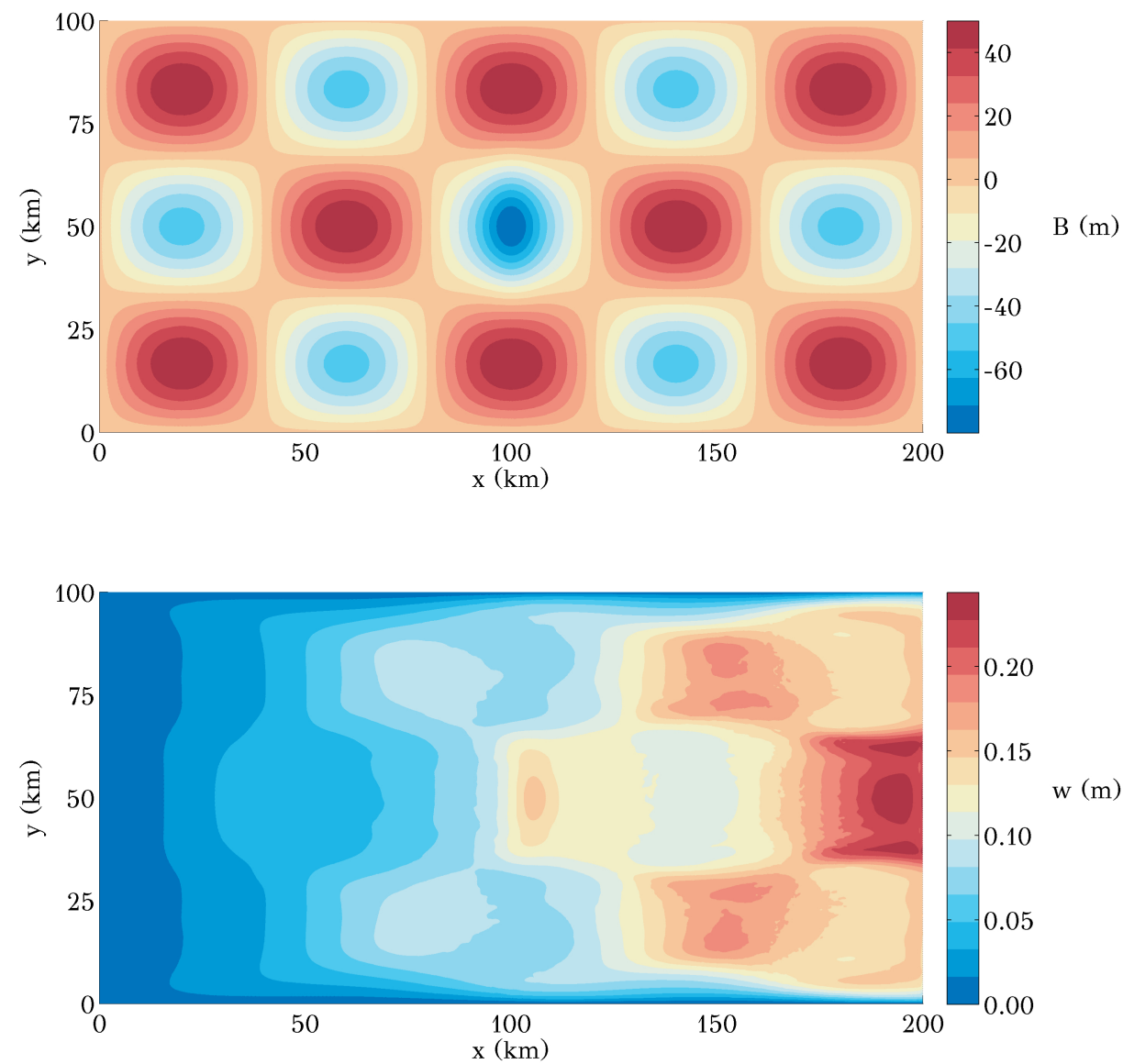

Figure 3.4 A)Basal topography (m) and B) water depth distrubution (m) for a depression $30 \mathrm{~m}$ below the reference. 

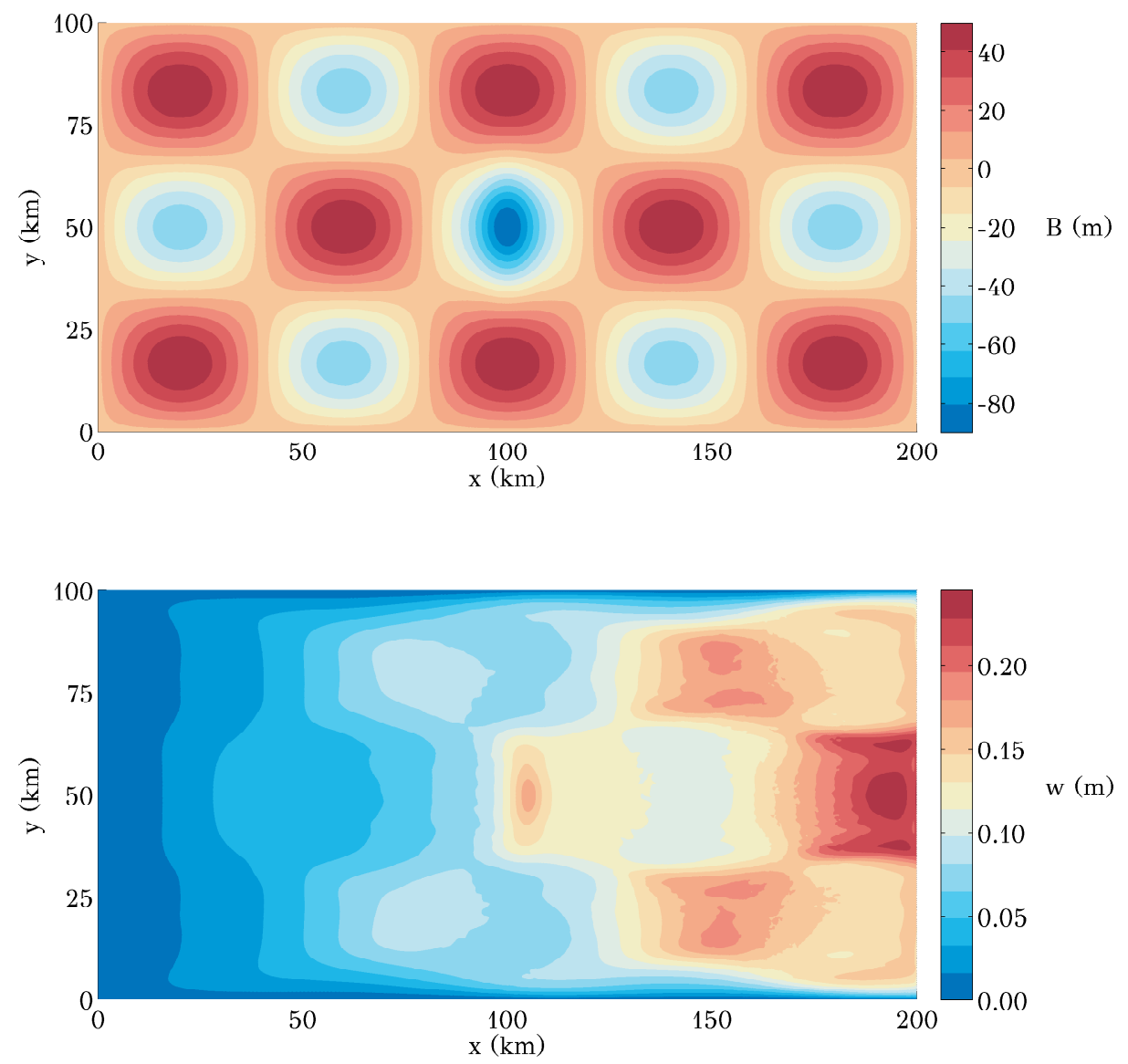

Figure 3.5 A)Basal topography (m) and B) water depth distrubution (m) for a depression $40 \mathrm{~m}$ below the reference. 

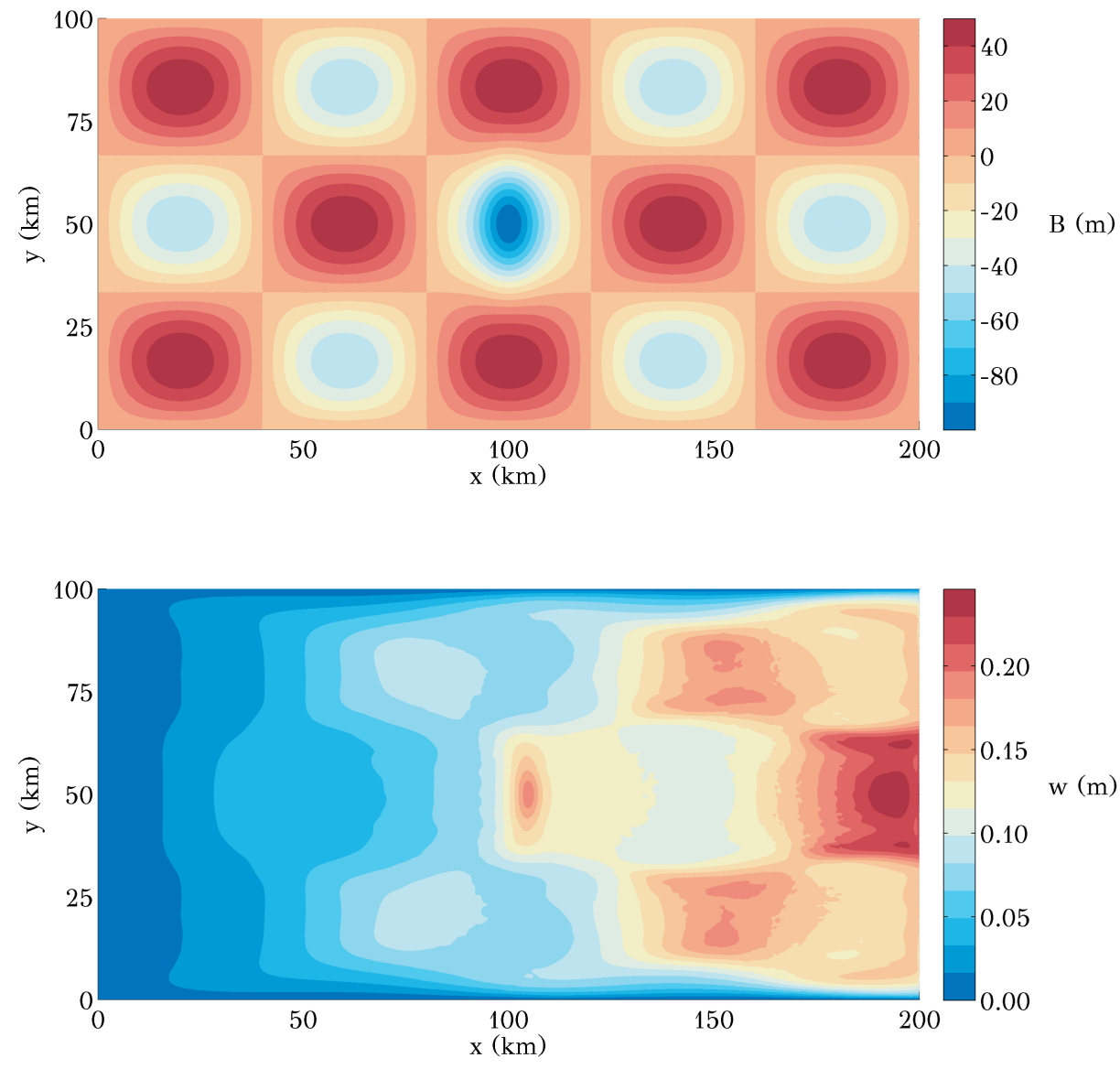

Figure 3.6 A)Basal topography (m) and B) water depth distrubution (m) for a depression $50 \mathrm{~m}$ below the reference. 


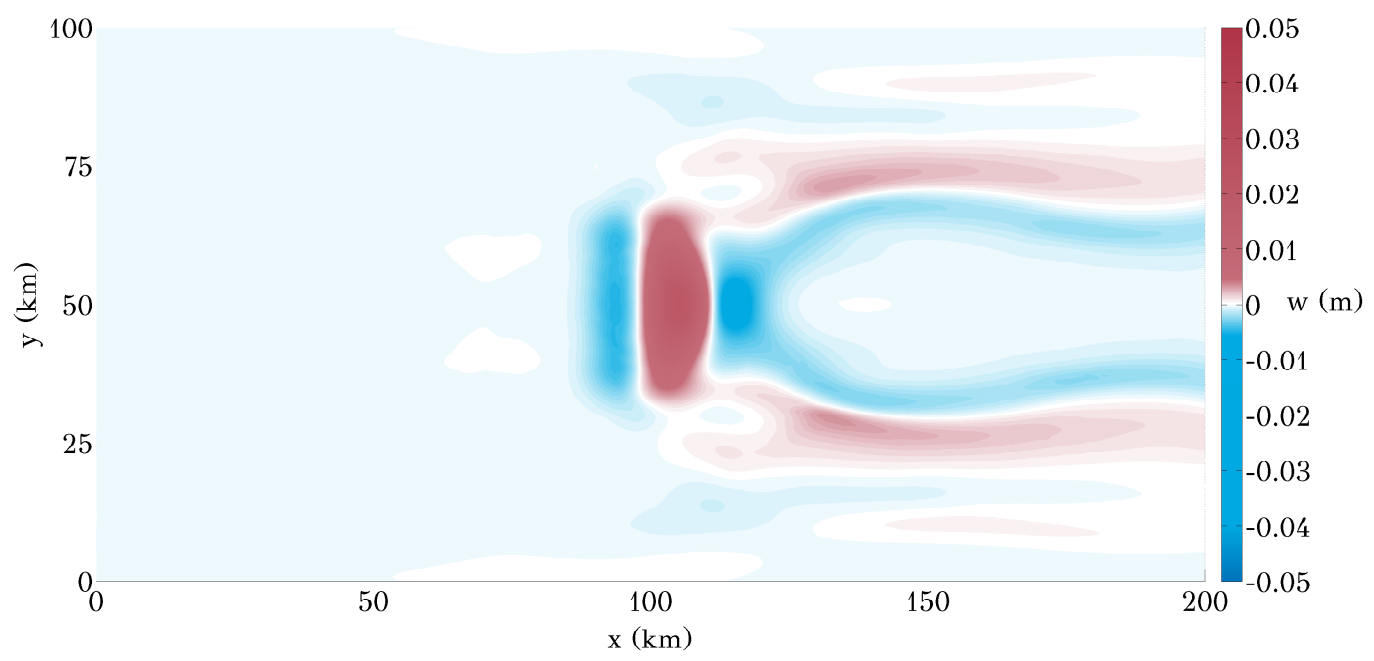

Figure 3.7 Difference in water depth distribution $(\mathrm{m})$ between the initial configuration and the configuration with a depression that is $10 \mathrm{~m}$ deeper.

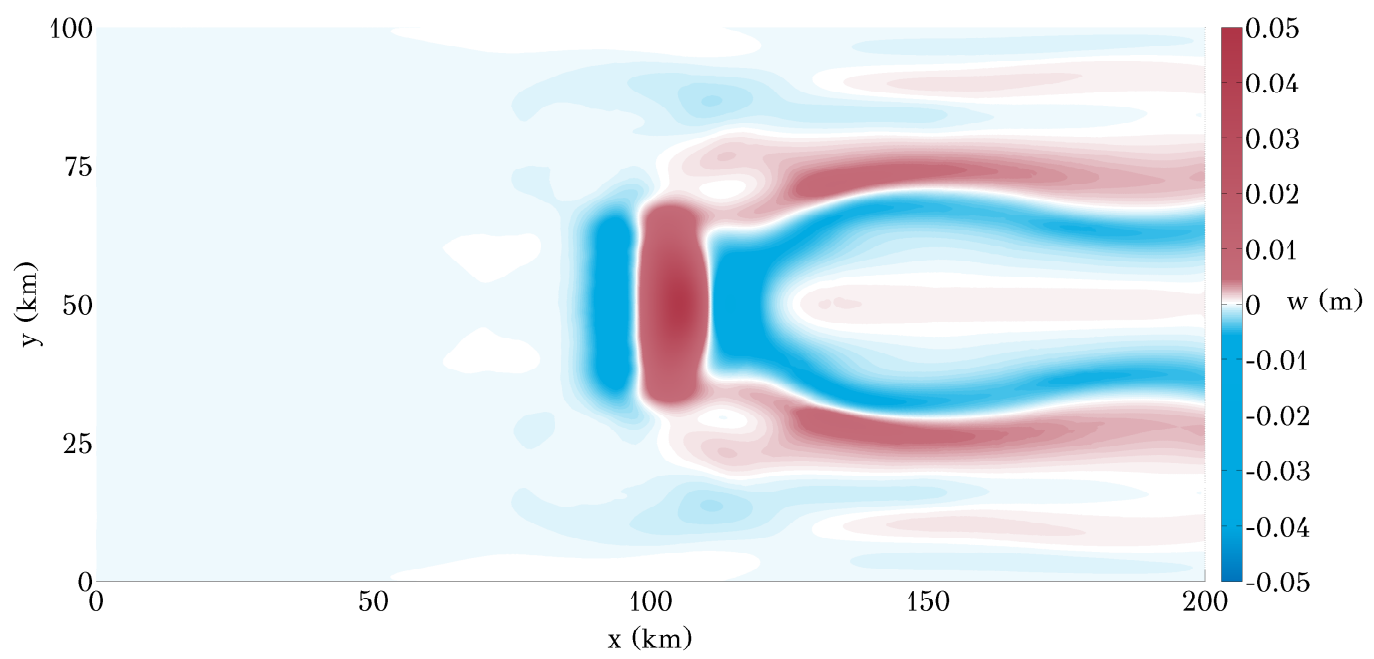

Figure 3.8 Difference in water depth distribution $(\mathrm{m})$ between the initial configuration and the configuration with a depression that is $20 \mathrm{~m}$ deeper. 


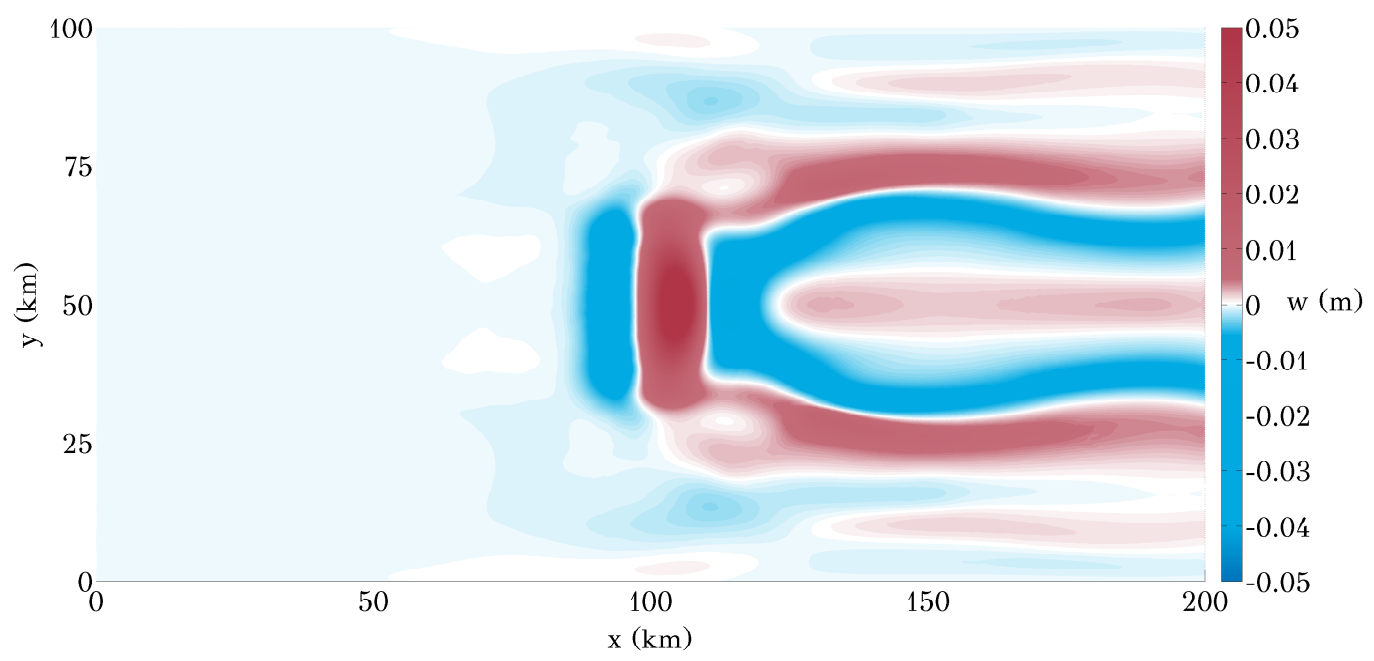

Figure 3.9 Difference in water depth distribution $(\mathrm{m})$ between the initial configuration and the configuration with a depression that is $30 \mathrm{~m}$ deeper.

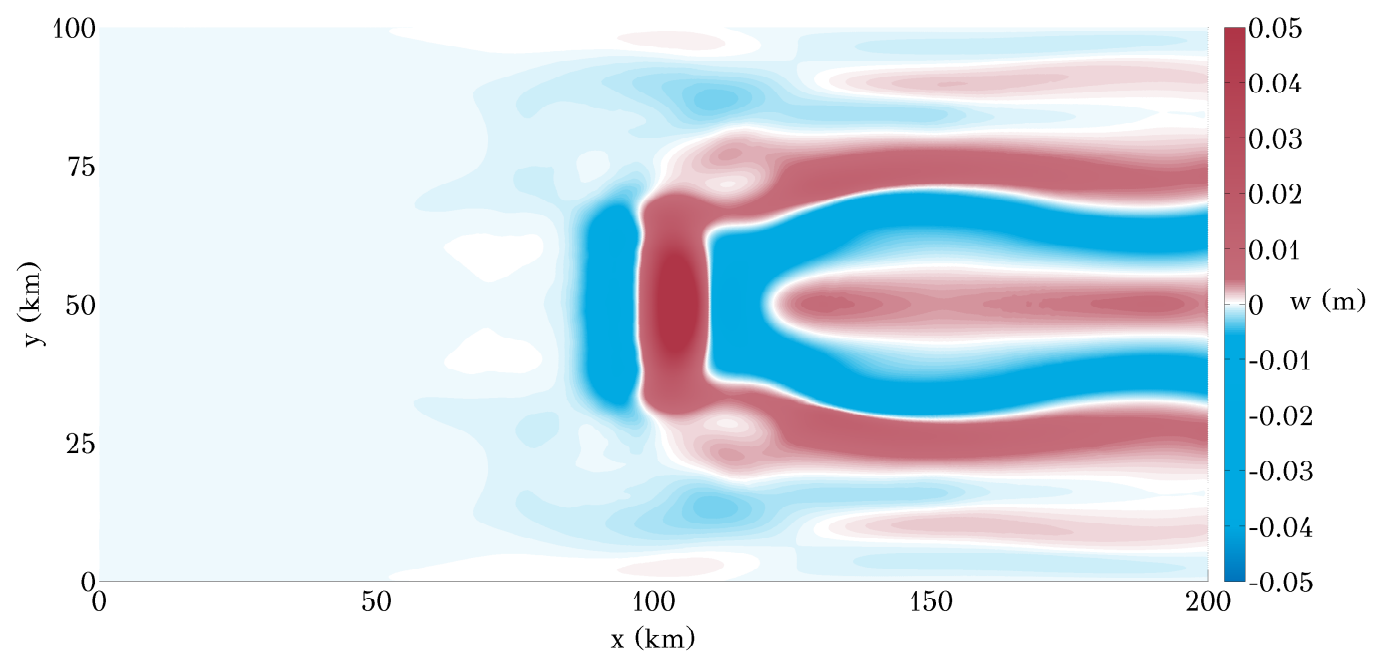

Figure 3.10 Difference in water depth distribution $(\mathrm{m})$ between the initial configuration and the configuration with a depression that is $40 \mathrm{~m}$ deeper. 




Figure 3.11 Difference in water depth distribution $(\mathrm{m})$ between the initial configuration and the configuration with a depression that is $50 \mathrm{~m}$ deeper.

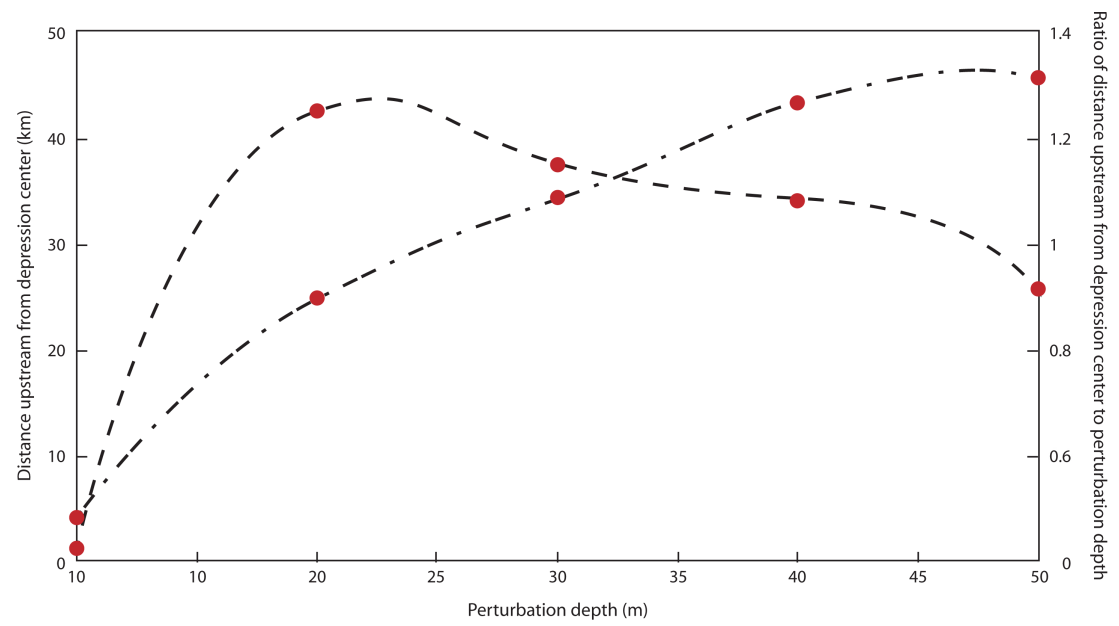

Figure 3.12 Maximum distance upstream to which the effects of increasing the perturbation reach (dashed line). Ratio of the distance upstream to which the effects of the increased perturbation reach to the depth of the perturbation (dotted line). 


\subsection{Basal topography}

\subsubsection{Experiment description}

The goal of this experiment is to investigate how the geometry of different bed morphologies might influence the transport and storage of water beneath an ice stream. The model for ice and water flow-described in Chapter 2-is used in conjunction with different basal topographies. The models are run forward from their initial state-described in Chapter 2-for ten years with 30 day time steps. The time series of each model is examined to identify locations in the domain that experience relatively large variations ice thickness, ice surface speed, and water layer depth. These variations are plotted as time series at those locations in order to identify characteristic time scales in the transient fields. Two types of patterns are of interest, those in which oscillations develop and those that tend towards a simpler steady state. Changes taking place over monthly and yearly timescales are of interest, and a time frame of ten years was chosen for the model runs based on the timescales of interest and observational data (see section 1.3).

In order to establish that oscillations in the model fields are attributes of the coupled system and not artifacts associated with model initialization, the first experiment is run out to 150 years and time series data are extracted at five randomly chosen points in the domain (figure 3.13). The points are restricted to the region where the water depth varies, i.e. $130 \leq$ $x \leq 200$ and $25 \leq y \leq 75$. Different linear trends are seen in the water depth at each point indicating that there is no problem with model drift (figure 3.14). That is, the model is not artificially accumulating or losing water over time, which would indicate a violation of mass

conservation. The oscillations in the model fields have complicated patterns in time, and 
these patterns are not reproduced across all locations. There is an initial period in which the models adjust to their boundary conditions and concurrent changes in ice height, ice surface velocity, and water depth. This initial time period for adjustment is short compared the ten year model run.

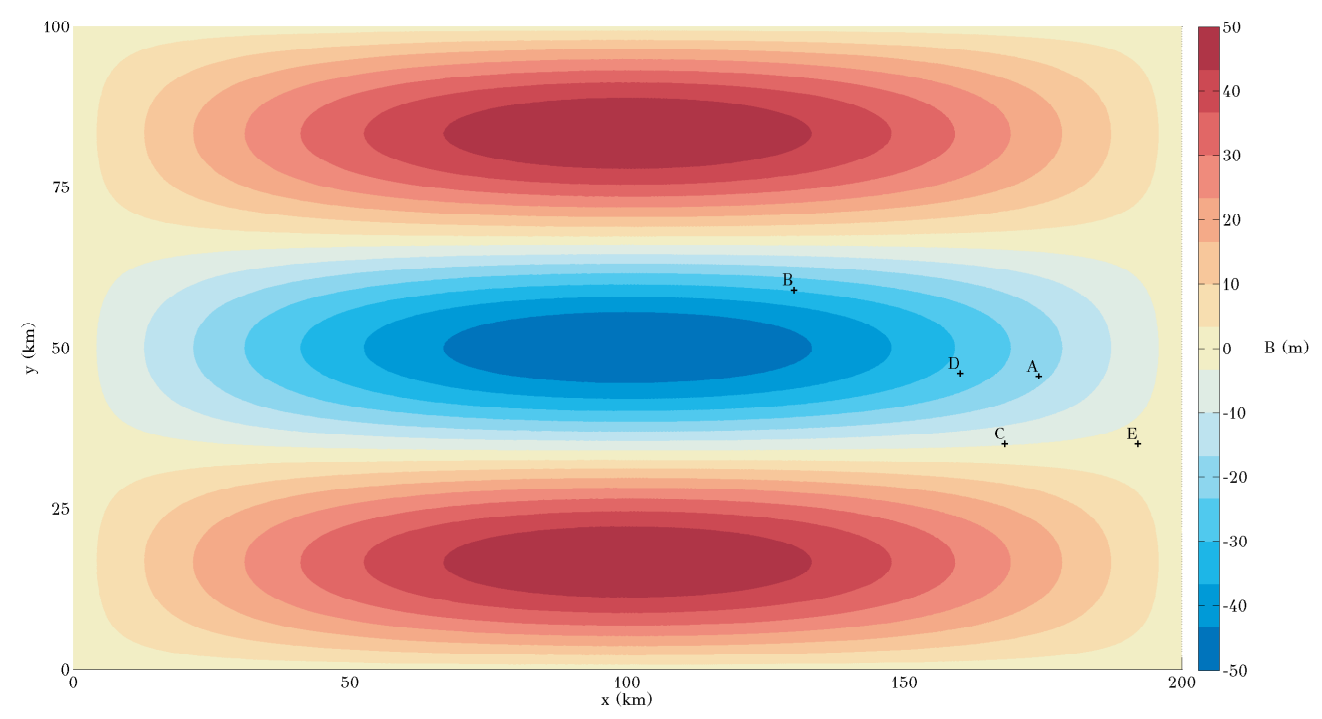

Figure $3.13 \mathrm{~A}$ ) Points in the domain at which water depth $(\mathrm{m})$ is tracked over 150 years. The coordinates of the points are $\mathrm{A}=(174 \mathrm{~km}, 35 \mathrm{~km}), \mathrm{B}=(130 \mathrm{~km}, 59 \mathrm{~km})$, $\mathrm{C}=(168 \mathrm{~km}, 35 \mathrm{~km}), \mathrm{D}=(160 \mathrm{~km}, 46 \mathrm{~km})$, and $\mathrm{E}=(192 \mathrm{~km}, 35 \mathrm{~km})$.

\subsubsection{Results}

The first geometry investigated consists of two ridges and a trough oriented parallel to ice flow (figure 3.15A). The features are created using equation 2.1 with $n_{x}=1$ and $n_{y}=$ 3. The features are $200 \mathrm{~km}$ long and $33 \mathrm{~km}$ wide. A fan-like distribution develops as the water emerges from within the depression. The fan originates on the upstream side of the depression and spreads out laterally confined by the two ridges at the downstream end.

The water distribution evolves from a single extensive pond into a distributed system that is continuously changing (figure 3.17). Changes in the distribution occur over monthly 

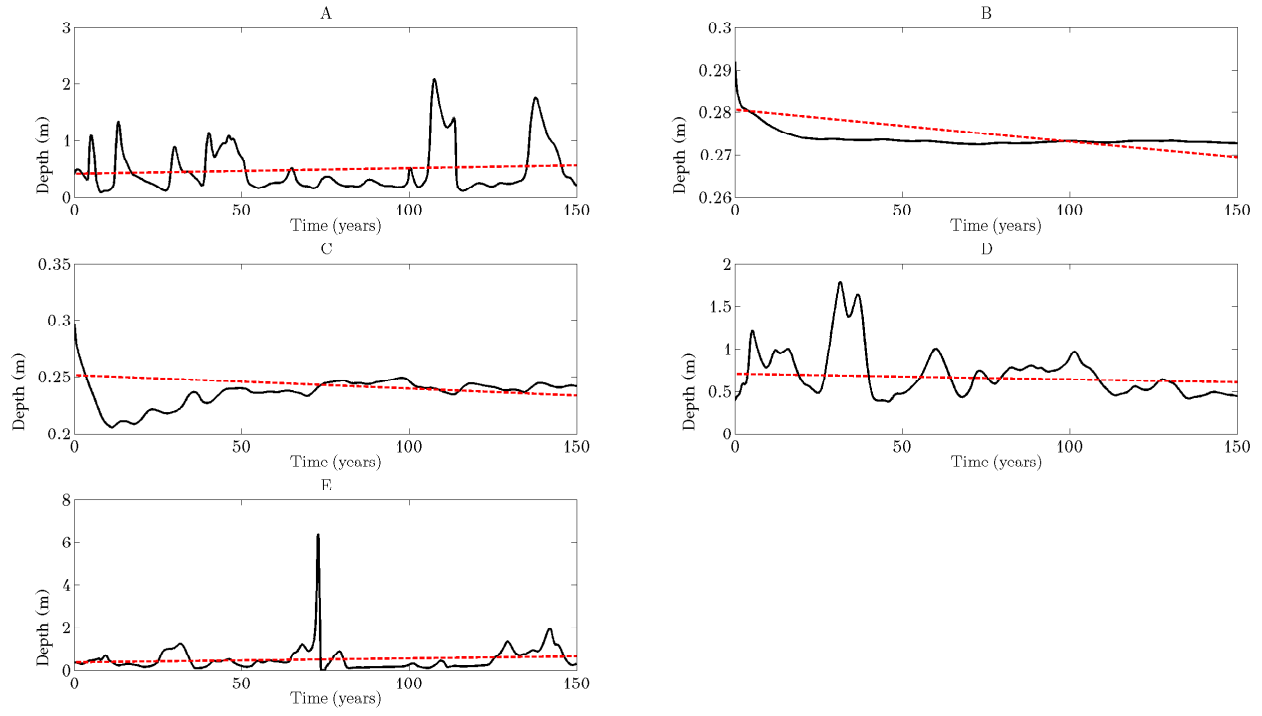

Figure 3.14 Values of water depth at five different points in the domain. The label of the panel corresponds to the point at which the water depth was tracked (figure 3.13). Notice that the trends do not all have the same sign.
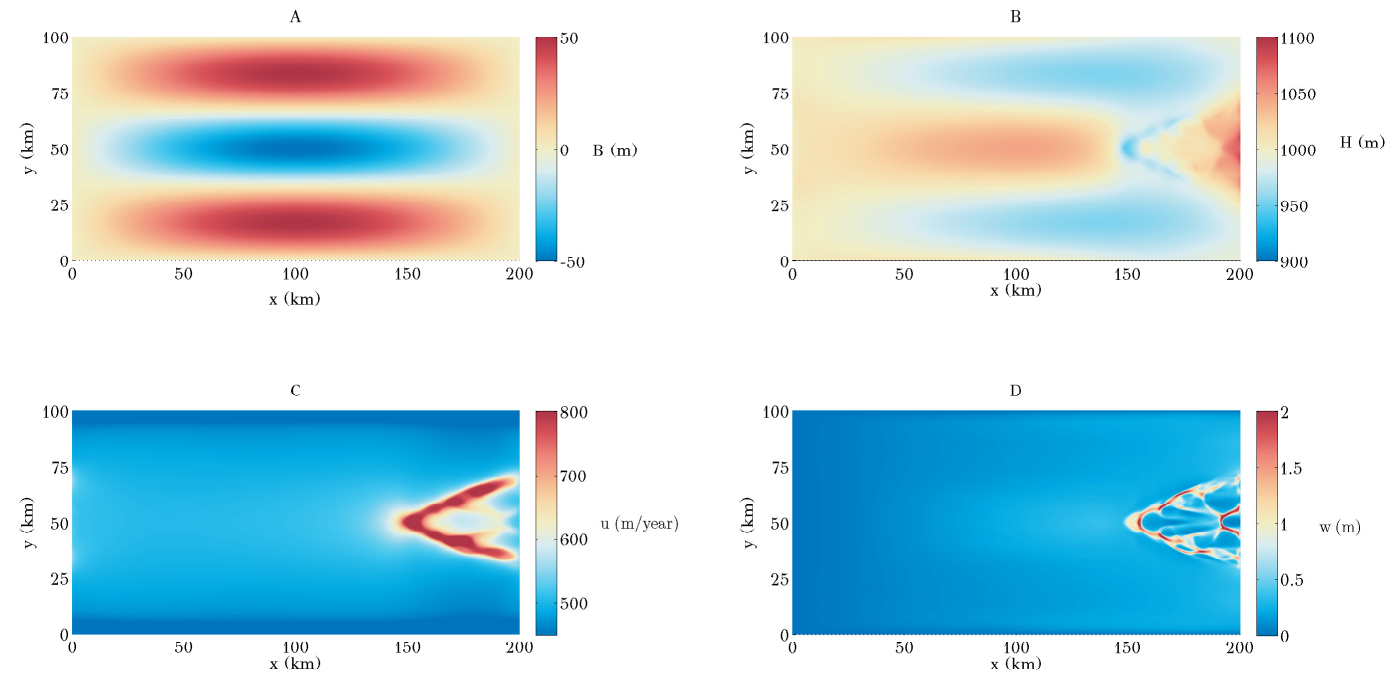

Figure 3.15 A) Values and spatial distributions of the bed topography (m) with $n_{x}=1$ and $\left.n_{y}=3, \mathrm{~B}\right)$ ice surface elevation $\left.(\mathrm{m}), \mathrm{C}\right)$ ice surface velocity $\left(\right.$ myear $^{-1}$ ), and $\mathrm{D})$ the depth of the subglacial water layer (m) after 10 years. 

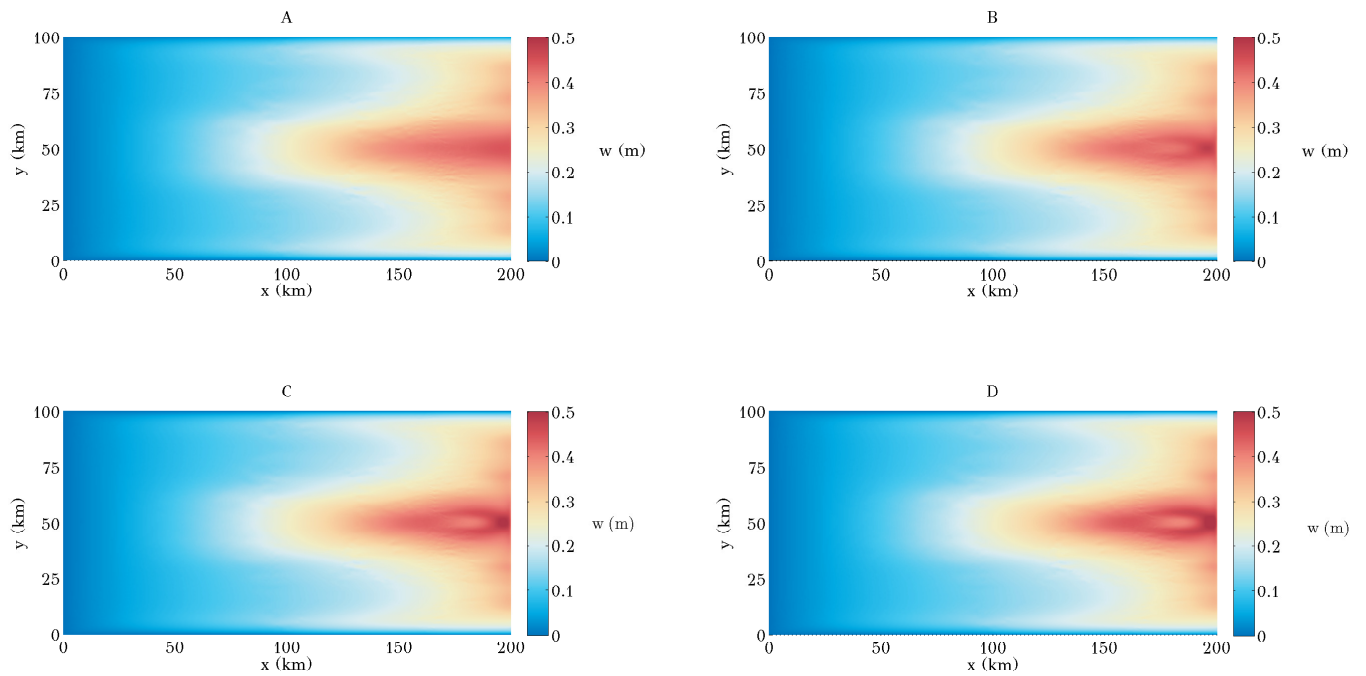

Figure 3.16 Change in the depth and spatial distribution of the subglacial water layer (m) from its initial state (A) over monthly timescales. B) Distribution after 1 month. C) Distribution after 2 months. D) Distribution after 3 months. Nascent branching features can be seen after 2 months and become more apparent as the model evolves.

and yearly time scales (figures 3.16 and 3.17). Patterns suggestive of the formation of thin, longitudinally extensive areas of relatively high water depths-branches-form after 2 months (figures 3.16B and 3.16C). By five years into the transient simulation, the overall water distribution pattern is set and an oscillation emerges, in which individual branches gain and lose water on monthly and yearly time scales (figure 3.17C).

Branches in the distribution migrate in both the along flow and across flow directions as the water flows out of the domain. The migration of the branches over time is better visualized when the evolution of the water depth is considered at a particular point on the bed over which the branches are seen to migrate (figure 3.18). At the point of interest there is a pulse of water-not imposed by the author-that increases in depth by $0.78 \mathrm{~m}$ over 1.1 years. The water reaches a maximum depth of $1.1 \mathrm{~m}$ before it declines by $1 \mathrm{~m}$ over three 
years. This pulse reflects the water moving in the lateral and longitudinal directions.
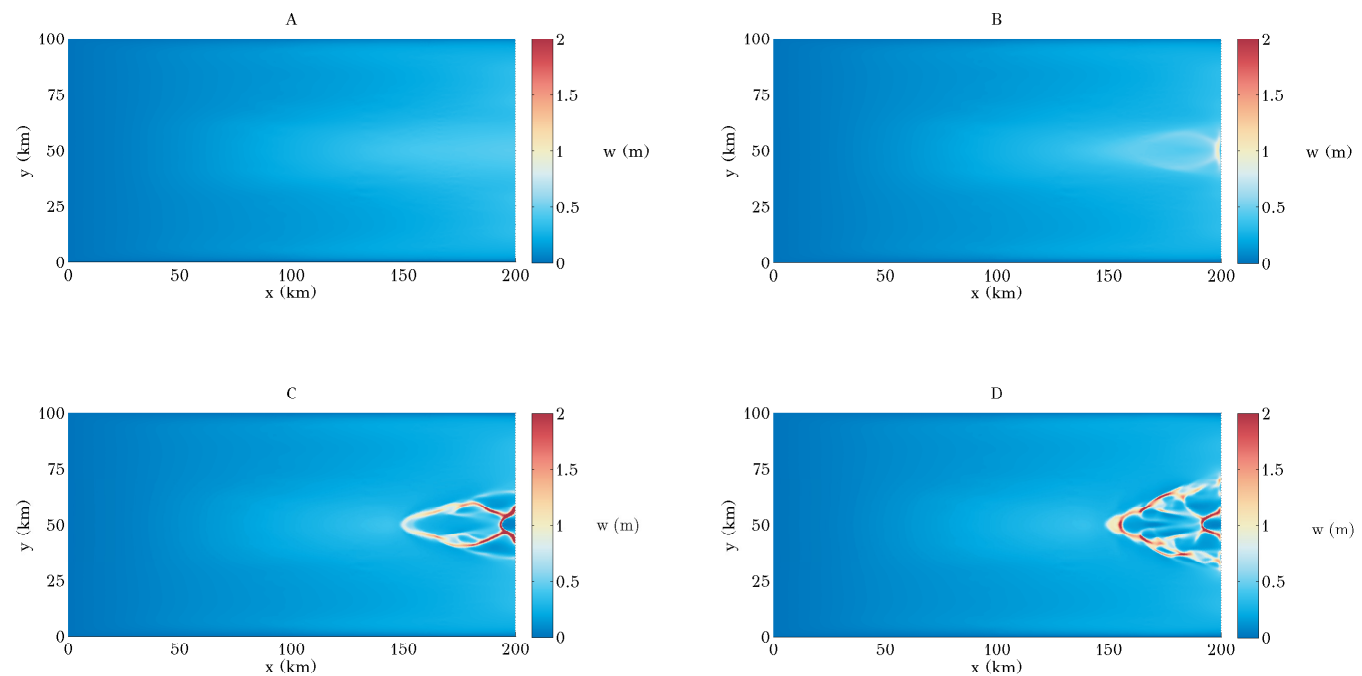

Figure 3.17 Change in the depth and spatial distribution of the subglacial water layer from its initial state (A) over several years. B) Distribution after 1 year. C) Distribution after 5 years. D) Distribution after 10 years. The branching pattern is well established after 5 years and continues to evolve. Changes in the patterns occur in both the longitudinal and lateral directions. Migration, combination, and divergence of the branches is most apparent in the lateral dimension.

The next bed geometry considered consists of two ridges and a trough oriented transverse to flow, created using $n_{x}=3$ and $n_{y}=1$ (figure 3.19A). The features of this bed are $67 \mathrm{~km}$ wide and $100 \mathrm{~km}$ long. The ice surface elevation is shallow over the first ridge and increases radially outward from the point of the feature's maximum height (figures 3.19B and figure 3.19C). The surface elevation is relatively high over the trough and decreases radially outward. At the downstream end of the domain the ice surface elevation reaches its minimal value where the water ponds.

The water distribution that develops on this bed is different from that of the previous experiment (figure 3.19D). Instead of flowing through the domain and spreading laterally where it emerges from the deepest part of the bed, the water flows out of the central depres- 

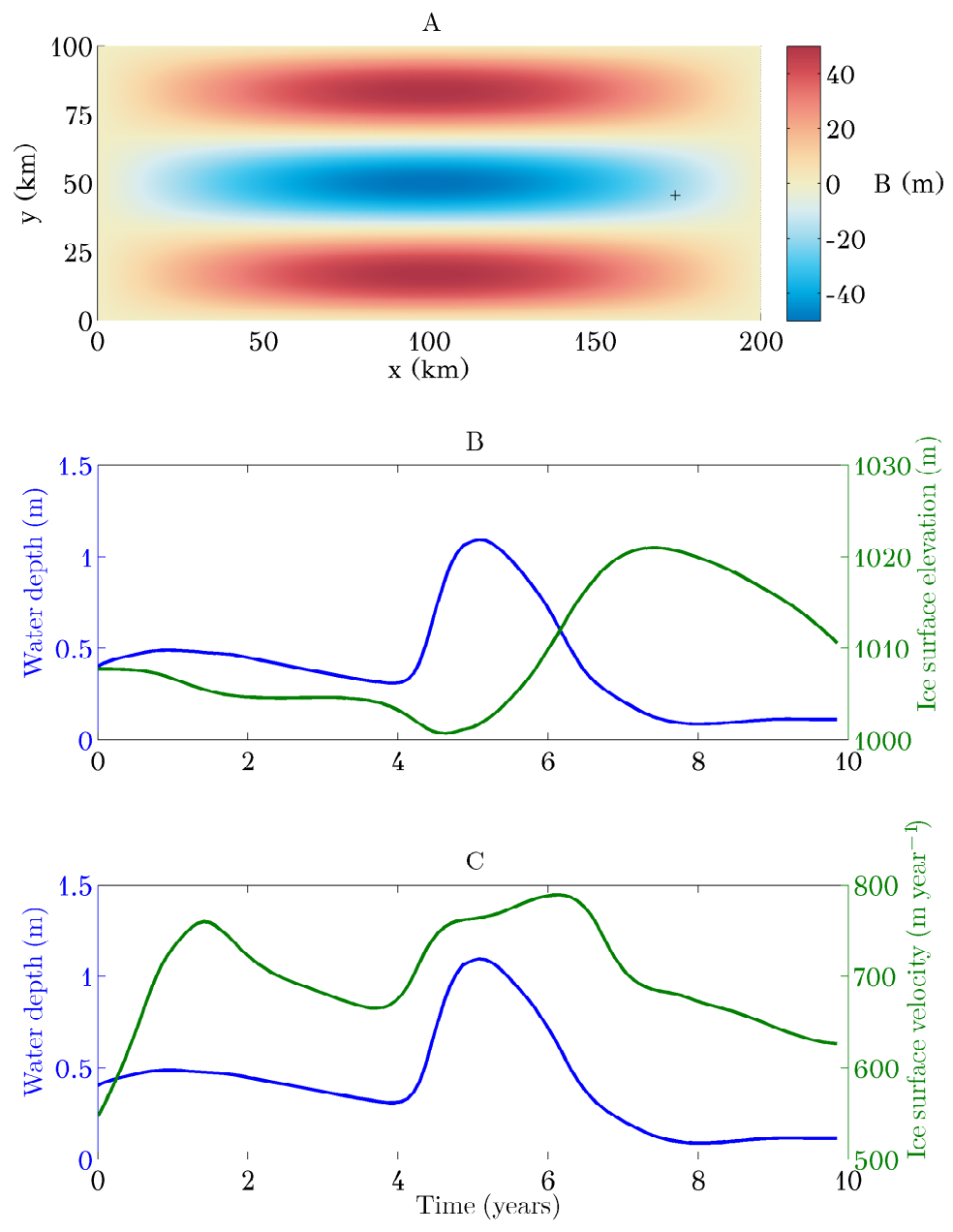

Figure 3.18 A) A probe was placed at $x=176 \mathrm{~km}, y=38 \mathrm{~km}$ on the bed-indicated by the black + symbol. At this point the evolution of ice surface elevation, ice surface velocity, and water depth were tracked over 10 years. B) Water depth and ice surface height over 10 years. C) Water depth and ice surface velocity over 10 years. 
sion, over and around the downstream topographic high, and pools at the downstream end of the domain in a laterally extensive pond.

The pond is established within the first month (figures 3.20 and 3.21). Pulses of water are tracked at a point near the downstream end of the domain as with the previous experiment (figure 3.22). Water depth at this location experiences fluctuations before a steady decline.
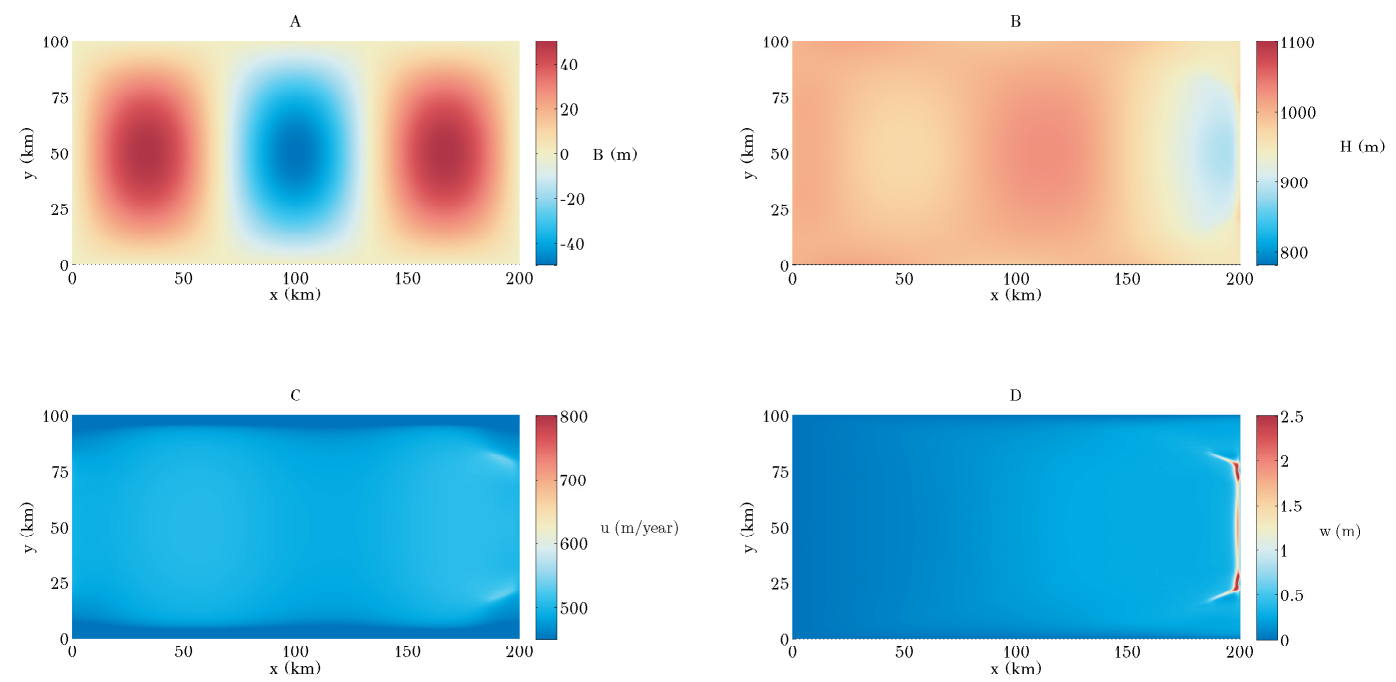

Figure 3.19 Values and spatial distributions of the bed topography with $n_{x}=3$ and $n_{y}=1(\mathrm{~A})$, ice surface elevation (B), ice surface velocity (C), and the depth of the subglacial water layer (D) after 10 years.

In the next experiment, the number of flow-parallel troughs and ridges is increased using $n_{x}=1$ and $n_{y}=10$ (figure $3.23 \mathrm{~A}$ ). The troughs and ridges are $200 \mathrm{~km}$ long and $10 \mathrm{~km}$ wide. Water is laterally confined by the ridges as it flows in the troughs to the downstream end of the domain. Topographic confinement is lost at the downstream end where water flows out of the troughs and is free to branch out with varying degrees of lateral spreading. The fans interact with one another as water moves laterally throughout the downstream end of the domain. 

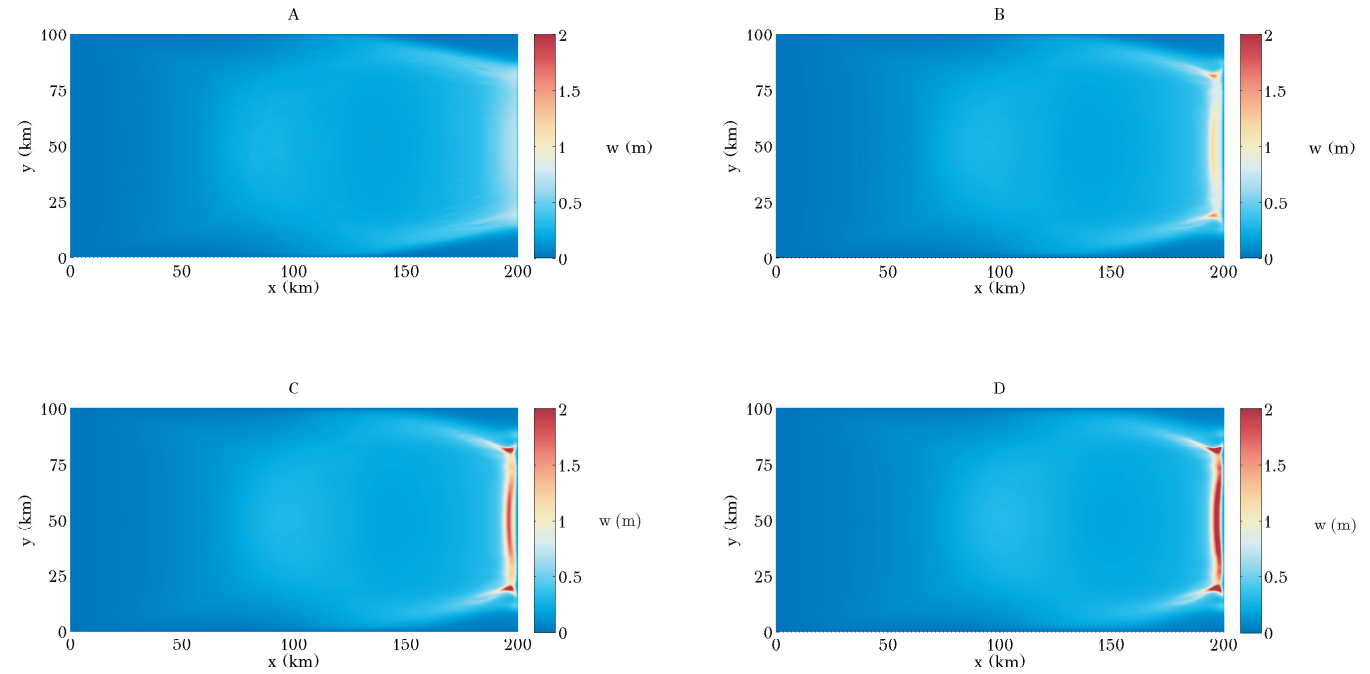

Figure 3.20 Change in the depth and spatial distribution of the subglacial water layer from its initial state (A) over monthly timescales. B) Distribution after 1 month. C) Distribution after 2 months. D) Distribution after 3 months. A laterally extensive pond develops at the downstream end of the domain.
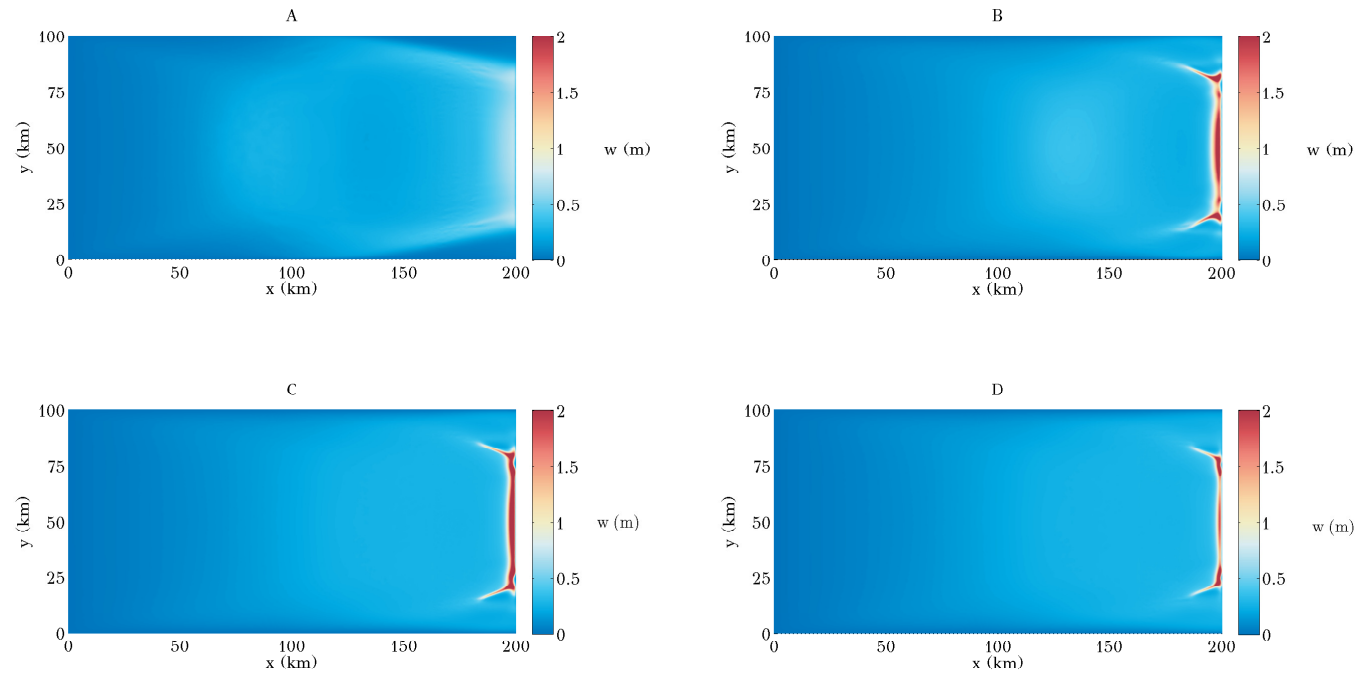

Figure 3.21 Change in the depth and spatial distribution of the subglacial water layer from its initial state (A) over several years. B) Distribution after 1 year. C) Distribution after 5 years. D) Distribution after 10 years. The water depth fluctuates over the lateral extent of the domain's downstream end suggesting that the water within the pond migrates. 

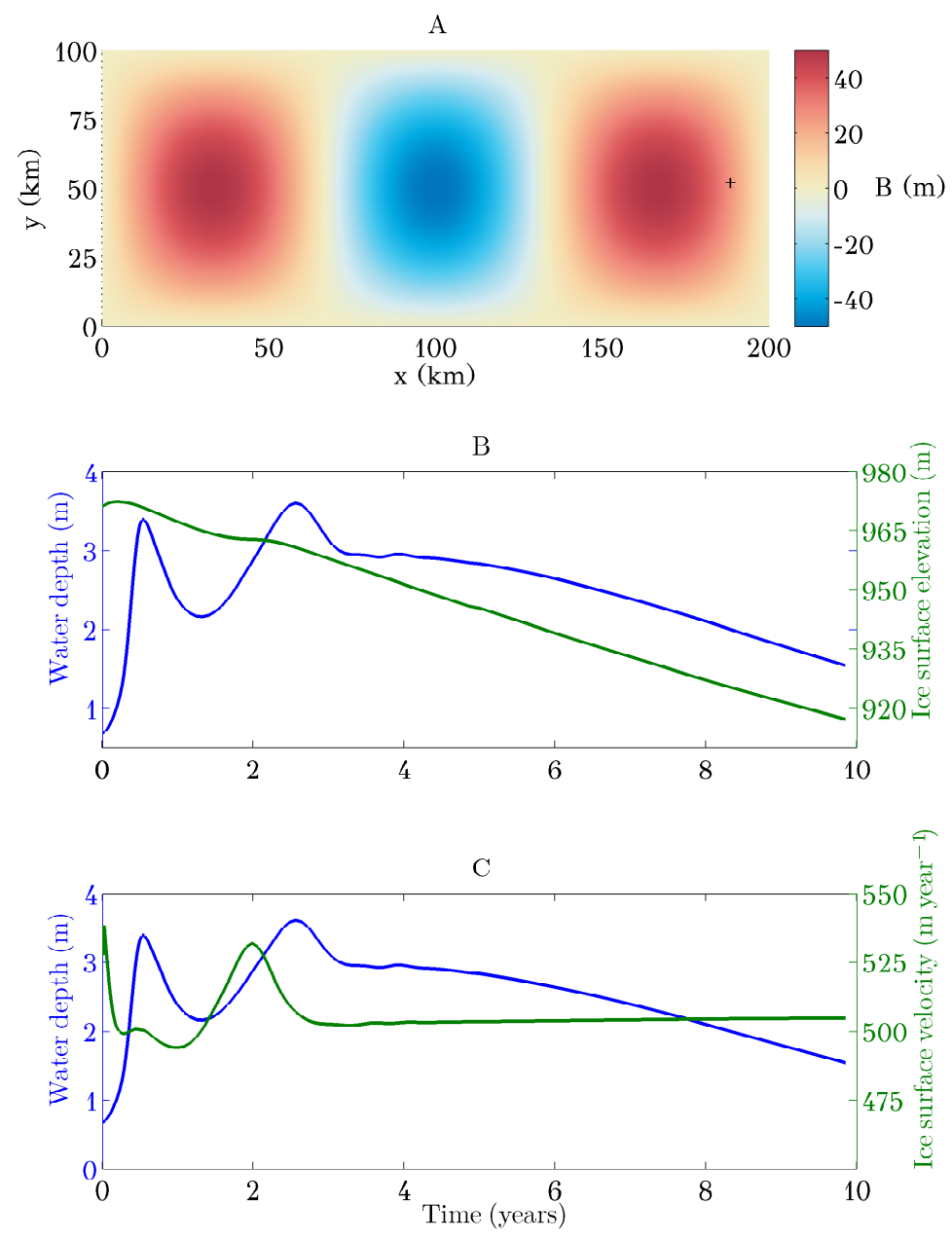

Figure 3.22 A) A probe was placed at $x=188 \mathrm{~km}, y=50 \mathrm{~km}$ on the bed-indicated by the black + symbol. At this point the evolution of ice surface elevation, ice surface velocity, and water depth were tracked over 10 years. B) Water depth and ice surface height over 10 years. C) Water depth and ice surface velocity over 10 years. 
Within the first three months the pattern has been established and the areas where the fans will develop is prominent (figure 3.24). Interaction between the branches over large areas takes place within the first five years but is limited and relatively localized up to the first year (figure 3.25). At five years a pattern of migrating branches is established.

Over the ten year period, one pulse of water is tracked (figure 3.26). This arrangement-ridges and troughs oriented along flow-produces oscillations. The two successive increases indicate the interaction and exchange of water between laterally migrating branches in the system.
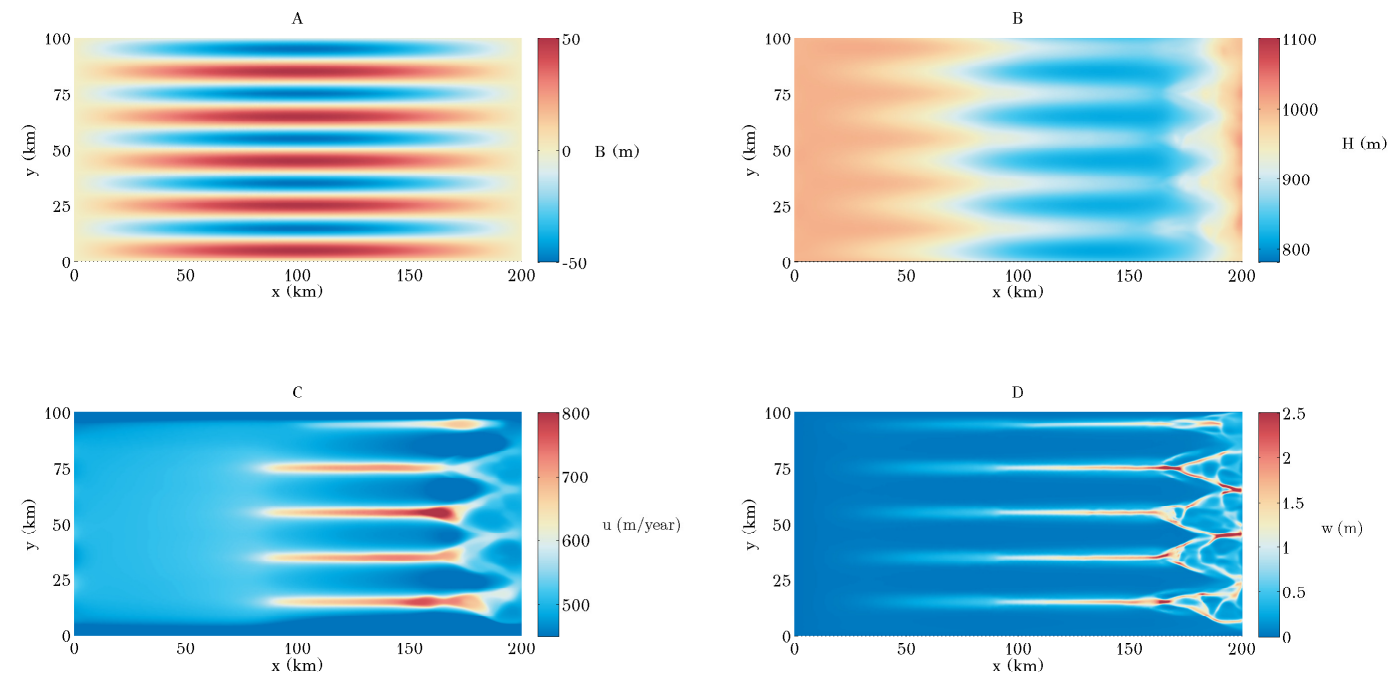

Figure 3.23 Values and spatial distributions of the bed topography with $n_{x}=1$ and $n_{y}=10$ (A), ice surface elevation (B), ice surface velocity (C), and the depth of the subglacial water layer (D) after 10 years.

The next topography investigated consists of 10 troughs and ridges oriented transverse to ice flow $\left(n_{x}=10\right.$ and $\left.n_{y}=1\right)$. The troughs and ridges are $20 \mathrm{~km}$ wide and $100 \mathrm{~km}$ long (figure 3.27A). The results of this experiment are similar to the three trough and ridge experiment, with the notable difference that after one year a second pond forms (figure 

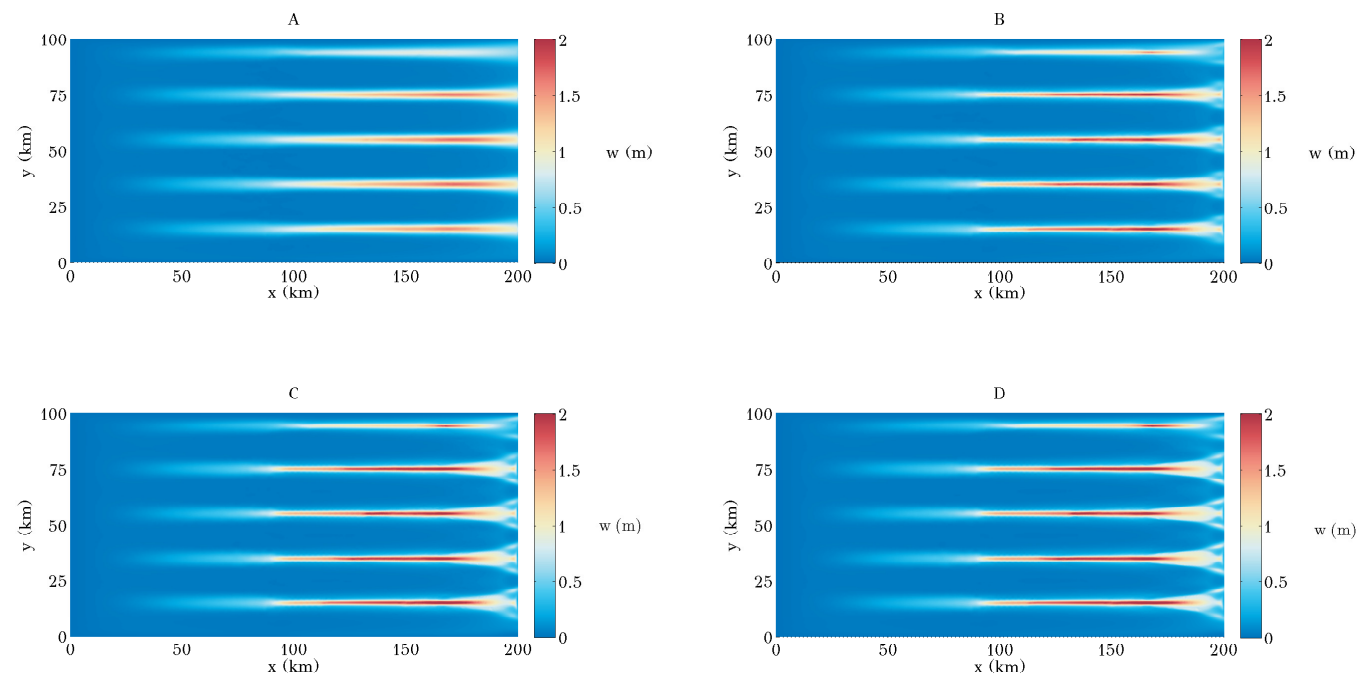

Figure 3.24 Change in the depth and spatial distribution of the subglacial water layer from its initial state (A) over monthly timescales. B) Distribution after 1 month. C) Distribution after 2 months. D) Distribution after 3 months. Nascent branching features can be seen after 2 months and become more apparent after 3 months.

3.27).

The geometries of both the upstream and downstream ponds are constrained by the bed geometry but differences emerge over time (figures 3.28 and 3.29). The upstream pond is less laterally extensive than the downstream pond, presumably because the reverse slope up which the water must flow is truncated at the downstream end of the model domain, constraining interaction between ice and water flow. At the upstream pond, once a critical water layer thickness is attained, water begins to flow around the peak of the transverse ridge, along a path directed by the evolving surface slope. These pathways facilitate water transport downstream.

Points in both ponds were tracked over time (figures 3.30 and 3.31). In the upstream 

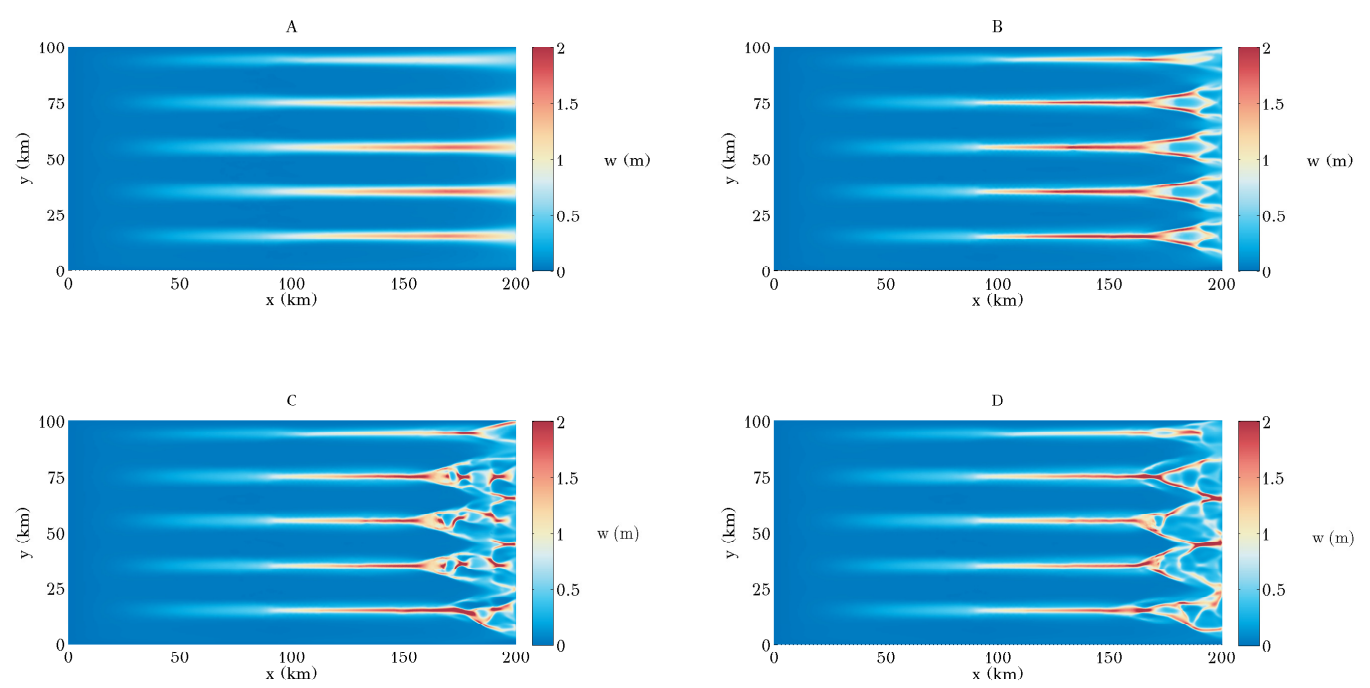

Figure 3.25 Change in the depth and spatial distribution of the subglacial water layer from its initial state (A) over several years. B) Distribution after 1 year. C) Distribution after 5 years. D) Distribution after 10 years. The branching pattern is well established after 5 years and continues to evolve. Changes in the patterns occur in both the longitudinal and lateral directions. Migration, combination, and divergence of the branches is most apparent in the lateral dimension. 

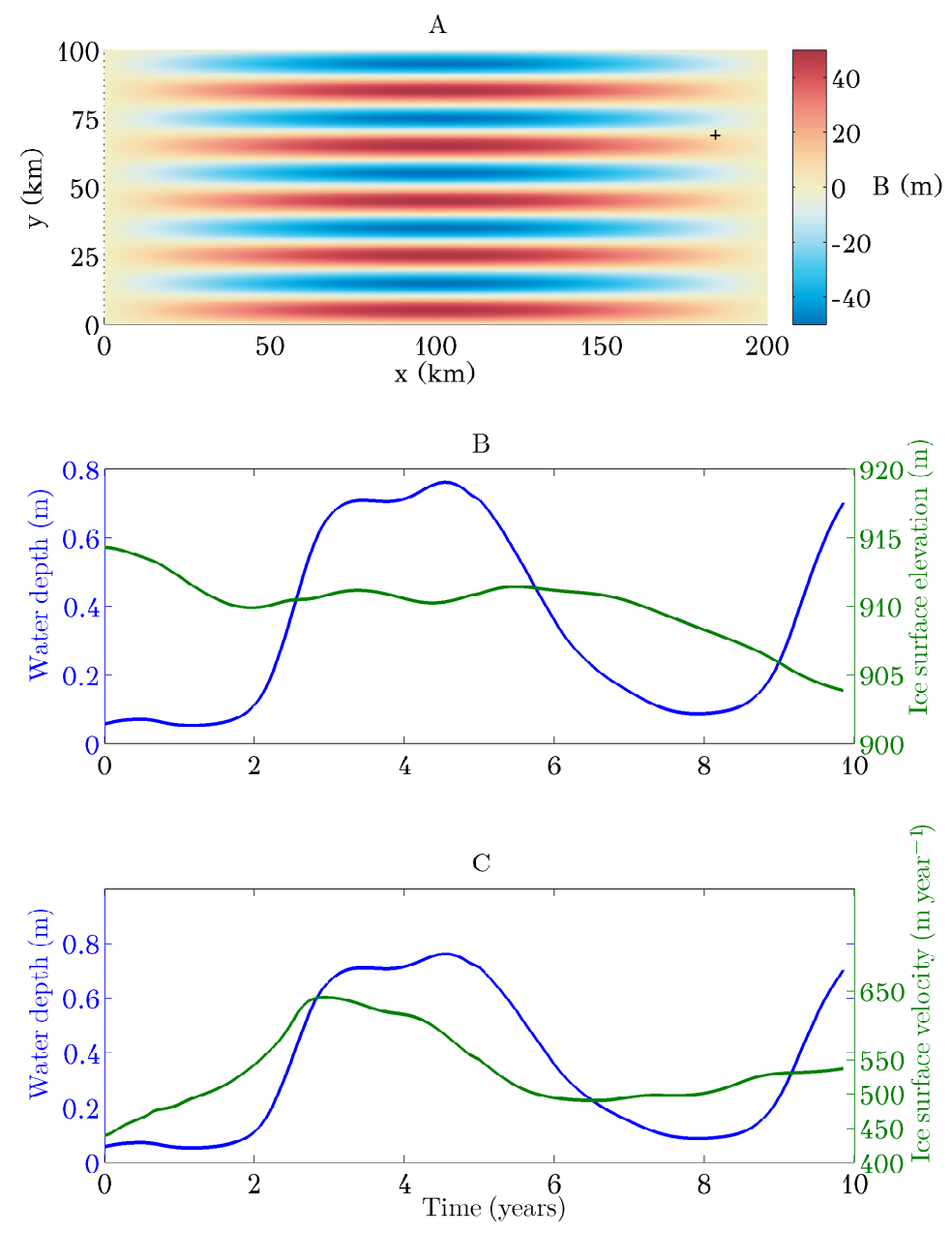

Figure 3.26 A) A probe was placed at $x=184 \mathrm{~km}, y=69 \mathrm{~km}$ on the bed-indicated by the black + symbol. At this point the evolution of ice surface elevation, ice surface velocity, and water depth were tracked over 10 years. B) Water depth and ice surface height over 10 years. C) Water depth and ice surface velocity over 10 years. 
pond, the water depth increases by $1.3 \mathrm{~m}$ over the 10 year period. The water depth increases at a gradual rate over the first 4 years after which the water depth increases at an increasing rate. No pulses of water are seen at this point in the upstream lake. This arrangement—ridges and troughs oriented across flow-does not produce oscillations.
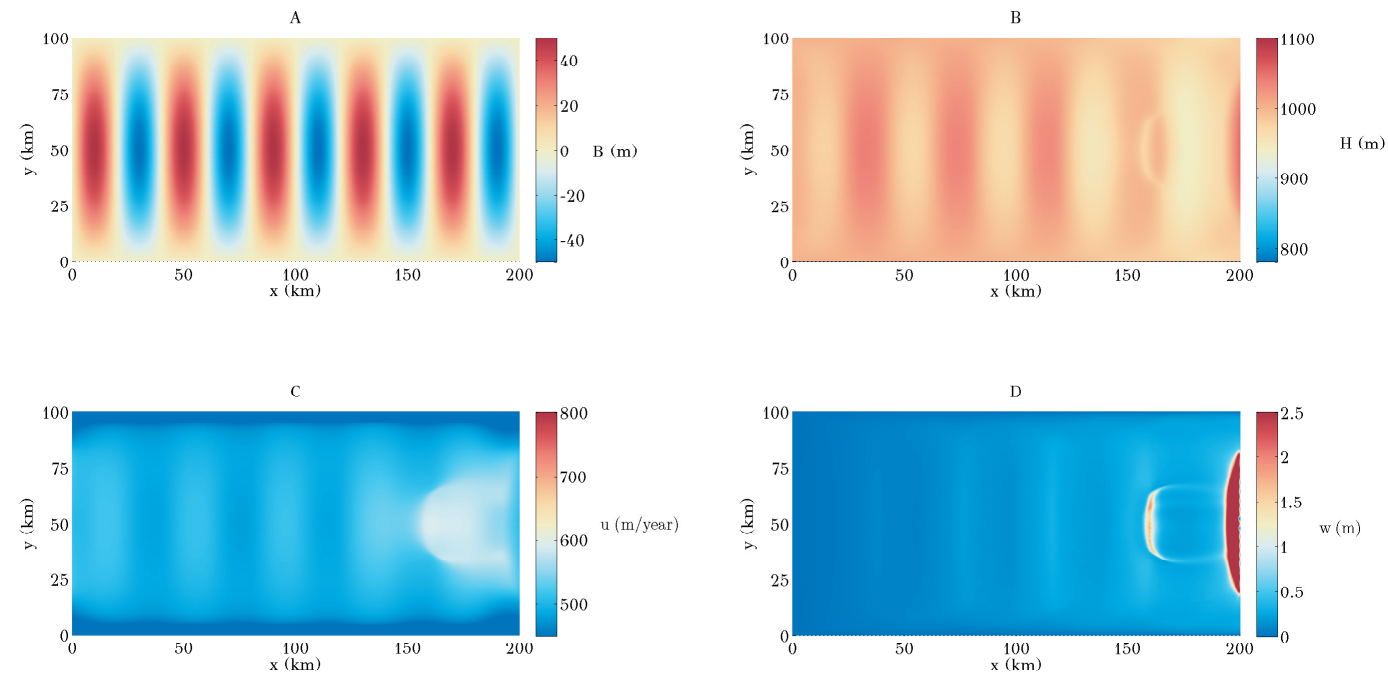

Figure 3.27 Values and spatial distributions of the bed topography with $n_{x}=10$ and $n_{y}=1(\mathrm{~A})$, ice surface elevation (B), ice surface velocity (C), and the depth of the subglacial water layer (D) after 10 years.

A topography is investigated in which the features are $20 \mathrm{~km}$ long and $5 \mathrm{~km}$ wide $\left(n_{x}=\right.$ 10 and $n_{y}=20$ ). The troughs and ridges are oriented parallel to flow (figure 3.32A). After ten years the system reaches a state in which much of the water is distributed over the lower half of the domain (figure 3.32D). The ice in this area thins and speeds up in response to the water (figures 3.32B 3.32C). The distributions of ice surface elevation and ice velocity mimic the distribution of the subglacial water.

This system is relatively static with time (figures 3.33 and 3.34). Water flows downglacier and no fans form. The ponds that form are constrained by the topography, i.e. they are 

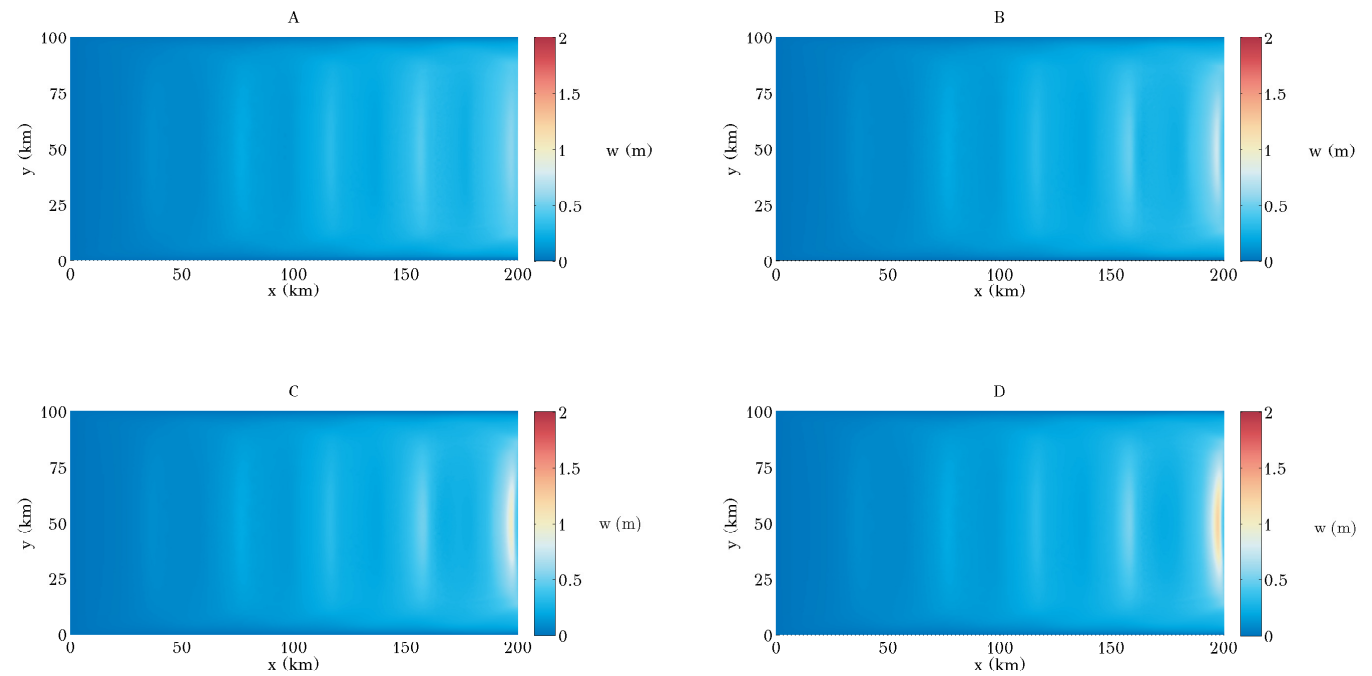

Figure 3.28 Change in the depth and spatial distribution of the subglacial water layer from its initial state (A) over monthly timescales. B) Distribution after 1 month. C) Distribution after 2 months. D) Distribution after 3 months. Nascent branching features can be seen after 2 months and become more apparent after 3 months.

elongated in the lateral, rather than the transverse, direction. Changes in the water depth take place on the $\mathrm{cm}$ scale throughout the downstream end of the domain (figure 3.35) with the most noticeable changes confined to the upper right portion of the domain. This system does not oscillate. The pulses in the first 1.5 years last from from 2 to 6 months. After 1.5 years no additional pulses are tracked and water depths increase gradually but at a decreasing rate.

The final experiment investigates a hummocky, equidimensional topography with smaller bed shapes (figure 3.37A). The features of the bed have a $5 \mathrm{~km}$ radius $\left(n_{x}=20\right.$ and $n_{y}=10$ ) and-since they are circular-display no particular orientation along or transverse to flow.

The ice is thinnest near the downstream end of the domain where the water depths are 

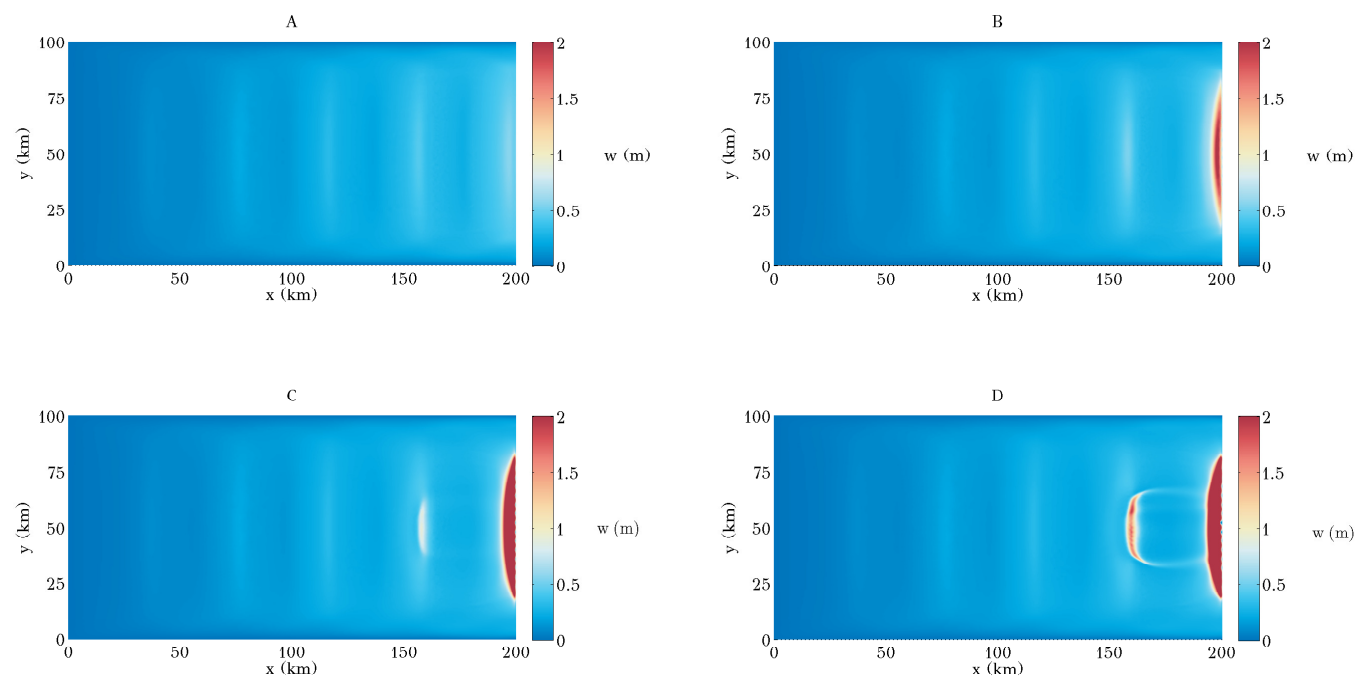

Figure 3.29 Change in the depth and spatial distribution of the subglacial water layer from its initial state (A) over several years. B) Distribution after 1 year. C) Distribution after 5 years. D) Distribution after 10 years. The branching pattern is well established after 5 years and continues to evolve. Changes in the patterns occur in both the longitudinal and lateral directions. Migration, combination, and divergence of the branches is most apparent in the lateral dimension. 

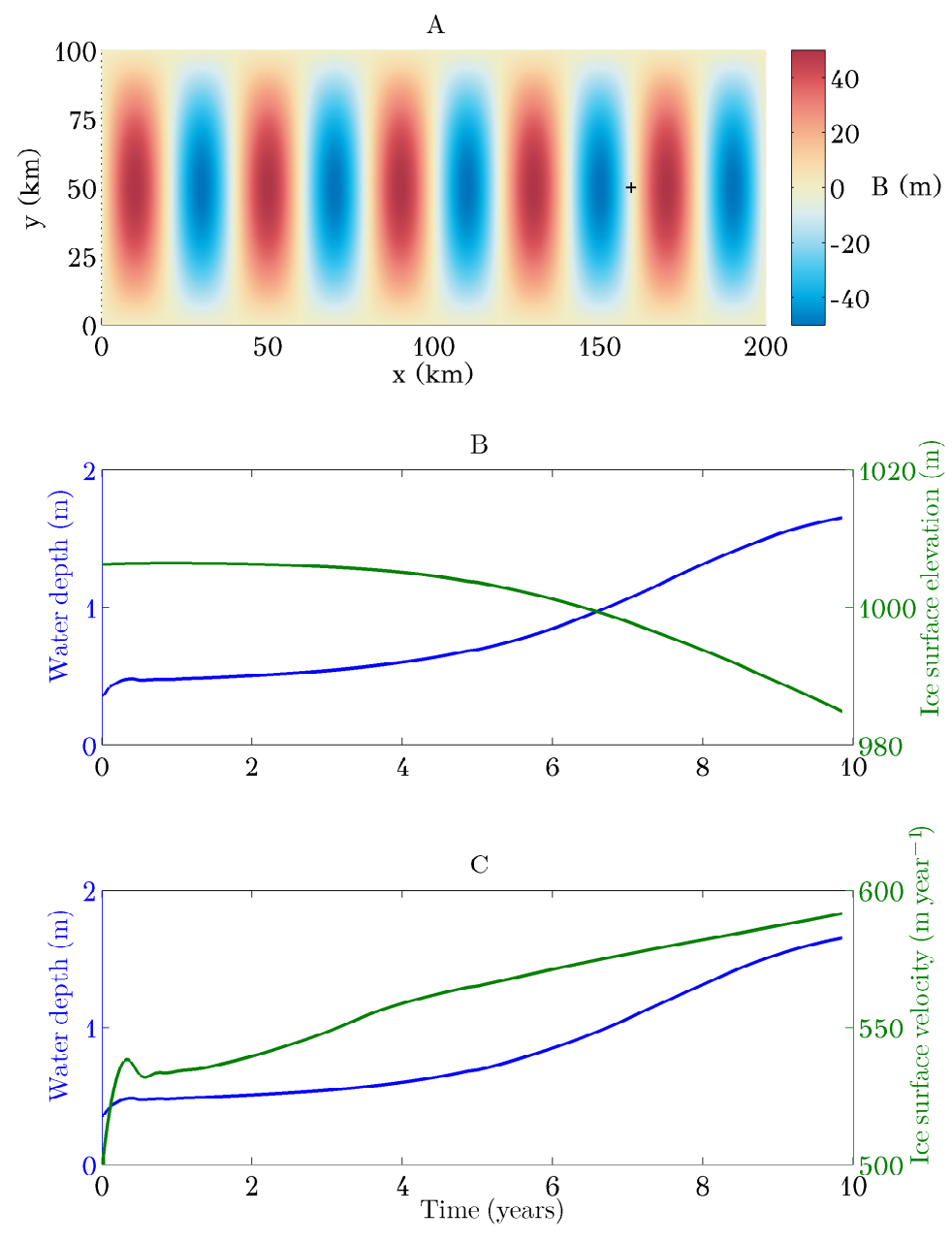

Figure 3.30 A) A probe was placed at $x=159 \mathrm{~km}, y=50 \mathrm{~km}$ on the bed-indicated by the black + symbol. At this point the evolution of ice surface elevation, ice surface velocity, and water depth were tracked over 10 years. B) Water depth and ice surface height over 10 years. C) Water depth and ice surface velocity over 10 years. 



Figure 3.31 A) A probe was placed at $x=198 \mathrm{~km}, y=50 \mathrm{~km}$ on the bed-indicated by the black + symbol. At this point the evolution of ice surface elevation, ice surface velocity, and water depth were tracked over 10 years. B) Water depth and ice surface height over 10 years. C) Water depth and ice surface velocity over 10 years. 

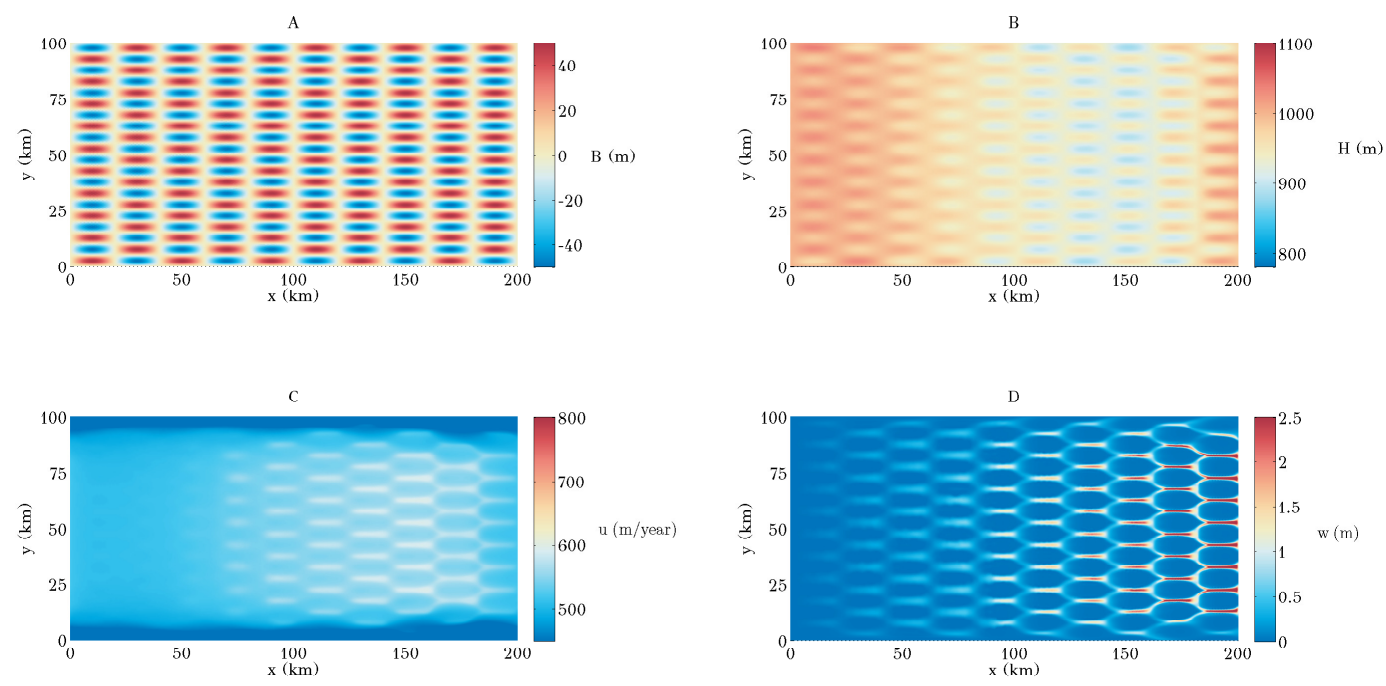

Figure 3.32 Values and spatial distributions of the bed topography with $n_{x}=10$ and $n_{y}=20(\mathrm{~A})$, ice surface elevation (B), ice surface velocity (C), and the depth of the subglacial water layer (D) after 10 years.
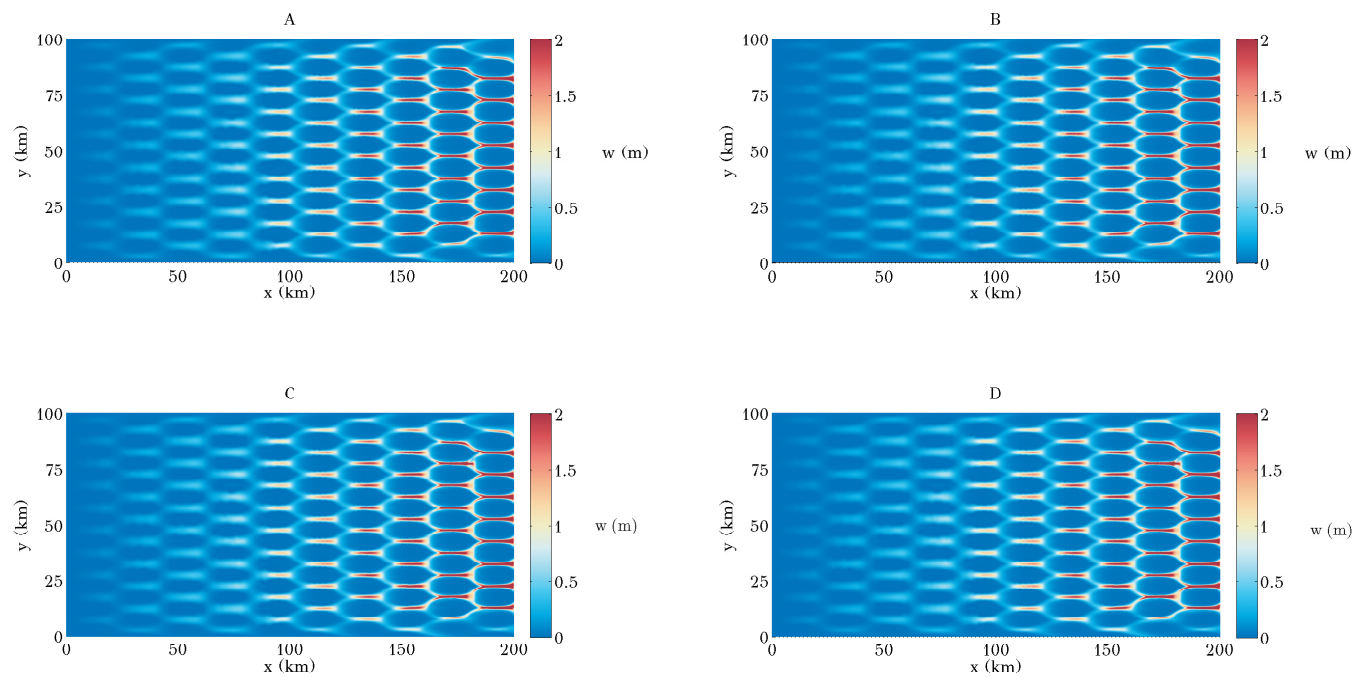

Figure 3.33 Change in the depth and spatial distribution of the subglacial water layer from its initial state (A) over monthly timescales. B) Distribution after 1 month. C) Distribution after 2 months. D) Distribution after 3 months. Nascent branching features can be seen after 2 months and become more apparent after 3 months. 

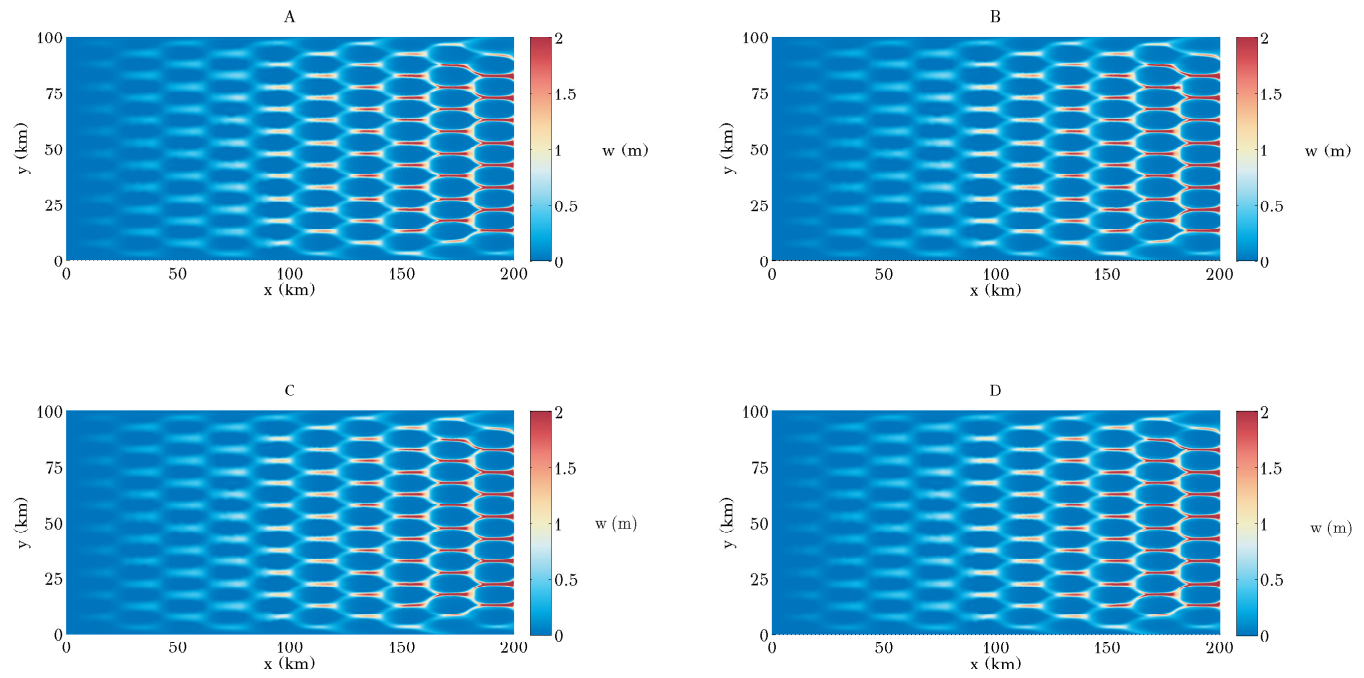

Figure 3.34 Change in the depth and spatial distribution of the subglacial water layer from its initial state (A) over several years. B) Distribution after 1 year. C) Distribution after 5 years. D) Distribution after 10 years. The branching pattern is well established after 5 years and continues to evolve. Changes in the patterns occur in both the longitudinal and lateral directions. Migration, combination, and divergence of the branches is most apparent in the lateral dimension.


Figure 3.35 Difference plots of the evolution of the depth and spatial distribution of the subglacial water layer. A) Difference between the initial state and 5 years. B) Difference between 10 years and 5 years. Most of the activity is confined to the upper right portion of the domain. 

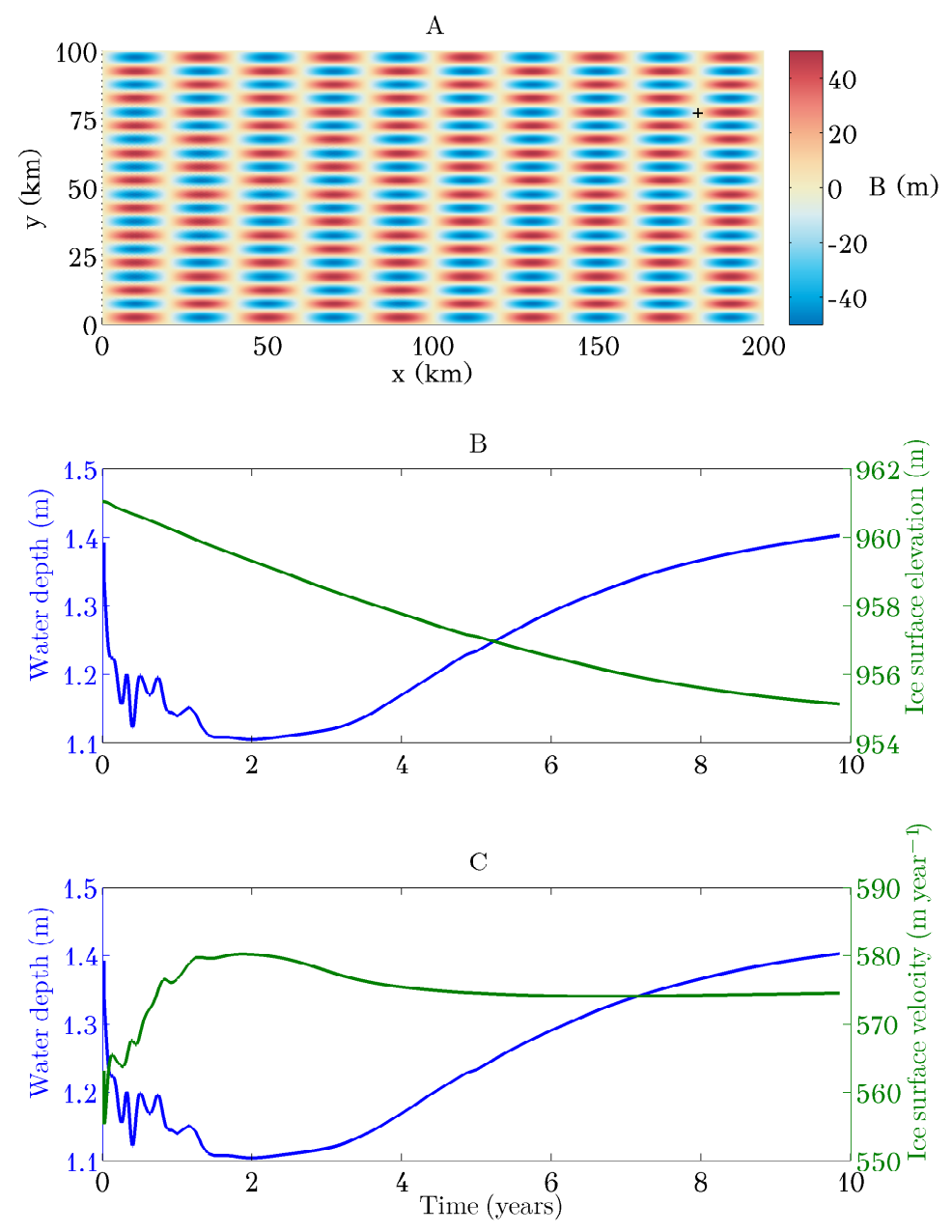

Figure 3.36 A) A probe was placed at $x=180 \mathrm{~km}, y=77 \mathrm{~km}$ on the bed-indicated by the black + symbol. At this point the evolution of ice surface elevation, ice surface velocity, and water depth were tracked over 10 years. B) Water depth and ice surface height over 10 years. C) Water depth and ice surface velocity over 10 years. 
greatest and the ponds are connected (figure 3.37). The ice surface velocity is high over ponds and streams connecting the ponds. The depth of the water in the ponds and the number of connected ponds increases in the downstream direction.

As time moves forward over the first few months the depths increase in the ponds as well as the branches connecting them (figure 3.38). Within five years the water depth begins to show a combination of patterns similar to previous experiments (figure 3.39). Water pools in some areas and fans out around and over obstacles in others (figures 3.39C and 3.39C and D).

The movement of water is tracked in the first year at sites marked by variability during the first few months of the model run. These fluctuations are followed by a pulse in the water depth. The pulse increases the water depth at different rates over 3.7 years. The water depth reaches a maximum value of $9.6 \mathrm{~m}$ before it steadily declines and tapers off over the next 3.6 years.

Streamlines were calculated to compare transit times for water moving over different bed morphologies. The streamlines are generated in COMSOL and postprocessed in MATLAB using builtin interpolation and integration functions. For each bed configuration 20 streamlines spaced out at $5 \mathrm{~km}$ intervals are calculated (figure 3.41). Speeds and water depths along each streamline are calculated. The water speed $s_{w}$ along each streamline is used to determine how much time water following a particular streamline spends in the domain. The speed of the water is calculated using

$$
s_{w}=\sqrt{u_{w}^{2}+v_{w}^{2}}
$$

in which $u_{w}$ and $v_{w}$ are the $\mathrm{x}$ and $\mathrm{y}$ components of the water velocity vector respectively. 

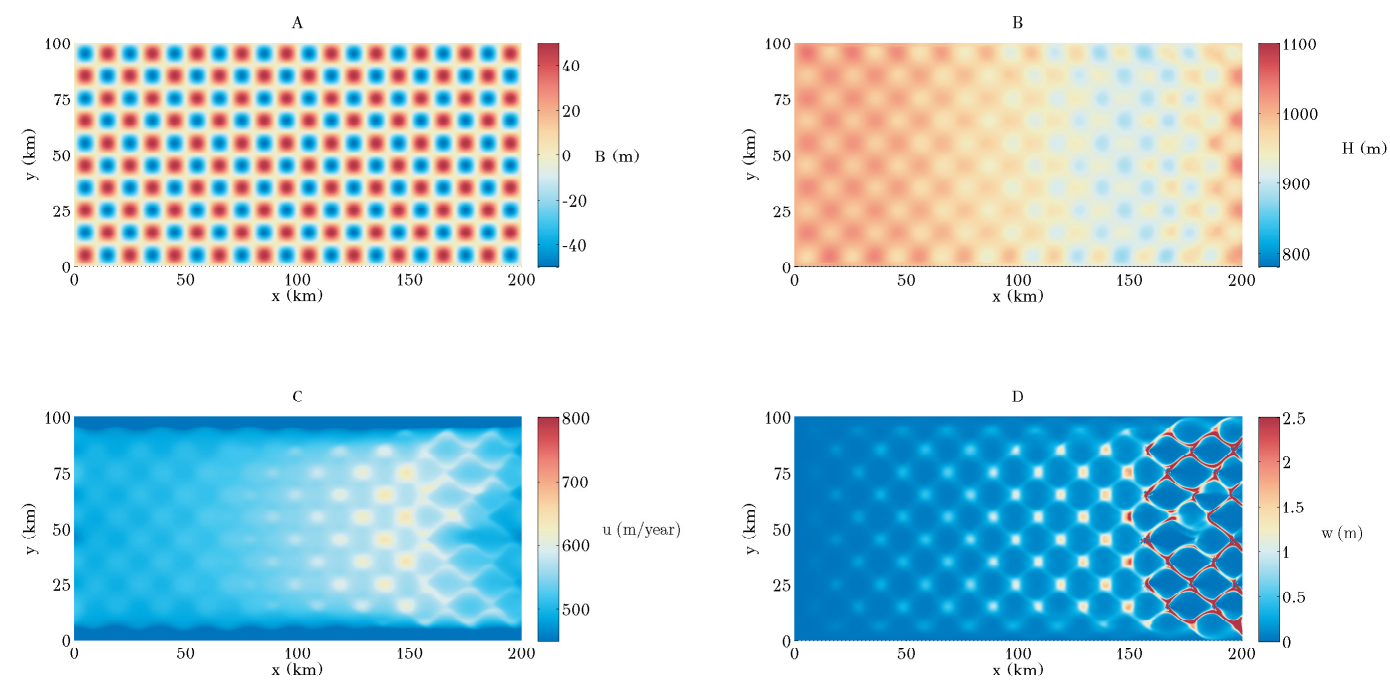

Figure 3.37 Values and spatial distributions of the bed topography with $n_{x}=20$ and $n_{y}=10(\mathrm{~A})$, ice surface elevation (B), ice surface velocity (C), and the depth of the subglacial water layer (D) after 10 years.
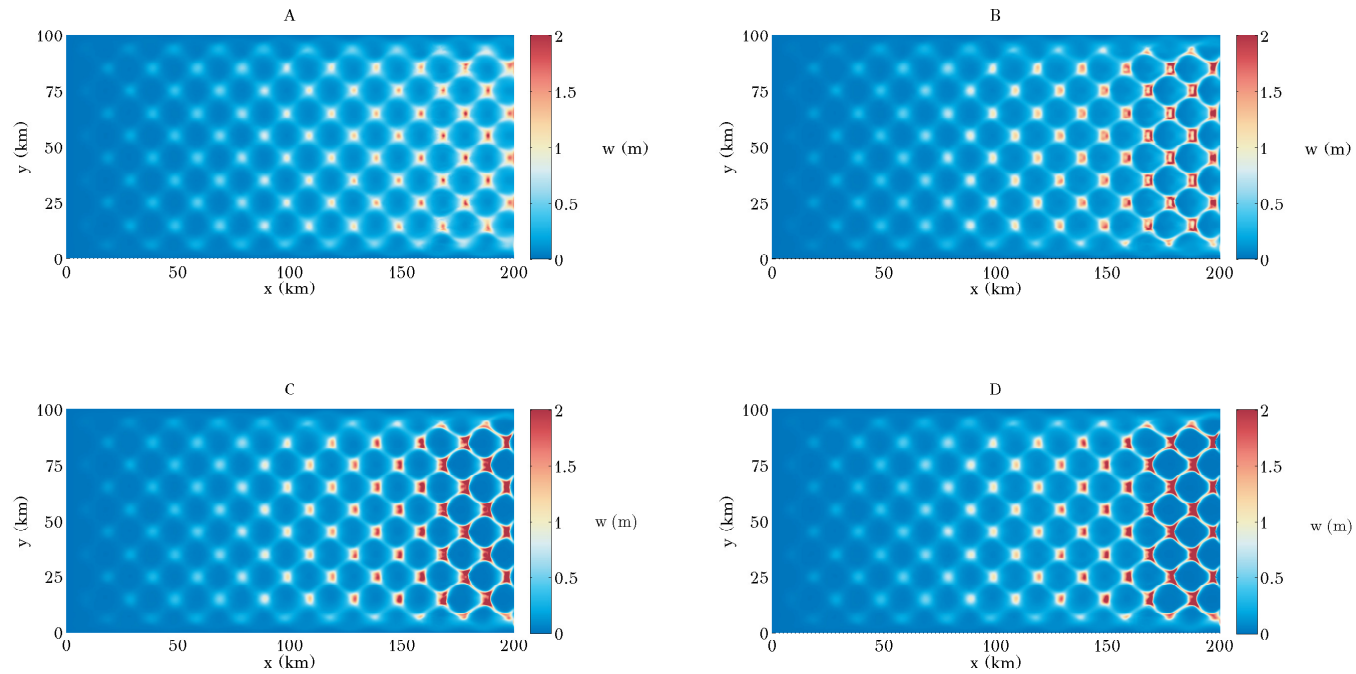

Figure 3.38 Change in the depth and spatial distribution of the subglacial water layer from its initial state (A) over monthly timescales. B) Distribution after 1 month. C) Distribution after 2 months. D) Distribution after 3 months. Nascent branching features can be seen after 2 months and become more apparent after 3 months. 

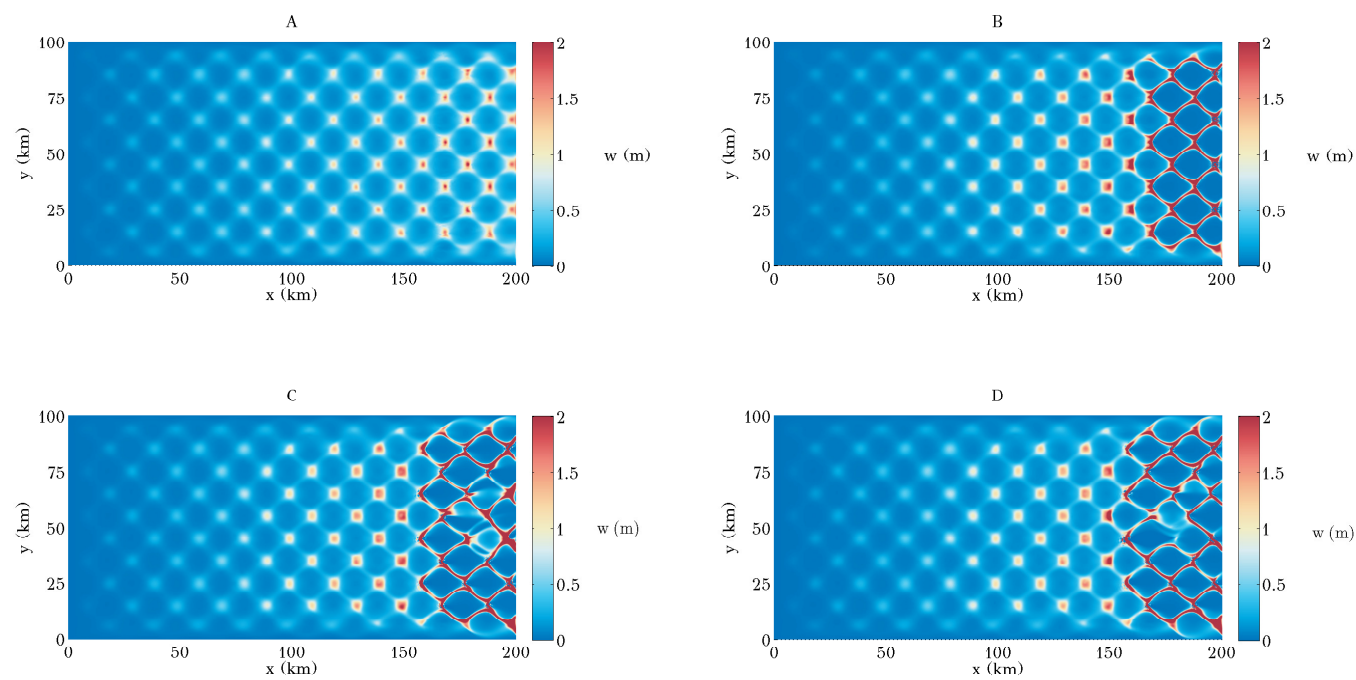

Figure 3.39 Change in the depth and spatial distribution of the subglacial water layer from its initial state (A) over several years. B) Distribution after 1 year. C) Distribution after 5 years. D) Distribution after 10 years. The branching pattern is well established after 5 years and continues to evolve. Changes in the patterns occur in both the longitudinal and lateral directions. Migration, combination, and divergence of the branches is most apparent in the lateral dimension. 

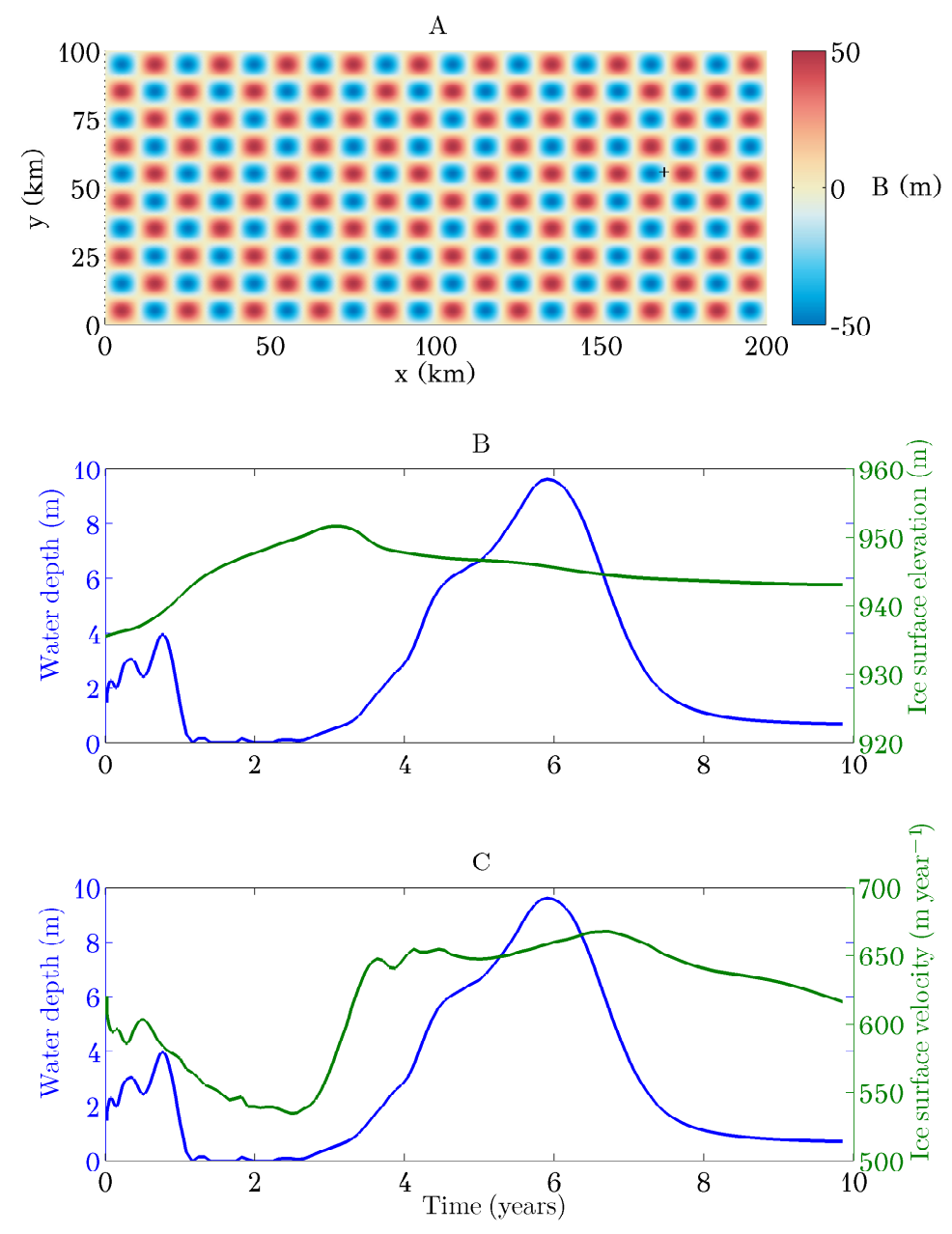

Figure 3.40 A) A probe was placed at $x=169 \mathrm{~km}, y=56 \mathrm{~km}$ on the bed-indicated by the black + symbol. At this point the evolution of ice surface elevation, ice surface velocity, and water depth were tracked over 10 years. B) Water depth $(m)$ and ice surface height $(m)$ over 10 years. C) Water depth and ice surface velocity $\left(\mathrm{myr}^{-1}\right)$ over 10 years. 
Average water velocities and residence times along the streamlines are calculated using these values (table 3.1). Increasing the number of features in the domain decreases the velocity of the water thus increasing the residence time. Topographies dominated by longitudinally oriented features are associated with lower water velocities and higher residence times than those oriented transverse to flow.

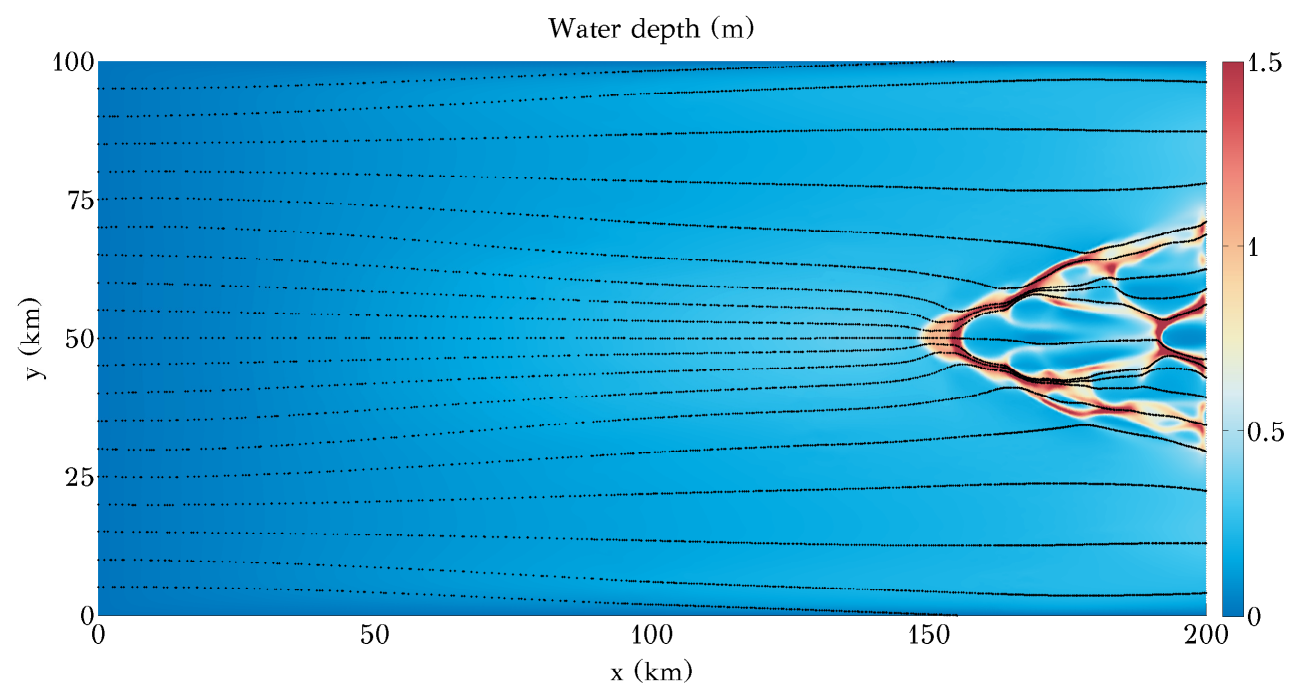

Figure 3.41 Streamlines for the topography with $n_{x}=1$ and $n_{y}=3$. The lines are spaced out at $5 \mathrm{~km}$ intervals. The distribution of points along the streamlines increases downstream as the mesh is refined. 
Table 3.1 Summary of average streamline data after 10 years for the six different bed geometries reported on in this study. Values shown are averages of the variables calculated using 25 streamlines in the domain spaced at $5 \mathrm{~km}$ increments (figure 3.41).

\begin{tabular}{ccc}
\hline Bed geometry & Water velocity $\left(\mathrm{km} \mathrm{yr}^{-1}\right)$ & Residence time $(\mathrm{yr})$ \\
\hline$n_{x}=1, n_{y}=3$ & 51.7 & 3.86 \\
$n_{x}=3, n_{y}=1$ & 54.2 & 3.69 \\
$n_{x}=1, n_{y}=10$ & 49.5 & 4.04 \\
$n_{x}=10, n_{y}=1$ & 51.5 & 3.88 \\
$n_{x}=10, n_{y}=20$ & 49.7 & 4.02 \\
$n_{x}=20, n_{y}=10$ & 46.9 & 4.27 \\
\hline
\end{tabular}




\section{CHAPTER 4}

\section{DISCUSSION AND CONCLUSIONS}

\subsection{Lake provinciality}

Increasing the depth of a centrally located topographic depression alters the distribution of water up and downstream of the depression. The relationship between the perturbation depth and the distance upstream to which the effects reach is nonlinear (figure 3.12). The effects of the increased depth reach further upstream with increasing perturbation depth. The relationship suggests that there is a limiting value to how far the effects of the perturbation are able to extend upstream. The ratio of the perturbation depth to the distance upstream to which the effects extend is not the same in each experiment (figure 3.12). The ratios decrease to a value near unity with increasing perturbation depth beyond an estimated value of $22 \mathrm{~m}$. Increasing the perturbation depth beyond $50 \mathrm{~m}$ will result in a negligible increase in its reach. These results suggest that there is an optimal depth:diameter ratio for basal ponds that - with more work - could be used to classify basal ponds in terms of their ability to influence ice stream flow.

Increasing the perturbation depth leads to a decrease in water depths at higher eleva- 
tions on the flanks of the topographic high and increase at lower elevations. The reason for the effect being felt upstream is that increasing the depth of the centrally located depression increases the thickness of the ice over that depression. Thicker ice from this region advects downstream over the adjacent topographic high increasing the thickness of the ice there. The thicker ice in these two regions in turn drives water away causing a reconfiguration of the water depths.

Progressively deepening a depression—such as with the formation of a tunnel valley—could deplete large areas of the bed both up and downstream of water. Water ponding in such a depression could become isolated from the hydraulic network beneath an ice stream. As the water depths increase at lower elevations on topographic highs different hydraulic connections become possible, and water is routed to or away from downstream ponds and drainage networks further affecting the both the flow of water and ice.

\subsection{Basal topography}

The coupled ice and water model developed here was used to examine the role of bed morphology in water flow. The results of the basal topography experiments show that the type of basal water system that develops beneath an ice stream—distributed network of migrating branches or large laterally extensive lakes-depends on the aspect ratio of the basal topography and the two-way coupling of the model. The vertical relief and horizontal geometry of features on the bed affect water flow in both space and time, and different arrangements with respect to the ice flow direction result in different temporal signatures. Features with their long dimensions oriented transverse to ice flow produce systems that are stable in time whereas features with their long dimensions oriented parallel to ice flow produce systems that oscillate in time. 
Ice surface elevations reflect the geometry of the subglacial topography and respond to its changes. Altering the basal topography alters the ice surface elevations which in turn alter the hydraulic gradient. This influence is reflected in the distributions of water throughout the experiments. As the system evolves and the ice and water respond to one another-via the two-way coupling-the hydraulic gradients are constantly shifting in both the lateral and longitudinal directions. The distributed networks of branches develop because-in response to the basal topography - the ice surface elevations are lower and the ice thinner on the lateral margins of the domains. These areas experience relatively low hydraulic gradients compared to the center portion of the domain where the hydraulic gradients are higher because of higher ice surface elevations and thicker ice. This difference forces water to flow towards the lateral margins as it flows downstream. In the experiments in which large, laterally extensive lakes form, the ice has a relatively uniform response to the basal topography in the lateral direction, and water is uniformly moved downstream over and around the topographic highs.

The relationship between feature orientation and the water system that develops can be disrupted by the addition of cross-cutting features. As the dimensions of the features are reduced, there are certain dimensions for which the hydraulic gradients in the lateral and longitudinal directions can balance one another and yield different water depth behaviors in time (figure 3.34). Given a basal topography in which the longitudinal dimensions of the topographic features are larger than the lateral, water is channeled by the topography as it flows downstream. Hydraulic gradients setup in response to this topography are such that the lateral and longitudinal components balance one another. This keeps the water confined to the areas between the features with limited ponding and lateral spreading. 
A mosaic of ponds and laterally migrating branches develops where the longitudinal and transverse dimensions of the bed undulations are equal. That is, branching network development begins but is inhibited to some degree (figure 3.39). In the case investigated here, the ability of the branching network to form is inhibited by the topography but not to the point that it is unable to affect the water distribution. Water is routed away from a particular area of the bed through the topography's influence on the hydraulic gradient. As the water is routed away from this portion of the bed, the ice responds by thickening and increasing the potential over the region which continues to force water away.

The water distributions that develop in response to bed morphologies with features oriented along flow are similar to drainage networks observed in benchtop experiments carried out by Catania and Paola (2001) (figure 4.1). Catania and Paola (2001) conducted laboratory experiments demonstrating that pressurized water flow over a non cohesive bed will produce a braided channel system controlled by variations in the lateral pressure gradients. Although the water flow in the model experiments is gravity driven and no substrate is considered, the model results bear strong resemblance to their experimental results. Given the right topographic configurations-longitudinally extensive ridges and troughs-a braided network of channels can form even without the effects of erosion into a substrate such as till and indeed, it is likely the development of spatial variations like these that promote spatial variation in erosion and the development of the braided network on sediment. Additionally, the model result here could have implications for drainage networks beneath the Greenland ice sheet where it is expected that water discharged to the bed through moulins flows over crystalline bedrock.

The most limiting simplifications made in the present model are the use of regular beds, 

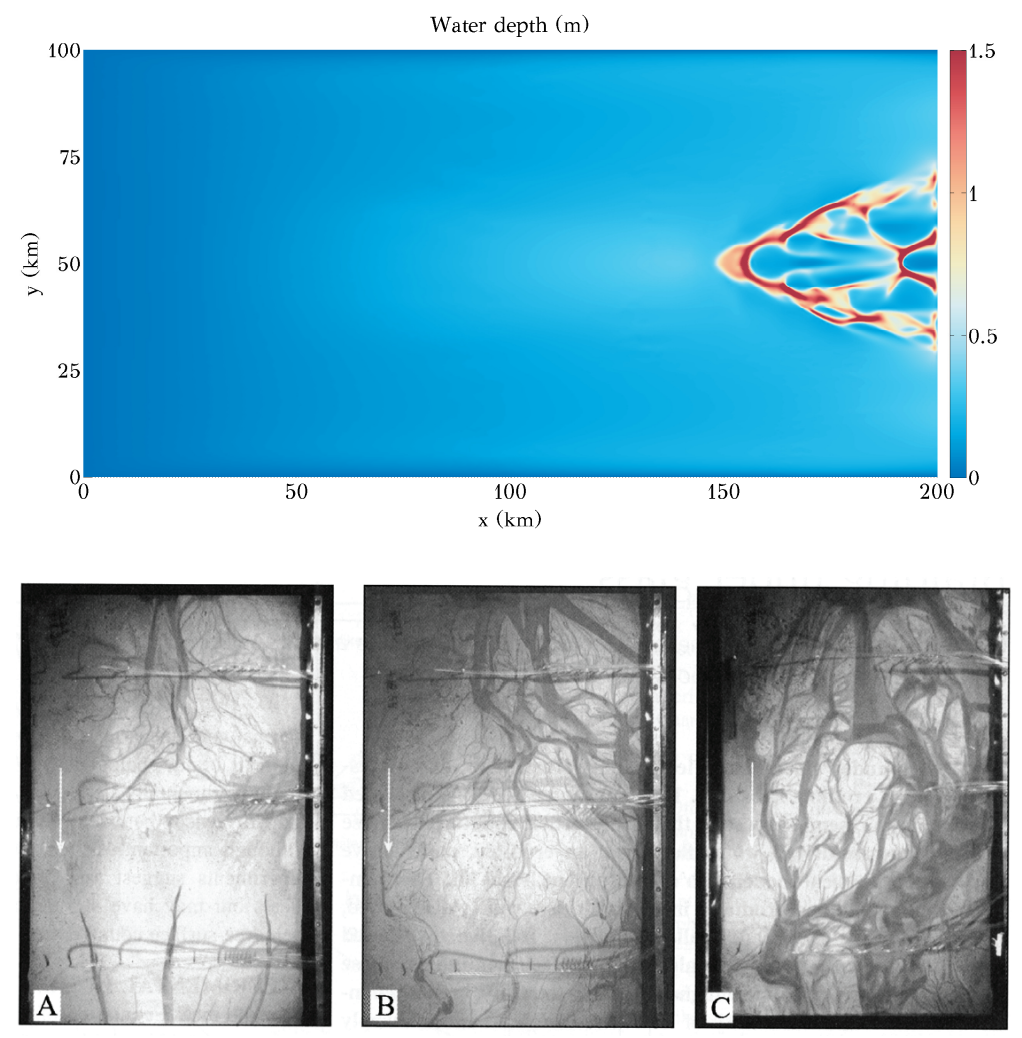

Figure 4.1 Upper panel, results from model showing water distribution after 10 years. Flow is from left to right. Lower panel, results from Catania and Paola (2001). Flow is from top to bottom. Panel A shows the distribution of channels after 1.5 hours. Panel B shows the distribution of channels after 18.5 hours. Panel $\mathrm{C}$ shows the distribution of channels after 34 hours. 
the omission ice/bed heat exchange, and the omission of till processes. These simplifications were in keeping with the research question, but including more processes would lead to additional insights. It would also be interesting to introduce time varying water flux from upstream. 


\section{REFERENCES}

Alley, R.B., Blankenship, D.D., Bentley, C.R., and Rooney, S.T., 1986, Deformation of till beneath ice stream b, West Antarctica. Nature, v. 322, p. 57-59.

Alley, R.B., Blankenship, D.D., Bentley, C.R., and Rooney, S.T., 1987, Till beneath ice stream b: 3. till deformation: evidence and implications. Journal of Geophysical Research, v. 92, p. 8921-8929.

Anderson, J., 1999, Antarctic marine geology. 1st edn., New York, USA, Cambridge University Press.

Bamber, J., and Layberry, R., 2001, A new ice thickness and bed data set for the Greenland ice sheet 1. measurement, data reduction, and errors. Journal of Geophysical Research, v. 106 , no. D24, p. 33,773-33,780.

Bindschadler, R., 1993, Siple coast project research of Crary Ice Rise and the mouths of Ice Streams B and C, West Antarctica: review and new perspectives. Journal of Glaciology, v. 39 , no. 133 , p. $538-552$.

Bindschadler, R., and Choi, H., 2007, Increased water storage at ice-stream onsets: a critical mechanism?. Journal of Glaciology, v. 53, no. 181, p. 163-171.

Blankenship, D.D., Bentley, C.R., Rooney, S.T., and Alley, R.B., 1986, Seismic measurements reveal a saturated porous layer beneath an active Antarctic ice stream. Nature, v. 322, p. $54-57$.

Blankenship, D.D., Bentley, C.R., Rooney, S.T., and Alley, R.B., 1987, Till beneath ice stream b: 1. properties derived from seismic travel times. Journal of Geophysical Research, v. 92, p. 8903-8911.

Brunt, K.M., Fricker, H.A., Padman, L., Scambos, T.A., and O’Neel, S., 2010, Mapping the grounding zone of the Ross Ice Shelf, Antarctica, using icesat laser altimetry. Annals of Glaciology, v. 55, no. 51, p. 71-79. 
Campbell, A., 2009, Numerical model investigation of Crane Glacier response to collapse of the Larsen B Ice Shelf, Antarctic Peninsula [master's thesis]. Portland, OR, Portland State University.

Carter, S., Blankenship, D., Peters, M., D.A., Y., Holt, J., and D.L., M., 2007, Radar-based subglacial lake classification in Antarctica. Geochem. Geophys. Geosyst., v. 8, p. 1-20.

Carter, S., Blankenship, D., Young, D., Peters, M., Holt, J., and Siegert, M., 2009, Dynamic distributed drainage implied by the flow evolution of the 1996-1998 adventure trench subglacial lake discharge. Earth and Planetary Science Letters, v. 283, p. 24-37.

Carter, S., Fricker, H., Blankenship, D., Johnson, J., Lipscomb, W., Price, S., and Young, D., 2011, Modeling 5 years of subglacial lake activity in the Macayeal Ice Stream (Antarctica) catchment through assimilation of icesat laser altimetry. Journal of Glaciology, v. 57, no. 206, p. 1098-1112.

Catania, G., and Paola, C., 2001, Braiding under glass. Geology, v. 29, no. 3, p. 259-262.

Clarke, G., 2005, Subglacial processes. Annual Review of Earth and Planetary Science, v. 33, p. 247-276.

Drewry, D., Jordan, S., and Jankowski, E., 1982, Measured properties of the Antarctic Ice Sheet: surface configuration, ice thickness, volume and bedrock characteristics. Annals of Glaciology, v. 3, p. 83-91.

Engelhardt, H., Humphrey, N., Kamb, B., and Fehnestock, M., 1990, Physical conditions at the base of a fast moving Antarctic ice stream. Science, v. 248, p. 57-59.

Fountain, A.G., and Walder, J.S., 1998, Water flow through temperate glaciers. Reviews of Geophysics, v. 36, no. 3, p. 299-328.

Fowler, A., 2010, Weertman, lliboutry and the development of sliding theory. Journal of Glaciology, v. 56, no. 200, p. 965-972.

Fricker, H., and Scambos, T., 2009, Connected subglacial lake activity on lower Mercer and Whillans Ice Streams, West Antarctica. Journal of Glaciology, v. 55, no. 190, p. 303-315.

Fricker, H., Scambos, T., Bindschadler, R., and Padman, L., 2007, An active subglacial water system in West Antarctica mapped from space. Science, v. 315, no. 5818, p. 1544-1548.

Gray, L., Joughin, I., Tulaczyk, S., Spikes, V., Bindschadler, R., and Jezek, K., 2005, Evidence for subglacial water transport in the West Antarctic Ice Sheet through three-dimensional satellite radar interferometry. Geophysical Research Letters, v. 32, no. 3. 
Haberman, R., 2004, Applied Partial Differential Equations with Fourier Series and Boundary Value Problems. 4th edn., New Jersey, USA, Pearson Prentice Hall.

Iken, A., 1981, The effect of the subglacial water pressure on the sliding velocity of a glacier in an idealized numerical model. Journal of Glaciology, v. 27, no. 97, p. 407-421.

Iken, A., and Bindschadler, R., 1986, Combined measurements of subglacial water pressure and surface velocity of Findelen-Gletscher, Switzerland: conclusions about drainage system and sliding mechanism. Journal of Glaciology, v. 32, no. 110, p. 101-119.

Johnson, J., and Staiger, J., 2007, Modeling long-term stability of the Ferrar Glacier, East Antarctica: Implications for interpreting cosmogenic nuclide inheritance. Journal of Geophysical Research, v. 112.

Joughin, I., and Alley, R., 2011, Stability of the West Antarctic Ice Sheet in a warming world. Nature Geoscience, v. 4, p. 506-513.

Joughin, I., MacAyeal, D., and Tulaczyk, S., 2004, Basal shear stress of the Ross ice streams from control method inversions. Journal of Geophysical Research, v. 109, no. B09405, p. $1-20$.

Joughin, I., Tulaczyk, S., Bindschadler, R., and Price, S., 2002, Changes in West Antarctic ice stream velocities: Observation and analysis. Journal of Geophysical Research, v. 107, no. B11, p. 1-22.

King, J., and Turner, J., 1997, Antarctic meteorology and climatology. 1st edn., Cambridge, Cambridge University Press.

Kuffey, M.C., and Paterson, W.S.B., 2010, The Physics of Glaciers. 4th edn., Burlington, MA, Academic press.

Lamb, H., 1945, Hydrodynamics. 6th edn., New York, Dover.

Le Brocq, A., A.J., P., Siegert, M., and Alley, R., 2009, A subglacial water-flow model for West Antarctica. Journal of Glaciology, v. 55, no. 193, p. 879-888.

Lemke, P., Ren, J., Alley, R., Allison, I., Carrasco, J., Flato, G., Fujii, Y., Kaser, G., Mote, P., Thomas, R., and Zhang, T., 2007, Climate change 2007: The physical science basis. contribution of working group $i$ to the fourth assessment report of the intergovernmental panel on climate change. Cambridge University Press.

Lliboutry, L., 1968, General theory of subglacial cavitation and sliding of temperate glaciers. Journal of Glaciology, v. 7, no. 49, p. 21-58. 
Lythe, M., Vaughan, D., and the BEDMAP Consortium, 2001, Bedmap: A new ice thickness and subglacial topographic model of Antarctica. Journal of Geophysical Research, v. 106, no. B6, p. 11,335-11,351.

MacAyeal, D., 1989, 'large-scale ice flow over a viscous basal sediment: Theory and application to ice stream B, Antarctica. Journal of Geophysical Research, v. 94, no. B4, p. 4071-4087.

Mercer, J.H., 1978, West Antarctic Ice Sheet and $\mathrm{CO}_{2}$ greenhouse effect: A threat of disaster. Nature, v. 272, p. 321-325.

Nye, J., 1953, The flow law of ice from measurements in glacier tunnels, laboratory experiments and the Jungfraufirn borehole experiment. Proceedings of the Royal Society of London, Series A, Mathematical and Physical Sciences, v. 219, no. 1139, p. 477-489.

Roe, G., and Lindzen, R., 2000, The mutual interaction between continental-scale ice sheets and atmospheric stationary waves. Journal of Climate, v. 14, p. 1450-1465.

Schmittner, A., Silva, T., Fraedrich, K., Kirk, E., and Lunkeit, F., 2011, Effects of mountains and ice sheets on global ocean circulation. Journal of Climate, v. 24, p. 2814-2829.

Schoof, C., 2006, A variational approach to ice stream flow. Journal of Fluid Mechanics, v. 556, p. 227-251.

Schoof, C., 2007, Ice sheet grounding line dynamics: steady states, stability, and hysteresis. Journal of Geophysical Research, v. 112, p. 1-19.

Sergienko, O., and Hulbe, C., 2011, 'sticky spots' and subglacial lakes under ice streams of the Siple Coast, Antarctica. Annals of Glaciology, v. 52, no. 58, p. 18-22.

Sergienko, O., MacAyeal, D., and Bindschadler, R., 2007, Causes of sudden, short-term changes in ice-stream surface elevation. Geophysical Research Letters, v. 34, p. 1-6.

Siegert, M., 2001, Ice sheets and late Quaternary environmental change. 1st edn., Chichester, John Wiley and Sons.

Siegert, M., and Bamber, J., 2000, Subglacial water at the heads of Antarctic ice-stream tributaries. Journal of Glaciology, v. 46, no. 155, p. 702-703.

Stearns, L., Smith, B., and Hamilton, G., 2008, Increased flow speed on a large East Antarctic outlet glacier caused by subglacial floods. Nature Geoscience, v. 1, p. 827-831.

Truffer, M., and Echelmeyer, K., 2003, Of isbræ and ice streams. Annals of Glaciology, v. 36, p. 66-72. 
Tulaczyk, S., Kamb, W., and Engelhardt, H., 2000, Basal mechanics of ice stream B, West Antarctica: 1. Till mechanics. Journal of Geophysical Research, v. 105, no. B1, p. 463-481.

Tulaczyk, S., Pettersson, R., Quintana, N., Krupinski, Fricker, H., Joughin, I., and Smith, B., 2008, Do dynamic subglacial lakes impact temporal behavior of fast-flowing ice streams? GPS and radar investigations on two West Antarctic ice streams. Geophysical Research Abstracts, v. 10.

Van der Veen, C., 1999, Fundamentals of Glacier Dynamics. 1st edn., Rotterdam, Netherlands, A.A. Balkema.

Weertman, J., 1957, On the sliding of glaciers. Journal of Glaciology, v. 3, p. 33-38.

Whillans, I., and Van der Veen, C., 1993, New and improved determinations of velocity of ice streams B and C, West Antarctica. Journal of Glaciology, v. 39, no. 133, p. 483-490.

Wingham, D., Siegert, M., Shepherd, A., and Muir, A., 2006, Rapid discharge connects Antarctic subglacial lakes. Nature, v. 440, p. 1033-1036.

Zotikov, I., 2006, The Antarctic subglacial Lake Vostok: Glaciology, biology and planetology. 1st edn., New York, USA, Springer. 